\title{
Article
}

\section{Diurnal Extrema Timing-A New Climatological Parameter?}

\author{
Ana Žaknić-Ćatović * [D and William A. Gough
}

Citation: Žaknić-Ćatović, A.; Gough, W.A. Diurnal Extrema Timing-A

New Climatological Parameter?Climate 2022, 10, 5. https://doi.org/10.3390/ cli10010005

Academic Editors: Salvatore Magazù and Chiara Bertolin

Received: 8 November 2021

Accepted: 31 December 2021

Published: 6 January 2022

Publisher's Note: MDPI stays neutral with regard to jurisdictional claims in published maps and institutional affiliations.

Copyright: (C) 2022 by the authors. Licensee MDPI, Basel, Switzerland. This article is an open access article distributed under the terms and conditions of the Creative Commons Attribution (CC BY) license (https:// creativecommons.org/licenses/by/ $4.0 /)$.

\author{
Department of Physical and Environmental Sciences, University of Toronto Scarborough, 1265 Military Trail, \\ Toronto, ON M1C 1A4, Canada; william.gough@utoronto.ca \\ * Correspondence: ana.zaknic.catovic@utoronto.ca
}

\begin{abstract}
We address the following question: Are turning points of daily air temperature function a piece of relevant climatological information worth recording and analyzing? Diurnal Extrema Timing (DET) are daily occurrence times of air temperature minimum and maximum. Although unrecognized and unrecorded as a meteorological variable, the exact timing of daily temperature extrema plays a crucial role in the characterization of air temperature variability. In this study, we introduce the DET concept and assess the plausibility of this potential parameter in detecting temperature extrema timing changes. Conceptualization of the DET parameter has, for a primary goal, the supplementation of vital spatial information to the daily measurements of air temperature extrema. The elementary analysis of annual trends of daily DET examines the significance of this parameter in describing changes in the time domain of air temperature variability. The introduction of the new Climate Parameter Sensitivity Index (CPSI) for evaluating the susceptibility of climate parameters to climate change directs attention to the importance of the systematic acquisition of the timing of daily extrema in climate observations. The results of this study reveal the timing of daily air temperature maximum as the most vulnerable to climate change among temperature and timing extrema indices.
\end{abstract}

Keywords: air temperature; climate change; climate indices; daily temperature extrema; extrema timing; mid-latitude; temperature variability; trend analysis

\section{Introduction}

The importance of accurate identification of daily extrema for climatological analysis and various scientific operations cannot be overstated. Due to the common absence of long-term high-frequency air temperature observations, daily extrema are often the only available choice for climate analysis. Consequently, the authenticity of air temperature trend analysis and daily mean calculation is often entirely dependent on the accuracy of daily extrema [1-4].

A proper definition of daily temperature extrema is the key to understanding and correctly recreating diurnal temperature variability. Discrete identification of daily air temperature extrema is, by rule, the selection of the highest and lowest temperatures of the day involving a common search interval for maxima and minima. However, the discrete air temperature extrema search is strongly conditioned by the selection of length and the starting point of the extrema search window. Consequently, the vagueness of the daily extrema definition presents a root cause of systematic biases in temperature observations. The frequent mischaracterization of daily minima is found to be induced by the rigidity of the climatological observing window and the lack of consideration for the geographical location of the observational site. An improved climatological day, however, needs to take into account the season and latitude of the site to accommodate the identification of extrema within continuous nighttime and daytime intervals. Daily extrema identified in such a way represent the mathematical extrema or the turning points of the oscillatory air temperature function [5]. 
Identification of daily temperature extrema is further aggravated by various factors, inducing observational and physical inhomogeneities to the extrema time series. On one hand, the effects of changes in instrumental sampling rates and average processing algorithms, that are based on instantaneous values of meteorological variables, are a large cause of uncertainty and bias in daily extrema reporting [6,7]. On the other hand, a disregard for the physical heterogeneity of temperature time series is a concealed cause of improper extrema definition [8]. The physical nature of daily temperature extrema, distinguishable based on the timing span between minima and maxima, is systematically disregarded due to the absence of the timing observation of daily extrema. Furthermore, the interpretation and reconstruction of air temperature variability, based solely on daily extrema, rest on the knowledge of daily extrema timing. As a result, diurnal extrema timing plays a crucial role in the calculation of areas under the temperature curve for the estimation of air temperature-related quantities using degree-day formulae [9].

Numerous scientific efforts to generate diurnal temperature wave, based exclusively on daily extrema, witness the lack of important temporal information necessary for the recreation of daily temperature variability. Various algorithms for the generation of hourly temperature values using daily minimum, maximum, and mean of daily extrema extend beyond the domain of climatological use [10-12]. The information when the derivative of the daily temperature curve changes its sign is critically important for a wide range of scientific applications. Diurnal extrema timing is necessary for the improvement of air, soil, and water temperature modeling, civil engineering building simulation programs, calculating chilling units and chill hours for agricultural applications, and other degree-day estimations [13-21].

Hourly temperature data are usually modeled by fitting an algorithm through daily extrema located at assumed or estimated times of their daily occurrence. One study applied a method of temperature approximation assigning the calculated sunrise time to a daily minimum and a fixed local standard time for a maximum [22]. Other examples describe a simple cosine fit of a three-term cosine Fourier series to parts of the diurnal curve at assumed local standard times. A different study applies a hyperbolic tangent function with the temperature transformed to a linear function of the hour and a cosine fit with variable sunrise to obtain the diurnal temperature distribution [23].

Regardless of the intended use of artificial temperature data, the best fit is achieved when approximating function connects consecutive extrema of known temperature-time coordinates. Synthetic temperature data based on correctly identified extrema and their timing are a platform for modification of a standard degree-day approach [24]. The improvement in the calculation of daily temperature-related quantities based on diurnal extrema timing goes beyond the estimation of snowmelt and meltwater refreezing volumes [9,24]. The knowledge of the diurnal extrema timing represents a basis for the extension of the temperature-index approach in general.

However, despite the obvious or implied need for knowledge on the position of daily temperature extrema, the timing of daily temperature extrema has not yet acquired the status of an observed variable.

In this work, we analyze hourly air temperature data from twenty-four Canadian stations to identify the turning points of the temperature-time function and examine their timing as information of potential climatological significance. To achieve that, we apply an alternative climatological observing window to determine mathematical extrema and avoid the identification biases in air temperature minima [25]. The extrema timing obtained in such a way reveals the exact points in which daily air temperature function changes its sign. The use of mathematical extrema in this assessment bypasses inherent temperature and timing biases. Further, we examine the credibility of the information carried by this prospective parameter by studying its trends and time shifts in historical air temperature time series. Finally, we explore the sensitivity of the diurnal extrema timing parameter to climate change in contrast to its temperature extrema counterparts. 


\subsection{Definition of Air Temperature Extrema}

The diurnal extremum point of a continuous temperature-time function is defined as a set of air temperature-time coordinates $(t, T)$ with Diurnal Extrema Timing (DET) as the $x$-coordinate, and air temperature value of the extremum point being the $y$-coordinate. Obtaining daily temperature extrema for various climatological applications is considered a common task. However, routine extrema search does not necessarily yield the intended information, i.e., a diurnal pair of mathematical extrema. Mathematical air temperature extrema are the points on a temperature-time curve in which the daily temperature trend changes its sign, and the derivative of temperature function equals zero. Due to the lack of means for determining Diurnal Mathematical Extrema (DME) in practice, one naturally resorts to discrete methods for identifying the smallest and the largest value of temperature over a 24-h search period. The discrete extrema search applied on a calendar-based scale often omits the true temperature extrema and instead identifies the endpoints of the search period. Diurnal Endpoint Extrema (DEE) are the highest and the lowest identified temperature points found at the start or at the end of a time discretization interval for extrema search.

\subsection{Diurnal Extrema Timing}

Contrary to the concept of time playing the role of an independent variable in air temperature-time functional dependence, with the temperature being a periodic function of time, the timing of diurnal extrema plays a role of a variable that positions extrema within the temperature-time plane. We define DET as the occurrence time ( $t$ ) of a daily air temperature minimum $\left(t_{n}\right)$ and maximum $\left(t_{x}\right)$. The DET parameter presents two distinct points on the continuous air temperature curve that identify daily extrema with respect to temperature and time axes. Variations in temperature magnitude on the vertical axis define the amplitude and vertical shift of the temperature function. The horizontal shift on the $x$-axis, reflecting the phase and frequency of daily air temperature variation, results from the change in the timing of extrema occurrence. Figure 1 presents a set of typical seasonal curves of averaged daily variability on the example of Toronto, Ontario, Canada $\left(43^{\circ} 40^{\prime} 38^{\prime \prime} \mathrm{N}, 79^{\circ} 37^{\prime} 50^{\prime \prime} \mathrm{W}\right)$, and the seasonal dependence of the DET parameter. The temperature-time pair $(t, T)$ consisting of temperature extreme values for maximum $\left(T_{x}\right)$ and minimum $\left(T_{n}\right)$ is supplemented here with the DET of maximum $\left(t_{x}\right)$ and minimum $\left(t_{n}\right)$. Subsequently, we refer to a daily minimum as the $\left(t_{n}, T_{n}\right)$ and maximum as the $\left(t_{x}, T_{x}\right)$ pair.

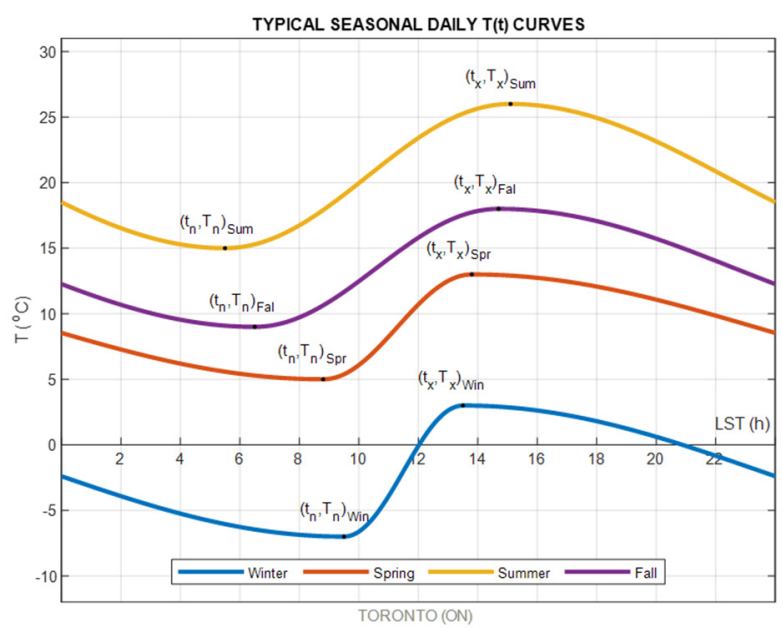

Figure 1. Averaged daily variability of a temperature-time function during four seasons on the example of Toronto, Ontario, Canada $\left(43^{\circ} 40^{\prime} 38^{\prime \prime}\right.$ N, $79^{\circ} 37^{\prime} 50^{\prime \prime}$ W). Diurnal Extrema Timing minimum is denoted as $t_{n}$, while Diurnal Extrema Timing maximum is denoted as $t_{x}$. Abbreviations: Win represents Winter, Spr represents Spring, Sum represents Summer, and Fal represents Fall. 
Three different types of oscillatory behavior are observable on this graph: a periodic diurnal minimum to maximum air temperature oscillation, a vertical seasonal variation of diurnal curves due to seasonal temperature changes, and, lastly, a horizontal variation due to seasonal changes in time of occurrence of daily temperature extrema. The vertical oscillation of all four curves represents the annual variation between diurnal temperature averages. Horizontal oscillation in opposite directions, for each, the timing of minima and maxima, represents a seasonal shift in the timing of extrema.

\subsection{Canadian Temperature Extrema Bias}

Canadian air temperature recording history has been associated with difficulties in defining the starting point of the observational window. On 1 July 1961, the nationwide observing time for air temperature recording was redefined to correct the mischaracterization of diurnal minima caused by the preceding observing window. The starting point of the Canadian temperature observing window was changed from 0:00 UTC to 6:00 UTC to alleviate the observational bias in minima [26]. Nonetheless, the change to the new observing window introduced the cold bias to the observations by increasing the potential for recording minimal temperatures on two consecutive days, affecting $15 \%$ to $38 \%$ days annually [27]. Changes to the time limits of the day have been known in general to affect the records of a daily air temperature minimum $[28,29]$.

\subsection{Calendar Day vs. Climatological Day for Extrema Observations}

A climatological day is the extent of the observational day used to identify extrema that are reflective of air temperature variation. Yet, the climatological day presently in use frequently reaches out of the bounds of a 24-h period in attempts to capture the true extrema. For meteorological sites in Canada reporting two daily observations of temperature extrema, the operational definition of a daily air temperature minimum and maximum differs from the calendar day definition that applies only to sites reporting extrema once per day. The reason for the development of the climatological day in place of a calendar day was to improve the capturing of true "peaks and lows" of periodic temperature variation [30].

\subsection{Climatological Observing Window}

A climatological observing window $(\mathrm{COW})$ is a time frame over which continuous or extreme air temperature measurements are collected. A fixed 0-24 h observing window, $\left(\mathrm{COW}_{0-24}\right)$, potentially leads to misidentification of minima due to fragmentation of the nighttime into two subsequent segments caused by the time discretization interval [5]. As a result, some identified diurnal minima do not conform with the definition of the DME. Systematic fragmentation of the nighttime period, caused by the rigidity of the $\mathrm{COW}_{0-24}$ search window's position, is further magnified by the inconsistency of applying a COW indifferent to latitude and season of temperature observing location. However, correct identification of diurnal temperature extrema is achievable using a COW that identifies a minimum over a nighttime period and a maximum over a daytime period, per sunrise and sunset times. The Climatological Observing Window Night and Day $\left(\mathrm{COW}_{\mathrm{N}-\mathrm{D}}\right)$ aims to identify the true turning points of the air temperature-time function. A randomly selected measured air temperature interval presented in Figure 2 contrasts the performance of $\mathrm{COW}_{0-24}$ and $\mathrm{COW}_{\mathrm{N}-\mathrm{D}}$ extrema identification methods in air temperature tracking. Linear temperature tracking refers to the approximation of hourly temperatures between daily extrema points for the validation of extrema identification methods. This subject is explored later in this paper. The temperature approximating curve based on $\mathrm{COW}_{\mathrm{N}-\mathrm{D}}$ diurnal extrema pairs (blue curve) visibly conforms better with the observed temperatures (gray line) in comparison with the approximating curve based on daily extrema obtained by the $\mathrm{COW}_{0-24}$ method (red curve). 
LINEAR TRACKING OF DIURNAL AIR TEMPERATURE (COW O-24 vs COW $\left._{\mathrm{N}-\mathrm{D}}\right)$

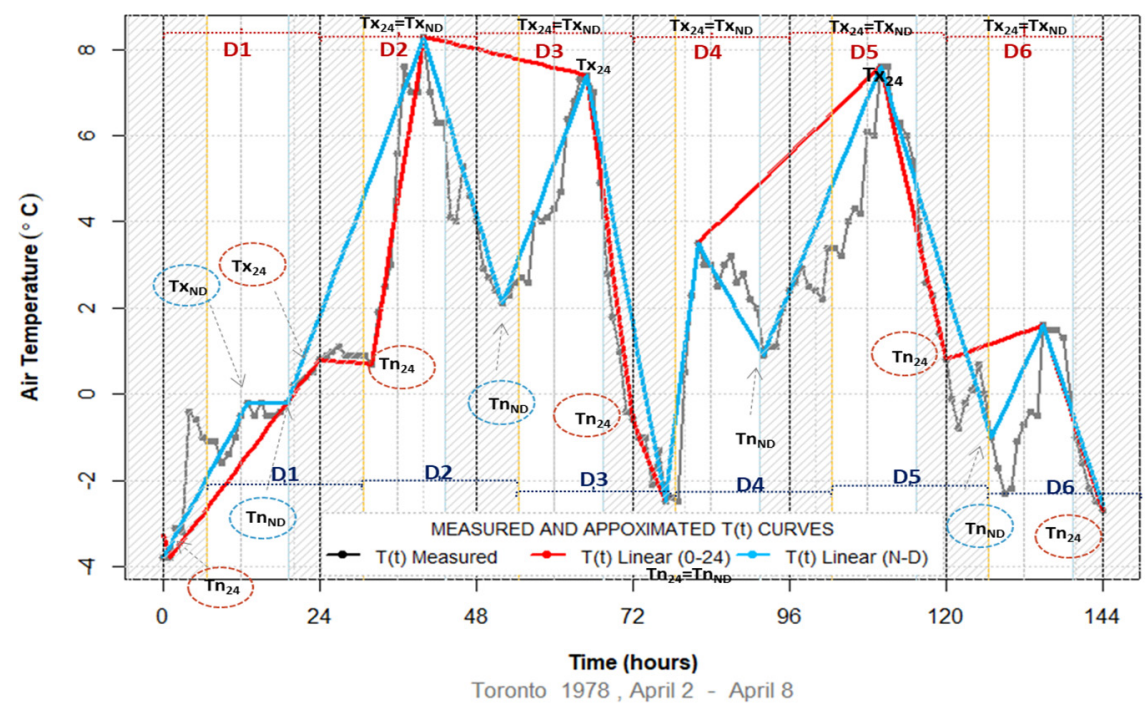

Figure 2. Comparison of $\mathrm{COW}_{0-24}$ and $\mathrm{COW}_{\mathrm{N}-\mathrm{D}}$ observing windows. Linear temperature tracking highlights the effect of the choice of a diurnal observing window on the accuracy of temperature extrema identification. Gray solid lines represent measured hourly temperature, while red and blue lines correspond to linearly interpolated temperatures based on $\mathrm{COW}_{0-24}$ and $\mathrm{COW}_{\mathrm{N}-\mathrm{D}}$ extrema. Hatched areas represent the duration of nighttime, while vertical yellow lines indicate sunrise. The $\mathrm{COW}_{0-24}$ days extend between consecutive midnights (vertical black dotted lines), while $\mathrm{COW}_{\mathrm{N}-\mathrm{D}}$ days extend between consecutive sunrises (vertical solid yellow lines).

Examples of incorrect characterization of minima by the $\mathrm{COW}_{0-24}$ extrema identification method are evident on the third, the fourth, fifth, and sixth day of the temperature sample in Figure 2, mostly due to the association of the $\mathrm{COW}_{0-24}$ minima with the second nighttime segment.

If the temperature in the second night segment is lower than the temperature in the first night segment, such as on the third, fifth, and the sixth day, the $\mathrm{COW}_{0-24}$ extrema identification method omits the warmer minimum occurring in the first night segment and instead identifies a DEE or the endpoint as a minimum in the second night segment. On the fourth day, the $\mathrm{COW}_{0-24}$ method skips the legitimate warmer minimum due to double-counting of the same temperature dip with the previous day. On the fifth day, the $\mathrm{COW}_{0-24}$ extrema identification method wrongfully identifies a DEE, specifically an endpoint minimum, and continues to the sixth day by omitting one more time the warmer first segment minimum. On all other days, except for the second day, minima and maxima detected by the $\mathrm{COW}_{\mathrm{N}-\mathrm{D}}$ method better coincide with the true extrema. The $\mathrm{COW}_{\mathrm{N}-\mathrm{D}}$ skips the second-day and the sixth-day minimum that occurs just after dawn due to the fact that the method searches exclusively for the nighttime minima.

\section{Materials and Methods}

\subsection{Air Temperature Data and Analysis}

Hourly air temperature data from twenty-four international or regional airports (Table 1, Figure 3) were obtained from the digital archive of Environment and Climate Change, Government of Canada [31]. The majority of weather station records encompass 66 years of data, apart from the 64 year-long air temperature record from Cold Lake (Alberta), and a 60 year-long record from St. John's (Newfoundland and Labrador). Although air temperature measurements at Baker Lake (Nunavut) extend over the entire study range, the interval from 1953 to 1963 is excluded from the timing analysis due to the data sparsity problem. All hourly temperatures used in this study were recorded in Local Standard Time (LST). The percent of missing data varies between 0.03 (Vancouver, Toronto, Montreal, 
Moncton) to 1.49 percent (Trenton) of missing hourly measurements over the length of the acquired data range.

Table 1. List of weather stations used in the study. All temperature data examined in this study represent hourly measurements obtained from Canadian international or regional airports using consistent observation standards. Hourly temperature data range from the year 1953 to 2018 for most stations.

\begin{tabular}{|c|c|c|c|c|c|}
\hline Provinces \& Territories & Location & Latitude $\left({ }^{\circ} \mathbf{N}\right)$ & Longitude $\left({ }^{\circ} \mathrm{W}\right)$ & Data Range & Missing Data (\%) \\
\hline \multirow[t]{3}{*}{ Alberta } & Calgary & 51.1139 & 114.0203 & $1953-2018$ & 0.04 \\
\hline & Cold Lake & 54.4167 & 110.2833 & 1955-2018 & 0.10 \\
\hline & Fort McMurray & 56.6500 & 111.2167 & $1953-2018$ & 0.35 \\
\hline \multirow[t]{2}{*}{ British Columbia } & Vancouver & 49.1950 & 123.1819 & $1953-2018$ & 0.03 \\
\hline & Victoria & 48.6472 & 123.4258 & $1953-2018$ & 0.07 \\
\hline \multirow[t]{2}{*}{ Manitoba } & Churchill & 58.7392 & 94.0664 & $1953-2018$ & 0.17 \\
\hline & Winnipeg & 49.9167 & 97.2333 & $1953-2018$ & 0.06 \\
\hline \multirow{2}{*}{ New Brunswick } & Fredericton & 45.8776 & 66.5279 & 1953-2018 & 0.13 \\
\hline & Moncton & 46.1053 & 64.6838 & $1953-2018$ & 0.03 \\
\hline \multirow[t]{2}{*}{ Newfoundland \& Labrador } & Goose & 53.7083 & 57.0350 & 1953-2018 & 0.06 \\
\hline & St. John's & 47.6222 & 52.7428 & $1959-2018$ & 0.05 \\
\hline \multirow{2}{*}{ Nova Scotia } & Greenwood & 44.9833 & 64.9167 & 1953-2018 & 0.05 \\
\hline & Yarmouth & 43.8308 & 66.0886 & $1953-2018$ & 0.16 \\
\hline \multirow[t]{3}{*}{ Ontario } & Ottawa & 45.3225 & 75.6692 & $1953-2018$ & 0.05 \\
\hline & Toronto & 43.6772 & 79.6306 & 1953-2018 & 0.03 \\
\hline & Trenton & 44.1167 & 77.5333 & $1953-2018$ & 1.49 \\
\hline Prince Edward Island & Charlottetown & 46.1719 & 63.0743 & 1953-2018 & 0.13 \\
\hline \multirow[t]{2}{*}{ Quebec } & Bagotville & 48.3333 & 71.0000 & $1953-2018$ & 0.04 \\
\hline & Montreal & 45.2814 & 73.4427 & 1953-2018 & 0.03 \\
\hline \multirow[t]{2}{*}{ Saskatchewan } & Estevan & 49.2167 & 102.9667 & $1953-2018$ & 0.07 \\
\hline & Saskatoon & 52.1667 & 106.7167 & 1953-2018 & 0.06 \\
\hline Northwest Territories & Yellowknife & 62.2746 & 114.2625 & $1953-2018$ & 0.05 \\
\hline Nunavut & Baker Lake & 64.2989 & 96.0778 & 1963-2018 & 0.69 \\
\hline Yukon & Whitehorse & 60.7094 & 135.0686 & $1953-2018$ & 0.04 \\
\hline
\end{tabular}

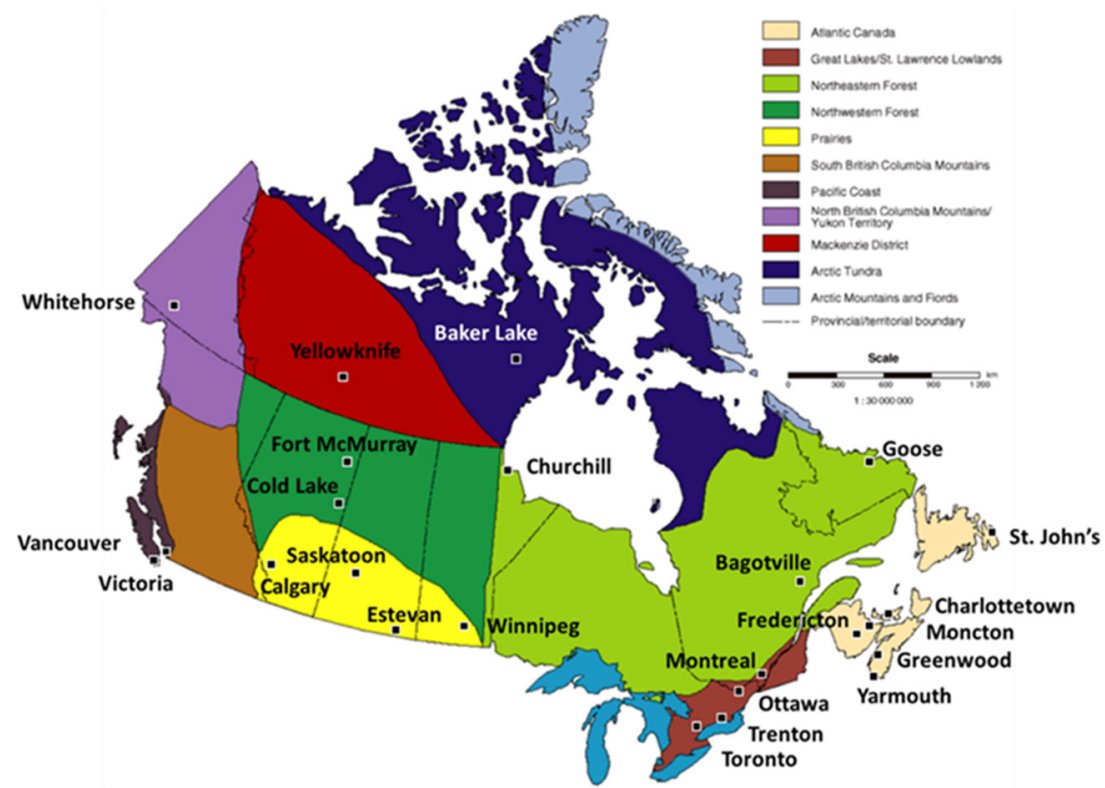

Figure 3. The map of twenty-four locations of weather stations used in this study presented on the map of Canadian climate regions (source: Environment Canada, Atmospheric Environment Service, Climate Research Branch, 1998, Climate Trends and Variation Bulletin for Canada, Ottawa).

Data analysis was conducted in the R programming language [32] using the following steps: 
1. Daily minimum and maximum and their timing are identified using $\mathrm{COW}_{0-24}$ and $\mathrm{COW}_{\mathrm{N}-\mathrm{D}}$ methods to obtain a series of daily extrema. A common point between the methods is that both use MIN/MAX functions to find the lowest/largest number on a preselected time interval. The key difference between the methods is the specification of the search interval. While the $\mathrm{COW}_{0-24}$ extrema identification method identifies the lowest and largest value within the 24-h interval starting at midnight, the $\mathrm{COW}_{\mathrm{N}-\mathrm{D}}$ method divides $24 \mathrm{~h}$ into a daytime and nighttime interval starting at sunrise and sunset, respectively. The $\mathrm{COW}_{\mathrm{N}-\mathrm{D}}$ approach uses the advantage of prior knowledge or expectation that true mathematical extrema occur during separate nighttime and daytime periods. The extrema further serve as connection points for artificial temperature generation used in the testing of conformity of air temperature tracking with hourly temperature observations.

2. Air temperature tracking connects consecutive extrema into a continuous approximation of temperature variability used for the calculation of hourly differences between measured and calculated temperatures. The accuracy of each hourly point generated by $\mathrm{COW}_{0-24}$ and $\mathrm{COW}_{\mathrm{N}-\mathrm{D}}$ methods is verified against the measured temperature for comparing the performance of COW methods in the identification of mathematical extrema. The error distributions in air temperature tracking are then contrasted for benchmarking and identification of systematic biases. Due to the higher accuracy of the $\mathrm{COW}_{\mathrm{N}-\mathrm{D}}$ search method in temperature tracking, the $\mathrm{COW}_{\mathrm{N}-\mathrm{D}}$ chronologically ordered sequence of daily temperature extrema is used further as a close representation of true temperature variability.

3. The daily mean of extrema, i.e., the Min-Max Average (MMA), and the difference between daily maximum and minimum, i.e., Diurnal Temperature Range (DTR) are determined for calculation of discrepancies between the $\mathrm{COW}_{0-24}$ and $\mathrm{COW}_{\mathrm{N}-\mathrm{D}}$ extrema identification methods.

4. Nighttime and daytime populations of minima and maxima temperature-time pairs are further divided into "before" and "after" subpopulations for the examination of counts and their "migration" across midnight and noon delineations. The migration of DET counts refers to a displacement of "before" timing members to the "after" subpopulations effectively causing shifts in minima and maxima timing.

5. The timing subpopulations are subjected to analysis of time trends and shifts in historical temperature-time series. Time trends of timing subpopulations are analyzed using the Mann-Kendal (MK) trend test in the R code.

6. The sensitivity of diurnal temperature and timing parameters to climate change is evaluated afterward with the newly introduced Climate Parameter Sensitivity Index that examines the change of temperature and timing indices relative to their range of variability.

\subsection{Identification of Diurnal Temperature-Time Extrema Pairs}

The application of the $\mathrm{COW}_{0-24}$ search method to hourly air temperature data series creates a temperature-time extrema population from a common search interval. The $\mathrm{COW}_{\mathrm{N}-\mathrm{D}}$ method, on the contrary, separates search periods into nighttime and daytime segments to identify one temperature-time extremum per interval (Figure 4). 
INPUT: HIGH FREQUENCY DIURNAL AIR TEMPERATURE MEASUREMENTS

DIURNAL AIR TEMPERATURE EXTREMA ANALYSIS: COW COMPARISON

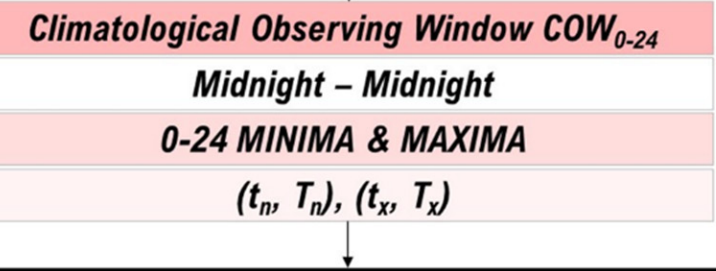

\begin{tabular}{|c|c|}
\hline \multicolumn{2}{|c|}{ Climatological Observing Window COW $_{N-D}$} \\
\hline \multicolumn{2}{|c|}{ Sunrise - Sunrise } \\
\hline NIGHTTIME MINIMA & DAYTIME MAXIMA \\
\hline$\left(N t_{n}, N T_{n}\right)$ & $\left(D t_{x}, D T_{x}\right)$ \\
\hline
\end{tabular}

LINEAR AIR TEMPERATURE TRACKING BASED ON DIURNAL EXTREMA POINTS ANNUAL AIR TEMPERATURE AVERAGING \& TREND ANALYSIS

Figure 4. Approach for diurnal air temperature analysis and comparison of $\mathrm{COW}_{0-24}$ and $\mathrm{COW}_{\mathrm{N}-\mathrm{D}}$ methods.

Populations of $\mathrm{COW}_{0-24}$ and $\mathrm{COW}_{\mathrm{N}-\mathrm{D}}$ temperature-time pairs are then utilized for air temperature tracking and averaging assessment. Due to the different starting points and lengths of the search interval, two discrete search methods will generate a temperature discrepancy based on a number of disparate extrema. Diurnal air temperature-time $(t, T)$ pairs obtained using 0-24 h time discretization scale are referred to as "0-24 Minima and Maxima Extrema Pairs." In contrast, the $(t, T)$ pairs obtained using the Night and Day discretization scale are denoted as "Nighttime Minima and Daytime Maxima Extrema Pairs." The $\mathrm{COW}_{\mathrm{N}-\mathrm{D}}$ extrema identification method produces a chronologically ordered extrema sequence consisting of consecutive Nighttime Minima $\left(\mathrm{Nt}_{n}, \mathrm{NT}_{n}\right)$ and Daytime maxima $\left(\mathrm{Dt}_{\mathrm{x}}, \mathrm{DT}_{\mathrm{x}}\right)$ temperature-time pairs.

Differences in diurnal extrema between the $\mathrm{COW}_{0-24}$ and $\mathrm{COW}_{\mathrm{N}-\mathrm{D}}$ methods are most evident in the identification of minima. A misidentified extremum produces an incorrect connection point for the air temperature approximating function. Consequently, the longterm accumulation of such extrema presents a cause of systematic biases in air temperature tracking, averaging, and climate analysis and application.

\subsection{Linear Temperature Tracking}

Linear temperature tracking is a procedure for the evaluation of the COW method's accuracy in the identification of daily mathematical extrema (Figure 2). The linear tracking procedure consists of the following steps:

a. Consecutive daily extrema are linearly connected and air temperatures for hours in between the extrema are calculated. This step yields two artificial or recreated sets of hourly temperatures based on $\mathrm{COW}_{0-24}$ and $\mathrm{COW}_{\mathrm{N}-\mathrm{D}}$ extrema.

b. The calculated hourly temperatures are compared to the corresponding measured hourly temperatures to form two sets of hourly differences or errors associated with $\mathrm{COW}_{0-24}$ and $\mathrm{COW}_{\mathrm{N}-\mathrm{D}}$ extrema identification methods.

c. Two sets of error distributions in linear tracking are then statistically assessed and compared against each other for accuracy benchmarking. The benchmarking criteria are symmetry, mean, and standard deviation of the distribution.

\subsection{Annual averaging of $\mathrm{COW}_{0-24}$ and $\mathrm{COW}_{N-D}$ Air Temperature Extrema}

Annual averages of $\mathrm{COW}_{0-24}$ and $\mathrm{COW}_{\mathrm{N}-\mathrm{D}}$ daily minima $\left(\mathrm{T}_{\mathrm{n}}\right)$, maxima $\left(\mathrm{T}_{\mathrm{x}}\right)$, MinMax averages (MMA), and diurnal temperature ranges (DTR) are calculated for demonstration of COW effects on the selection of daily extrema and comparison of annual temperature discrepancies. 


\subsection{Analysis of Diurnal Extrema Timing}

Figure 5 presents steps for the analysis of nighttime and daytime DET populations, and their subpopulations obtained using the $\mathrm{COW}_{\mathrm{N}-\mathrm{D}}$ extrema search method.

INPUT: SEQUENCE OF DIURNAL EXTREMA TIMING (DET) POINTS IDENTIFIED USING COWND

DIURNAL EXTREMA TIMING (DET) ANALYSIS

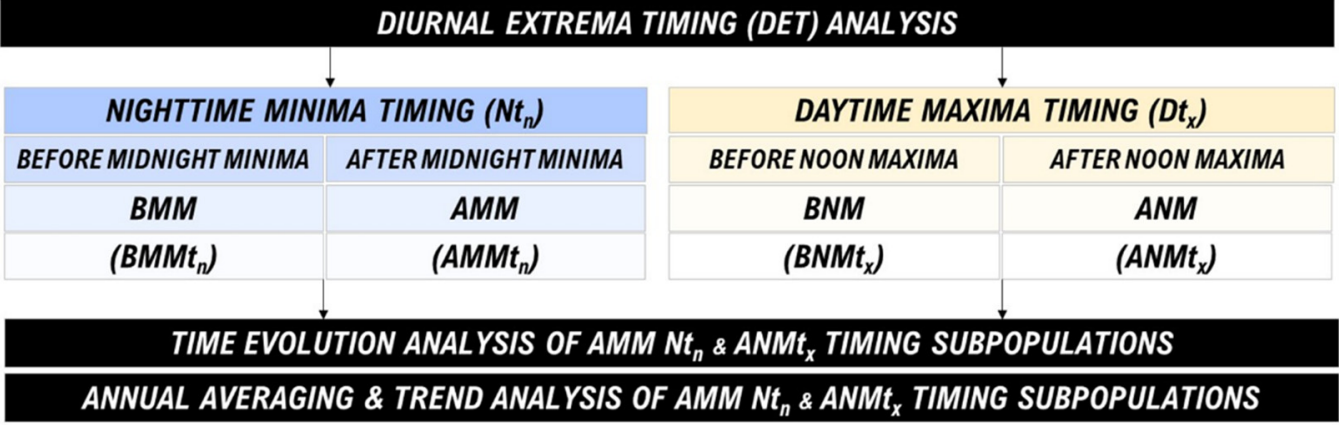

Figure 5. The approach for the DET analysis is based on the $\mathrm{COW}_{\mathrm{N}-\mathrm{D}}$ extrema sequence.

Nighttime minima and daytime maxima periods of the $\mathrm{COW}_{\mathrm{N}-\mathrm{D}}$ extrema search method extend between sunrise and sunset. It is generally expected that minima occur close to sunrise, while maxima are expected after the meridional noon, on days when temperature changes are predominantly driven by solar radiation. However, on days when air mass movements dominate air temperature changes, daily extrema can occur at various times. Hence, we divide nighttime minima and daytime maxima timing populations into smaller diurnal timeframes using midnight and noon delineation points to improve the accuracy of long-term DET averaging, greatly affected by the 0-24-h day partitioning. Since we correlate DET with hourly integers that correspond to reported hourly temperatures, high integer values associated with the "before midnight" DET occurrences complicate diurnal averaging of this parameter and justify the separation of the nighttime DET population. The separation of the daytime and nighttime DET populations around midnight and noon delineation points is also based on physical differences between the "regular" and the DET populations that achieve the temperature extremum outside of their expected, radiativelydriven timing range. Accordingly, the midnight delineation further divides the nighttime minima timing population into the Before Midnight Minima $\left(\mathrm{BMMt}_{\mathrm{n}}\right)$ and After Midnight Minima $\left(\mathrm{AMMt}_{\mathrm{n}}\right)$ subpopulations, while the noon divides daytime maxima into the Before Noon Maxima $\left(\mathrm{BNMt}_{\mathrm{x}}\right.$ ) and After Noon Maxima (ANMt $\mathrm{t}_{\mathrm{x}}$ ) timing subpopulations. The $\mathrm{AMMt}_{\mathrm{n}}$ and $\mathrm{ANMt}_{\mathrm{x}}$ subpopulations are further subjected to the time evolution analysis for identification of extrema migration, and the subsequent averaging and trend analysis of the accrued changes to the annual DET. Trends analysis of AMMt $\mathrm{n}_{\mathrm{n}}$ and $\mathrm{ANMt}_{\mathrm{x}}$ subpopulations is employed using the Mann-Kendal (MK) trend test in the R code. The MK test is a commonly used nonparametric test for assessing the significance of monotonic time trends in variables with no assumption on the data to be normally distributed.

\subsection{Climate Parameter Sensitivity Index (CPSI)}

In this work, we introduce the Climate Parameter Sensitivity Index (CPSI) for the evaluation of the susceptibility of temperature and timing indices to external changes in climate relative to the parameter's range of variability. Equations (1)-(3) relate to estimation of the CPSI value of the nighttime temperature minima of a location, while Equations (4)-(6) relate to estimation of the CPSI of the associated AMM timing subpopulation.

In simple terms, CPSI is defined as the ratio of two types of variability, the one that is ascribable to climate change and the other that represents the overall variability of the parameter (Equations (1) and (4)). Climate change variability is quantified as the slope of a linear trend of parameter's annual averages calculated for the length of the study range and multiplied by the time range (Equations (2) and (5)). The overall variability of a parameter 
can be specified as a standard deviation of detrended data or the difference between the largest and the lowest parameter's observed value (Equations (3) and (6)).

The estimation of the CPSI for the Nighttime Temperature Minima $\left(N T_{n}\right)$ parameter (Equation (1)) contrasts the change in the nighttime minima attributable to climate change (Equation (2)) with the change in the overall variability range of the nighttime minima (Equation (3)):

$$
\operatorname{CPSI}\left(N T_{n}\right)=\frac{\Delta N T_{n}}{\delta N T_{n}}
$$

where:

$\operatorname{CPSI}\left(\mathrm{NT}_{n}\right)=$ Climate sensitivity index of the nighttime temperature minima.

$\Delta N T_{n}=$ Variability of the nighttime temperature minima due to climate change.

$\delta N T_{n}=$ Overall variability range of the nighttime temperature minima.

$$
\Delta N T_{n}=m_{\text {lin }}\left(N T_{n}\right) \cdot(\text { time range })
$$

$m_{\text {lin }}\left(N T_{n}\right)=$ Slope of the linear trend of the nighttime minima.

time range $=$ Length of the study range.

$$
\delta N T_{n}=\max \left(N T_{n}\right)-\min \left(N T_{n}\right)
$$

$\max \left(N T_{n}\right)=$ Largest recorded nighttime minimum.

$\min \left(N T_{n}\right)=$ Smallest recorded nighttime minimum

While these definitions of parameter's variability ranges are open to modification, we emphasize that the main purpose of CPSI evaluation is to: (i) quantify the parameter's sensitivity to climate change and (ii) allow for quantitative intercomparison of different parameters and the ranking of their sensitivity to climate change.

The estimation of the CPSI for the After Midnight Minima timing $\left(A M M t_{n}\right)$ parameter (Equation (4)) contrasts the change in the timing of the nighttime minima attributable to climate change (Equation (5)) with the change in the overall variability range of the timing of the nighttime minima (Equation (6)):

$$
\operatorname{CPSI}\left(A M M t_{n}\right)=\frac{\Delta A M M t_{n}}{\delta A M M t_{n}}
$$

where:

$\operatorname{CPSI}\left(A M M t_{n}\right)=$ Climate sensitivity index of the $\mathrm{AMMt}_{\mathrm{n}}$ parameter.

$\triangle A M M t_{n}=$ Variability of the $A M M t_{n}$ parameter due to climate change.

$\delta A M M t_{n}=$ Overall variability range of the $A M M t_{n}$ parameter.

$$
\Delta A M M t_{n}=m_{\text {lin }}\left(A M M t_{n}\right) \cdot(\text { time range })
$$

$m_{\text {lin }}\left(A M M t_{n}\right)=$ Slope of the linear trend of the $A M M t_{n}$ parameter. time range $=$ Length of the study range.

$$
\delta A M M t_{n}=\max \left(A M M t_{n}\right)-\min \left(A M M t_{n}\right)
$$

$\max \left(A M M t_{n}\right)=$ Largest recorded $A M M t_{n}$ parameter.

$\min \left(A M M t_{n}\right)=$ Smallest recorded $A M M t_{n}$ parameter.

The climate sensitivity of the Daytime Temperature Maxima $\left(\mathrm{DT}_{\mathrm{x}}\right)$ and After Noon Maxima timing $\left(\mathrm{ANMt}_{\mathrm{x}}\right)$ are calculated using the same principles from Equations (1)-(6).

\section{Results}

The results of air temperature analysis, extrema timing analysis, and ranking of air temperature and timing parameters are presented in the following sections according to locations of individual weather stations within Canadian climate regions (Figure 3). 
The conformity of linearly tracked with measured hourly temperatures is evaluated first for obtaining a qualitative criterion used for the rating of success of discrete search methods in the identification of extrema. The following parts of this section compare the annual averages of $\mathrm{COW}_{0-24}$ and $\mathrm{COW}_{\mathrm{N}-\mathrm{D}}$ daily extrema indices before presenting the DET and the CPSI elements of analysis.

\subsection{Conformity of Linear Air Temperature Tracking with Hourly Temperature Measurements}

Diurnal temperature-time extrema pairs, identified with the $\mathrm{COW}_{0-24}$ and $\mathrm{COW}_{\mathrm{N}-\mathrm{D}}$ methods, are used to provide the connection points for air temperature interpolation. The key element for accurate reconstruction of the diurnal temperature-time $\mathrm{T}(\mathrm{t})$ curve, based on minimal data inputs, is the DET parameter that provides a spatial element to each measured air temperature value within the temperature-time space. The most plausible temperature reconstruction is achieved with piecewise functions that connect in extrema. Figure 6 displays distributions of differences between hourly measured and interpolated temperatures at four different stations based on daily extrema identified with $\mathrm{COW}_{0-24}$ and $\mathrm{COW}_{\mathrm{N}-\mathrm{D}}$ search methods. The $\mathrm{COW}_{0-24}$ (red) distributions present errors in linear temperature tracking based on $\mathrm{COW}_{0-24}$ extrema. Likewise, the $\mathrm{COW}_{\mathrm{N}-\mathrm{D}}$ (blue) distributions present errors in temperature tracking using $\mathrm{COW}_{\mathrm{N}-\mathrm{D}}$ extrema as connection points.

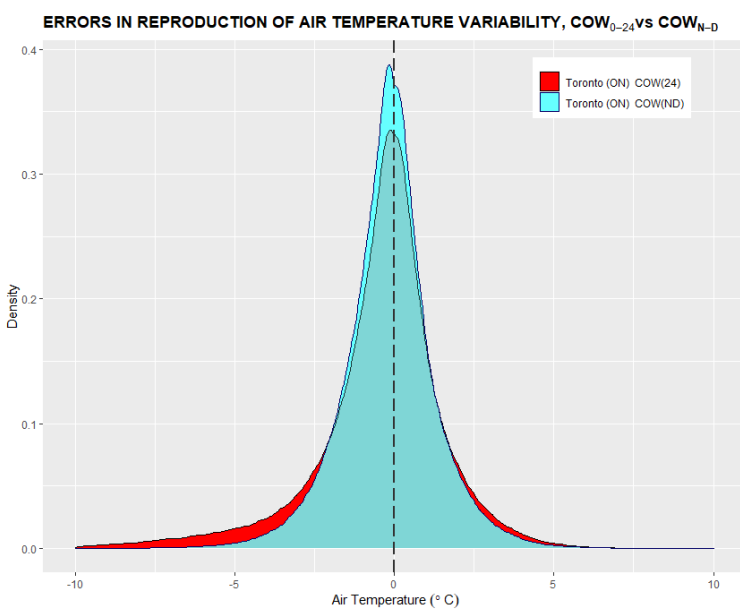

(a)

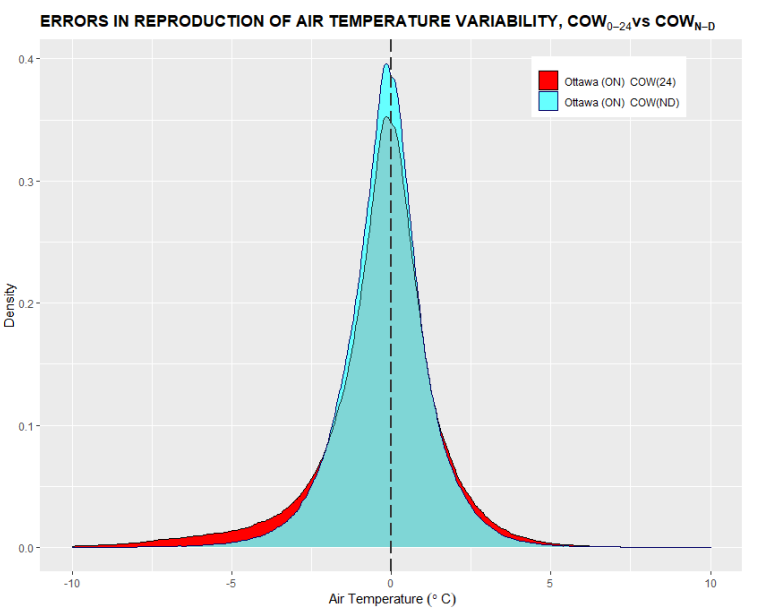

(c)

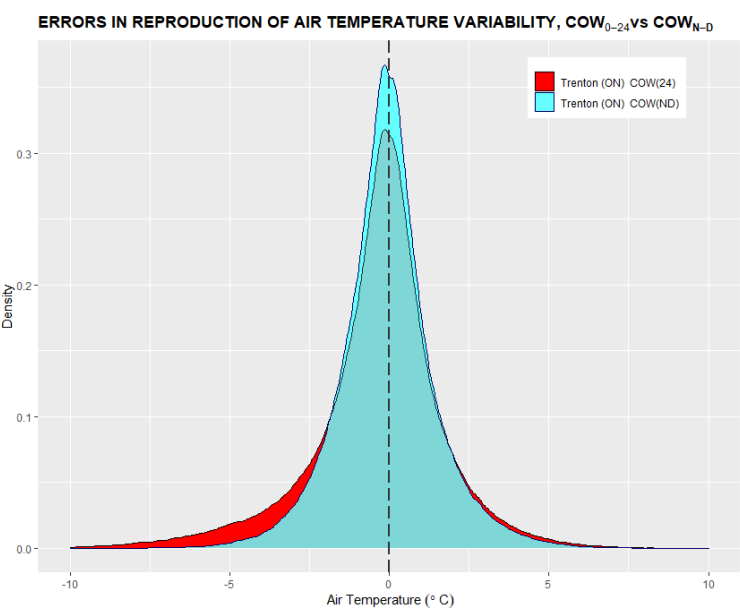

(b)

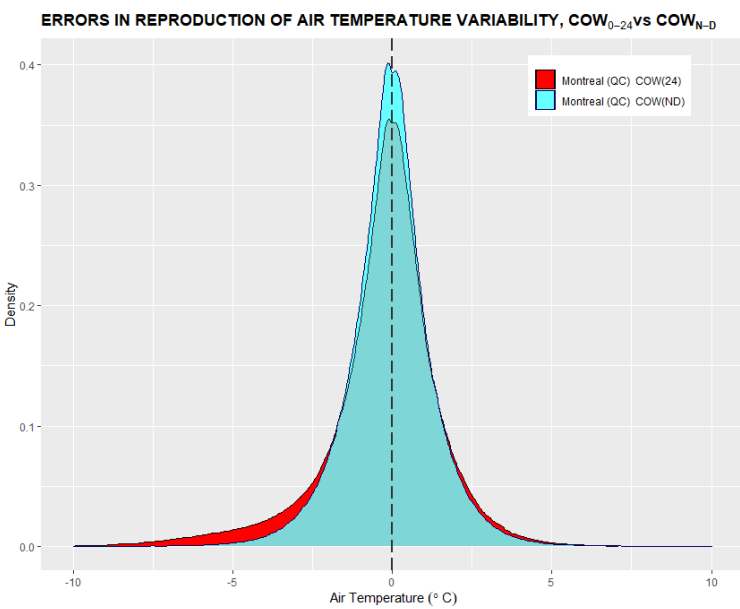

(d)

Figure 6. Histograms of conformity of $\mathrm{COW}_{0-24}$ and $\mathrm{COW}_{\mathrm{N}-\mathrm{D}}$ reproduced temperature with observed 66 year-long hourly temperature data from the Great Lakes/St. Lawrence Lowlands climate region at Toronto (a), Trenton (b), Ottawa (c), and Montreal (d) stations. 
The criteria for comparison of linear air temperature tracking between $\mathrm{COW}_{0-24}$ and $\mathrm{COW}_{\mathrm{N}-\mathrm{D}}$ extrema search methods against true temperature measurements are shape, mean, and standard deviation of compared error distributions.

The $\mathrm{COW}_{\mathrm{N}-\mathrm{D}}$ (blue) distributions of four locations from the Great Lakes/St. Lawrence Lowlands region systematically display more symmetric and narrower histograms in comparison with $\mathrm{COW}_{0-24}$ (red) distributions obtained from the errors associated with the linear tracking based on $\mathrm{COW}_{0-24}$ extrema. Consistent negative left-hand side bias, observable in all $\mathrm{COW}_{0-24}$ error distributions of all studied stations (presented in Appendix A), appears to be related to minima mischaracterization caused by the omission of warmer diurnal minima, therefore resulting in a larger number of negative differences between the measured and calculated temperature extrema.

The $\mathrm{COW}_{\mathrm{N}-\mathrm{D}}$ method's narrower distribution around zero is further confirmed by the summary statistics for the twenty-four temperature time series presented in Table 2.

Table 2. The mean and standard deviation of $\mathrm{COW}_{0-24}$ and $\mathrm{COW}_{\mathrm{N}-\mathrm{D}}$ error distributions presented in Figure 6 and Appendix A.

\begin{tabular}{|c|c|c|c|c|c|}
\hline \multirow[t]{2}{*}{ Provinces \& Territories } & \multirow[t]{2}{*}{ Location } & \multicolumn{2}{|c|}{$\mathrm{COW}_{0-24}$} & \multicolumn{2}{|c|}{$\mathrm{COW}_{\mathrm{N}-\mathrm{D}}$} \\
\hline & & Mean $\left({ }^{\circ} \mathrm{C}\right)$ & Std Dev $\left({ }^{\circ} \mathrm{C}\right)$ & Mean $\left({ }^{\circ} \mathrm{C}\right)$ & Std Dev $\left({ }^{\circ} \mathrm{C}\right)$ \\
\hline \multirow{3}{*}{ Alberta } & Calgary & -0.49 & 2.68 & -0.18 & 1.98 \\
\hline & Cold Lake & -0.30 & 2.14 & -0.11 & 1.56 \\
\hline & Fort McMurray & -0.33 & 2.45 & -0.12 & 1.77 \\
\hline \multirow[t]{2}{*}{ British Columbia } & Vancouver & -0.54 & 1.99 & -0.15 & 1.42 \\
\hline & Victoria & -0.32 & 1.44 & -0.09 & 1.04 \\
\hline \multirow{2}{*}{ Manitoba } & Churchill & -0.31 & 1.83 & -0.14 & 1.50 \\
\hline & Winnipeg & -0.36 & 2.41 & -0.09 & 1.67 \\
\hline \multirow[t]{2}{*}{ New Brunswick } & Fredericton & -0.48 & 2.20 & -0.30 & 1.62 \\
\hline & Moncton & -0.53 & 2.09 & -0.27 & 1.50 \\
\hline \multirow[t]{2}{*}{ Newfoundland \& Labrador } & Goose & -0.44 & 1.93 & -0.21 & 1.45 \\
\hline & St. John's & -0.70 & 1.82 & -0.35 & 1.35 \\
\hline \multirow[t]{2}{*}{ Nova Scotia } & Greenwood & -0.54 & 2.14 & -0.23 & 1.55 \\
\hline & Yarmouth & -0.52 & 1.75 & -0.23 & 1.30 \\
\hline \multirow[t]{3}{*}{ Ontario } & Ottawa & -0.37 & 1.91 & -0.18 & 1.41 \\
\hline & Toronto & -0.44 & 2.05 & -0.18 & 1.45 \\
\hline & Trenton & -0.36 & 2.09 & -0.07 & 1.53 \\
\hline Prince Edward Island & Charlottetown & -0.49 & 1.77 & -0.24 & 1.31 \\
\hline \multirow[t]{2}{*}{ Quebec } & Bagotville & -0.50 & 2.17 & -0.26 & 1.64 \\
\hline & Montreal & -0.28 & 1.83 & -0.06 & 1.36 \\
\hline \multirow[t]{2}{*}{ Saskatchewan } & Estevan & -0.52 & 2.65 & -0.30 & 1.89 \\
\hline & Saskatoon & -0.36 & 2.48 & -0.17 & 1.77 \\
\hline Northwest Territories & Yellowknife & -0.13 & 1.70 & -0.05 & 1.40 \\
\hline Nunavut & Baker Lake & -0.08 & 1.59 & -0.05 & 1.42 \\
\hline Yukon & Whitehorse & -0.12 & 1.97 & -0.04 & 1.58 \\
\hline Canadian Averages & & -0.40 & 2.07 & -0.17 & 1.53 \\
\hline
\end{tabular}

Overall, the error distribution associated with the $\mathrm{COW}_{\mathrm{N}-\mathrm{D}}$ method displays a smaller mean and standard deviation than the $\mathrm{COW}_{0-24}$ method, thus confirming a closer agreement between measured and linearly interpolated temperature curves. Therefore, based on a qualitative inspection of symmetry and quantitative measure of mean and standard deviation, it can be concluded that the $\mathrm{COW}_{\mathrm{N}-\mathrm{D}}$ air temperature tracking visibly outperforms the $\mathrm{COW}_{0-24}$ method in all instances in a remarkably similar fashion.

\subsection{Comparison of Annual Averages of $\mathrm{COW}_{0-24}$ and $\mathrm{COW}_{N-D}$ Daily Temperature Extrema}

The effects of COW selection on annual temperature averaging are illustrated on examples of the Great Lakes/St. Lawrence Lowlands climate region stations in Figure 7. 


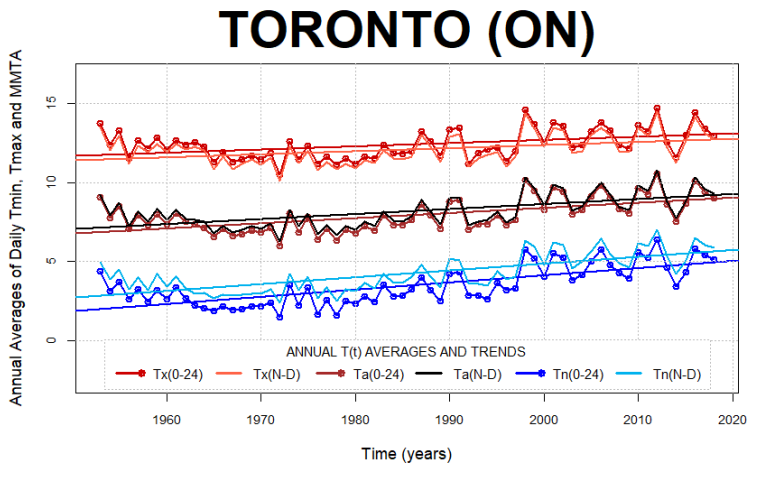

(a)

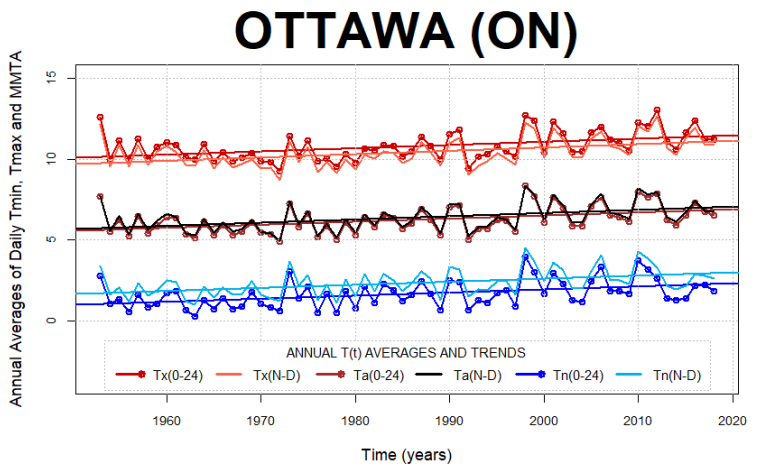

(c)

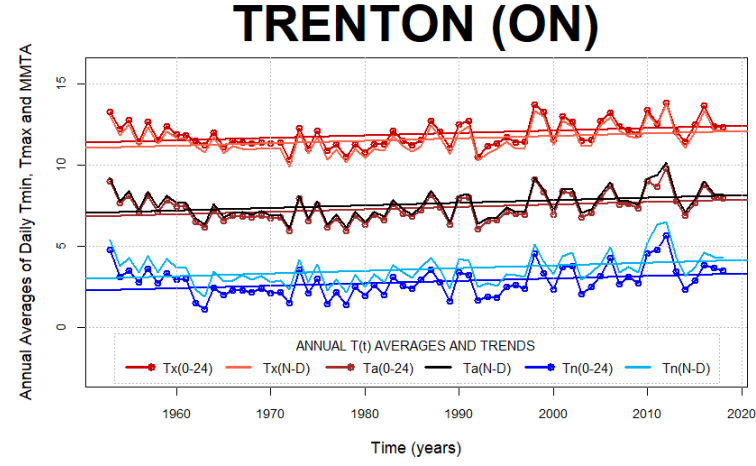

(b)

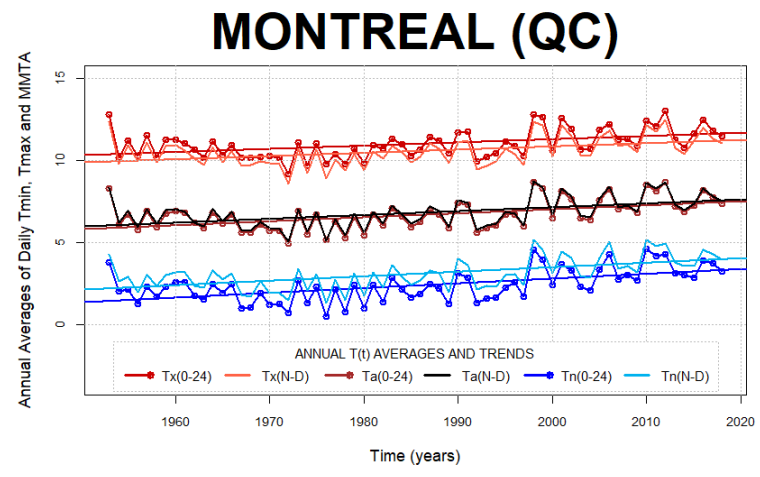

(d)

Figure 7. Effect of the observing window on long-term air temperature averaging for the Great Lakes/St. Lawrence Lowlands climate region at Toronto (a), Trenton (b), Ottawa (c), and Montreal (d) stations. Annually averaged diurnal air temperature minima, maxima, and Min-Max averages obtained with $\mathrm{COW}_{0-24}$ and $\mathrm{COW}_{\mathrm{N}-\mathrm{D}}$ air temperature approximating methods.

On each graph, the blue lines represent annual averages of minima, the dark blue corresponding to $\mathrm{COW}_{0-24}$, and light blue to $\mathrm{COW}_{\mathrm{N}-\mathrm{D}}$ minima. The red lines represent annual averages of maxima, the dark red corresponding to $\mathrm{COW}_{0-24}$, and light red to $\mathrm{COW}_{\mathrm{N}-\mathrm{D}}$ maxima. Brown and black lines represent diurnal averages of extrema, or MinMax averages, based on $\mathrm{COW}_{0-24}$ and $\mathrm{COW}_{\mathrm{N}-\mathrm{D}}$ extrema, respectively.

Annual averages of the $\mathrm{COW}_{0-24}$ and $\mathrm{COW}_{\mathrm{N}-\mathrm{D}}$ methods yield consistently very similar slopes for all six temperature indices at Toronto $(\mathrm{ON})$, Trenton $(\mathrm{ON})$, Ottawa $(\mathrm{ON})$, and Montreal (QC) locations of the Great Lakes/St. Lawrence Lowlands climate region. Similar observations can be made for all other examined Canadian temperature-time series (presented in Appendix B).

Table 3 summarizes temperature discrepancies between annual averages of $\mathrm{COW}_{0-24}$ and $\mathrm{COW}_{\mathrm{N}-\mathrm{D}}$ diurnal temperature indices.

The most considerable differences between the two COW discrete search methods are observable in annually averaged air temperature minima. The $\mathrm{COW}_{\mathrm{N}-\mathrm{D}}$ minima are systematically warmer and positively shifted by $\sim 0.73{ }^{\circ} \mathrm{C}$, on average, compared to the $\mathrm{COW}_{0-24}$ minima, thus revealing the cold bias in minima associated with the $\mathrm{COW}_{0-24}$ method. On the other hand, the $\mathrm{COW}_{\mathrm{N}-\mathrm{D}}$ based maxima are systematically lower by 0.41 ${ }^{\circ} \mathrm{C}$, revealing a warm bias in maxima associated with the $\mathrm{COW}_{0-24}$ method. The $\mathrm{COW}_{\mathrm{N}-\mathrm{D}}$ Min-Max Averages (MMA) are warmer, on average, by $\sim 0.17^{\circ} \mathrm{C}$ than the $\mathrm{COW}_{0-24}$ MMA. 
Table 3. Discrepancies between $\mathrm{COW}_{0-24}$ and $\mathrm{COW}_{\mathrm{N}-\mathrm{D}}$ annual averages of diurnal temperature indices. All temperature data examined in this study represent hourly measurements obtained from Canadian international or regional airports using consistent observation standards. Large differences in temperature trends and discrepancies between individual data sets are the result of regional climate differences. $\Delta \mathrm{T}_{\min }$ represents differences between $\mathrm{COW}_{0-24}$ and $\mathrm{COW}_{\mathrm{N}-\mathrm{D}}$ minima, while $\Delta \mathrm{T}_{\max }$ represents differences between $\mathrm{COW}_{0-24}$ and $\mathrm{COW}_{\mathrm{N}-\mathrm{D}}$ maxima. MMA stands for Min-Max Averages, while DTR stands for the Diurnal Temperature Range.

\begin{tabular}{|c|c|c|c|c|c|}
\hline Provinces \& Territories & Location & $\Delta \mathrm{T}_{\min }$ & $\Delta \mathrm{T}_{\max }$ & $\triangle \mathrm{MMA}$ & $\Delta \mathrm{DTR}$ \\
\hline & & $\left({ }^{\circ} \mathrm{C}\right)$ & $\left({ }^{\circ} \mathrm{C}\right)$ & $\left({ }^{\circ} \mathrm{C}\right)$ & $\left({ }^{\circ} \mathrm{C}\right)$ \\
\hline \multirow[t]{3}{*}{ Alberta } & Calgary & -0.74 & 0.35 & -0.19 & 1.01 \\
\hline & Cold Lake & -0.70 & 0.32 & -0.19 & 1.02 \\
\hline & Fort McMurray & -0.89 & 0.37 & -0.25 & 1.25 \\
\hline \multirow[t]{2}{*}{ British Columbia } & Vancouver & -0.27 & 0.08 & -0.10 & 0.35 \\
\hline & Victoria & -0.36 & 0.08 & -0.14 & 0.44 \\
\hline \multirow[t]{2}{*}{ Manitoba } & Churchill & -0.87 & 0.75 & -0.05 & 1.62 \\
\hline & Winnipeg & -0.96 & 0.44 & -0.26 & 1.40 \\
\hline \multirow[t]{2}{*}{ New Brunswick } & Fredericton & -0.82 & 0.33 & -0.25 & 1.15 \\
\hline & Moncton & -0.82 & 0.39 & -0.22 & 1.21 \\
\hline \multirow[t]{2}{*}{ Newfoundland \& Labrador } & Goose & -0.79 & 0.48 & -0.16 & 1.26 \\
\hline & St. John's & -0.72 & 0.50 & -0.11 & 1.22 \\
\hline \multirow[t]{2}{*}{ Nova Scotia } & Greenwood & -0.82 & 0.42 & -0.20 & 1.25 \\
\hline & Yarmouth & -0.59 & 0.43 & -0.08 & 1.02 \\
\hline \multirow[t]{3}{*}{ Ontario } & Ottawa & -0.69 & 0.39 & -0.15 & 1.09 \\
\hline & Toronto & -0.77 & 0.31 & -0.23 & 1.08 \\
\hline & Trenton & -0.77 & 0.32 & -0.22 & 1.09 \\
\hline Prince Edward Island & Charlottetown & -0.78 & 0.48 & -0.15 & 1.26 \\
\hline \multirow[t]{2}{*}{ Quebec } & Bagotville & -0.95 & 0.52 & -0.21 & 1.45 \\
\hline & Montreal & -0.70 & 0.44 & -0.13 & 1.14 \\
\hline \multirow[t]{2}{*}{ Saskatchewan } & Estevan & -0.27 & 0.40 & -0.27 & 1.27 \\
\hline & Saskatoon & -0.89 & 0.38 & -0.25 & 1.27 \\
\hline Northwest Territories & Yellowknife & -0.80 & 0.60 & -0.10 & 1.40 \\
\hline Nunavut & Baker Lake & -0.73 & 0.75 & 0.005 & 1.48 \\
\hline Yukon & Whitehorse & -0.75 & 0.42 & -0.16 & 1.17 \\
\hline Canadian Averages & & -0.73 & 0.41 & -0.17 & 1.16 \\
\hline
\end{tabular}

However, the average discrepancy between the Diurnal Temperature Range (DTR) of the two COW methods is significant $\left(\sim 1.16^{\circ} \mathrm{C}\right)$ due to large $\mathrm{COW}_{0-24}$ DTRs, resulting from antagonistic minima and maxima biases as opposed to small $\mathrm{COW}_{\mathrm{N}-\mathrm{D}}$ DTRs.

\subsection{Analysis of Diurnal Extrema Timing Subpopulation Counts}

The time evolution analysis of nighttime and daytime timing subpopulations was approached through the evaluation of four-year averages of "before" and "after" member counts at the beginning and ending of data ranges presented in Figures 8 and 9. The "before" DET members are the Before Midnight Minima $\left(\mathrm{BMMt}_{\mathrm{n}}\right)$ and Before Noon Maxima $\left(\mathrm{BNMt}_{\mathrm{x}}\right)$. Correspondingly, the "after" DET members are the After Midnight Minima $\left(\mathrm{AMMt}_{\mathrm{n}}\right)$ and After Noon Maxima (AMMtx).

In Figures 8 and 9, the initial DET subpopulations, corresponding to 1953-1956-year counts, are presented with the red bins, while the green bins represent the final timing configuration of 2015-2018-year counts. The left-hand side histograms present the time evolution of diurnal minima timing, with the middle blue line indicating the midnight delineation over which we monitor nighttime migration of the "before" to "after" subpopulation of extrema over time. The right-hand side histograms show the time evolution of diurnal maxima timing, with the middle blue line indicating the noon delineation point. 


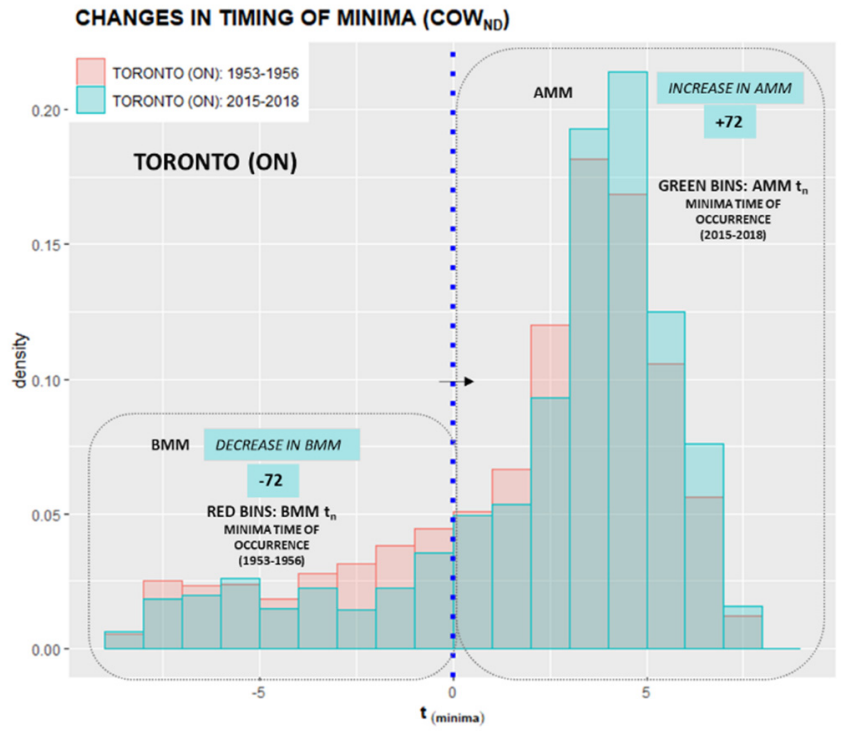

(a)

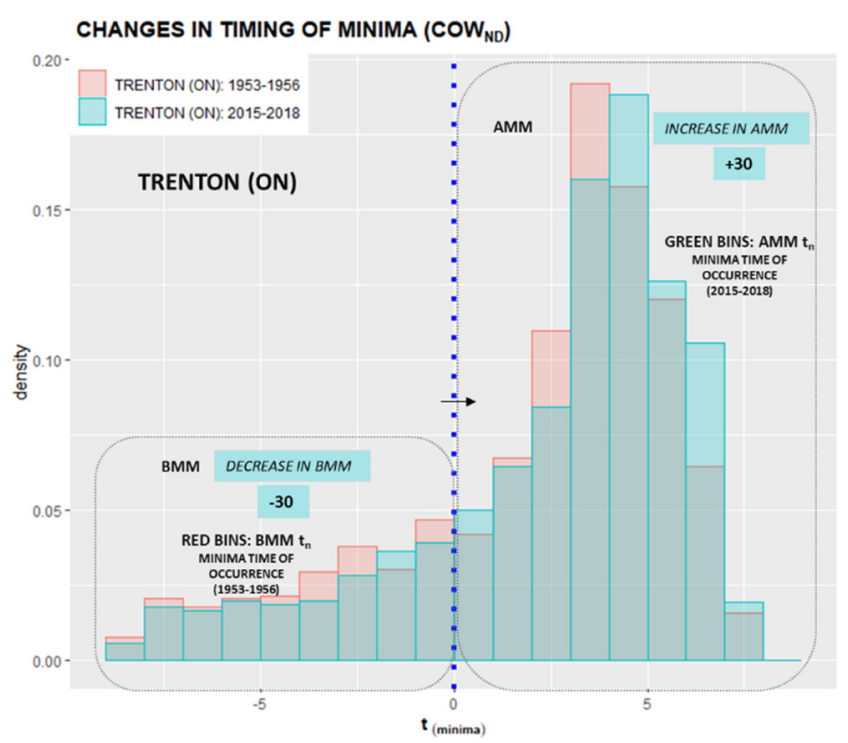

(c)

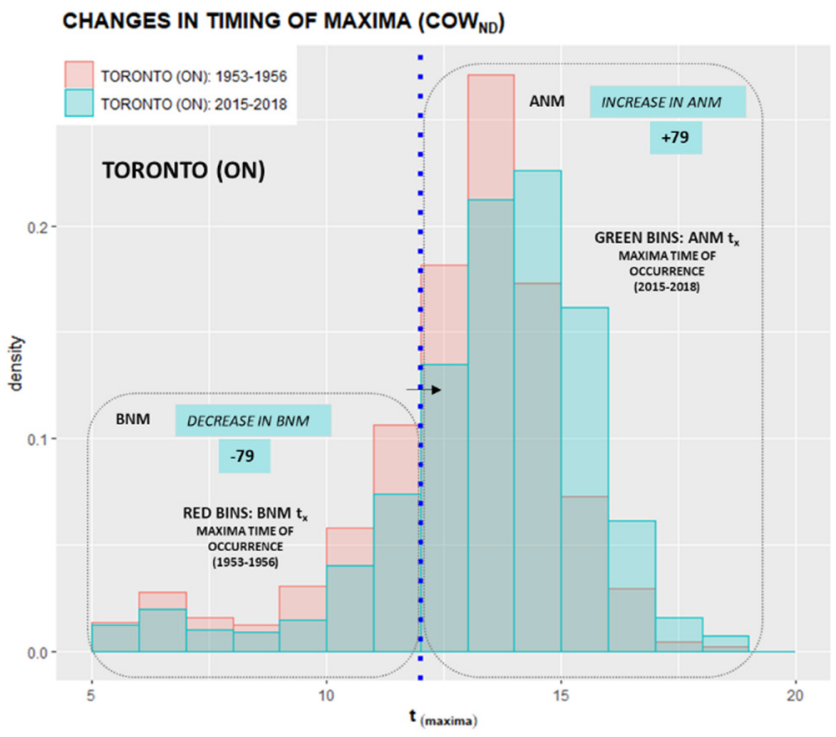

(b)

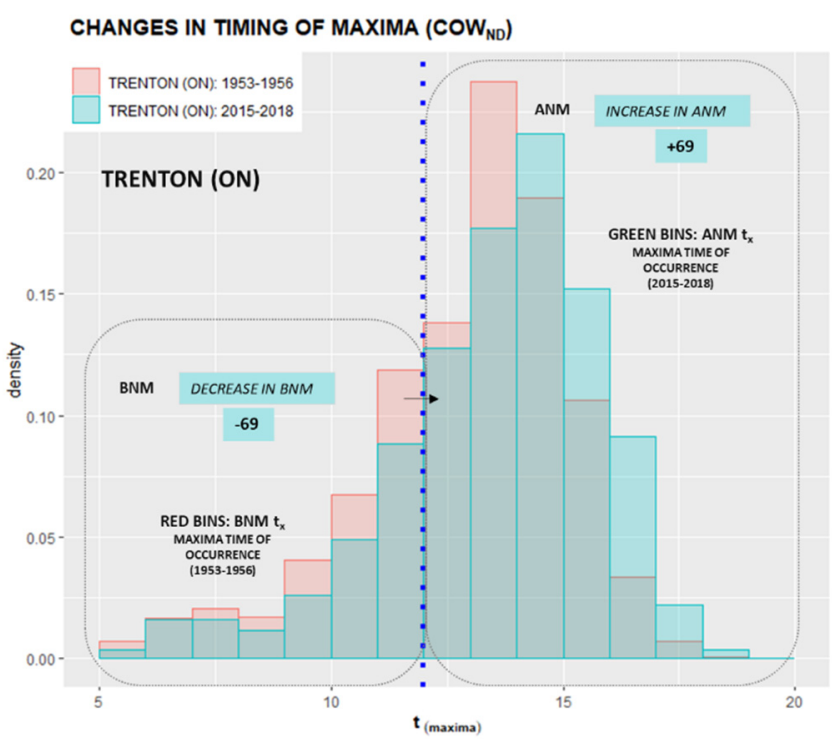

(d)

Figure 8. Time evolution of diurnal extrema timing histograms for the Great Lakes/St. Lawrence Lowlands climate region, at Toronto $(\mathbf{a}, \mathbf{b})$, and Trenton $(\mathbf{c}, \mathbf{d})$ stations. Migration of Before Midnight Minima $\left(\mathrm{BMMt}_{\mathrm{n}}\right)$ to After Midnight Minima $\left(\mathrm{AMMt}_{\mathrm{n}}\right)$ and Migration of Before Noon Maxima $\left(\mathrm{BNMt}_{\mathrm{x}}\right.$ ) to After Noon Maxima (ANMt $\mathrm{x}_{\mathrm{x}}$ ) between four-year averages at the beginning (1953-1956) and ending (2015-2018) of data ranges. The blue dotted line represents midnight delineation (left) and noon delineation (right). 


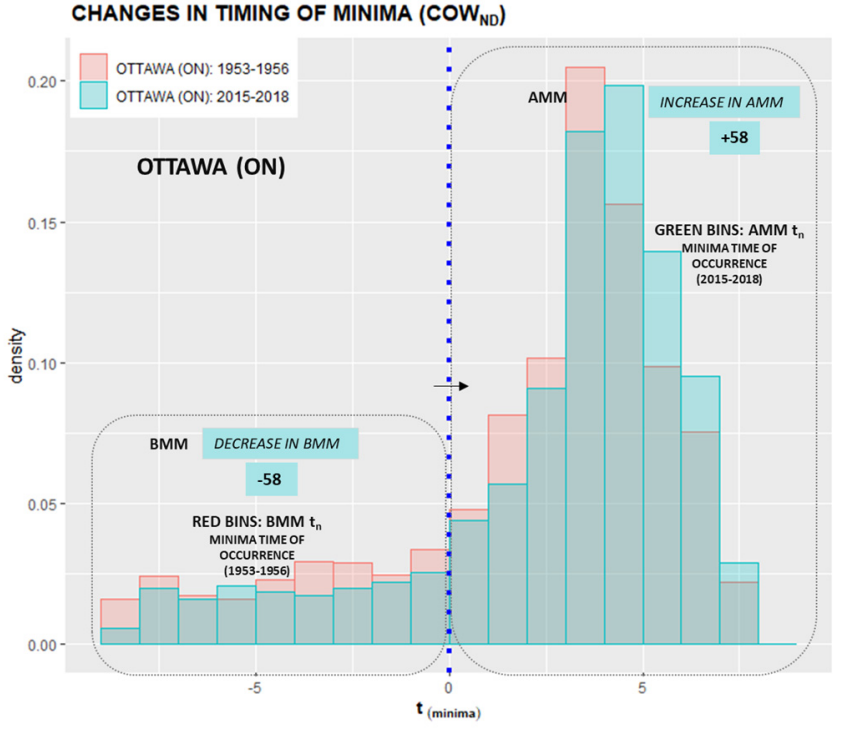

(a)

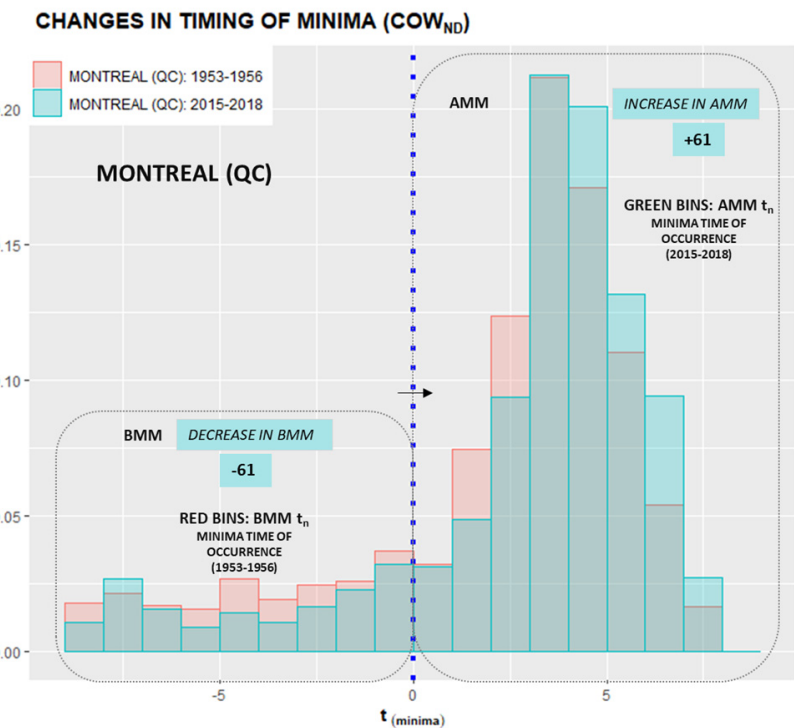

(c)

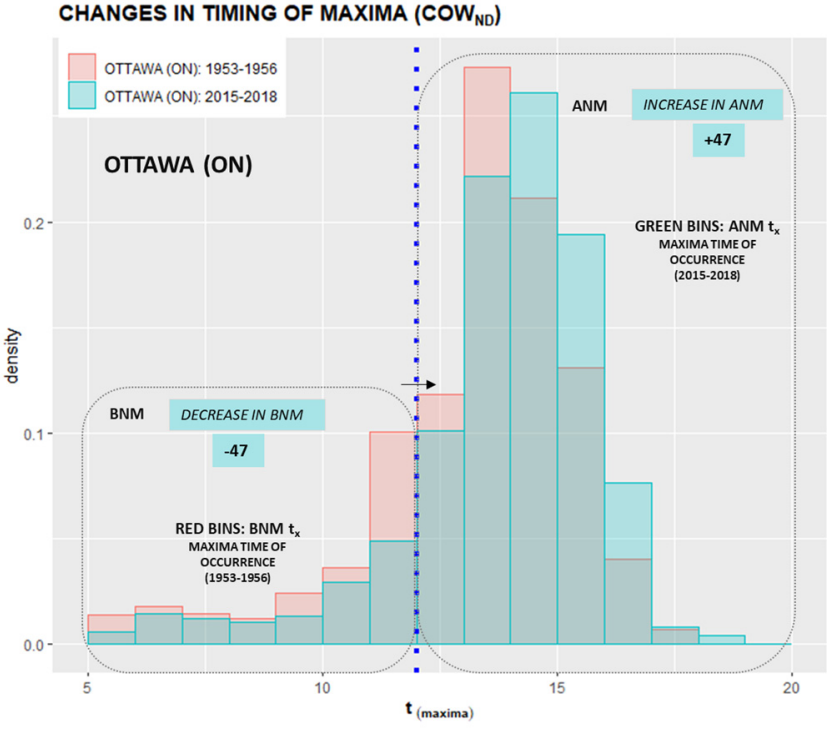

(b)

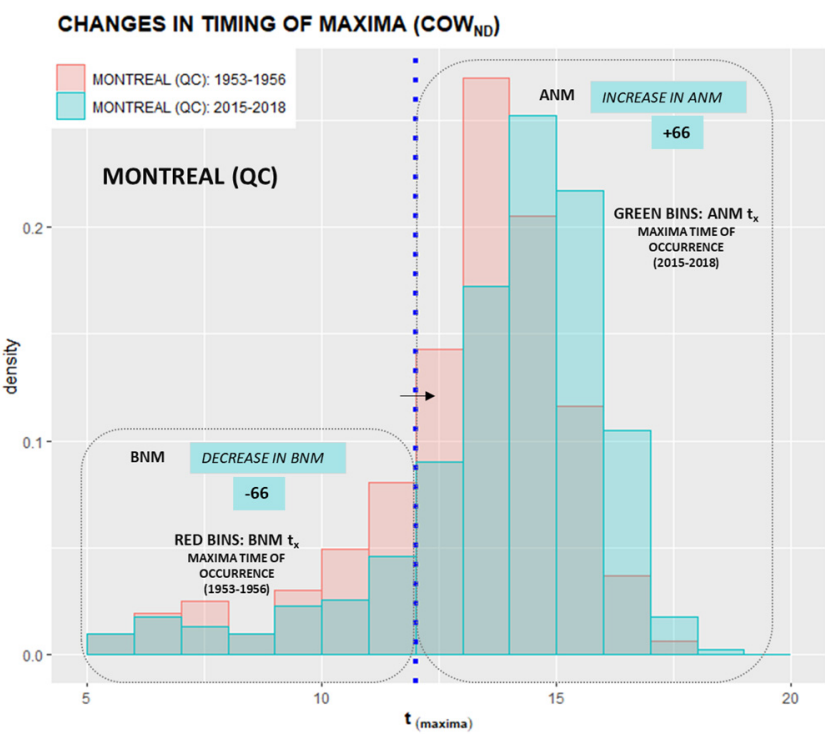

(d)

Figure 9. Time evolution of diurnal extrema timing histograms for the Great Lakes/St. Lawrence Lowlands climate region, at Ottawa (a,b), and Montreal (c,d) stations. Migration of Before Midnight Minima $\left(\mathrm{BMMt}_{\mathrm{n}}\right)$ to After Midnight Minima $\left(\mathrm{AMMt}_{\mathrm{n}}\right)$ and Migration of Before Noon Maxima $\left(\mathrm{BNMt}_{\mathrm{x}}\right)$ to After Noon Maxima $\left(\mathrm{ANMt}_{\mathrm{x}}\right.$ ) between four-year averages at the beginning (1953-1956) and ending (2015-2018) of data ranges. The blue dotted line represents midnight delineation (left) and noon delineation (right).

The left-hand side minima histograms in Figure 8 show the contrast in DET migration of the $\mathrm{BMMt}_{\mathrm{n}}$ to the $\mathrm{AMMt}_{\mathrm{n}}$ counts of Toronto and Trenton subpopulations over the 66-year study period with a more intense migration of minima observed at the Toronto (72 counts versus 30 counts at Trenton).

The intensity of minima migration of $\mathrm{BMMt}_{n}$ to $\mathrm{AMMt}_{n}$ counts between Ottawa and Montreal subpopulations in Figure 9 (left) is within a similar range $\left(58 \mathrm{BMMt}_{n}\right.$ and $61 \mathrm{BMMt}_{\mathrm{n}}$, respectively), while still less intense than at Toronto (72 $\mathrm{BMMt}_{\mathrm{n}}$ ). The migration of the DET maxima counts from the BNMt $t_{\mathrm{x}}$ to $\mathrm{ANMt}_{\mathrm{x}}$ in Figure 8 (right) is more intense at Toronto than Trenton (79 BNMt $t_{x}$ at Toronto and $69 \mathrm{BNMt}_{\mathrm{x}}$ at Trenton). The migration of Ottawa BNMt $t_{x}$ to $\mathrm{ANMt}_{\mathrm{x}}$ counts is the least intense $\left(47 \mathrm{BNMt}_{\mathrm{x}}\right)$ among the 
Great Lakes/St. Lawrence Lowlands stations (Figure 9). The histograms of other studied sites, presented in Appendix C, display similar migration patterns with a consistent decrease in the $\mathrm{BMMt}_{\mathrm{n}}$ and $\mathrm{BNMt}_{\mathrm{x}}$ counts due to the persistent migration of "before" to "after" subpopulations.

Although the direction of migration of both $\mathrm{BMMt}_{\mathrm{n}}$ and $\mathrm{BNMt}_{\mathrm{x}}$ subpopulations is unequivocally towards the later time of extrema occurrence, the intensity of migration and the proportion of the overall migrated population counts varies through Canada.

Table 4 summarizes the $\mathrm{BMMt}_{\mathrm{n}}$ and $\mathrm{BNMt}_{\mathrm{x}}$ migration counts of all studied locations. Total counts of $\mathrm{BMMt}_{\mathrm{n}}$ and $\mathrm{BNMt}_{\mathrm{x}}$ subpopulations are presented in columns 3 and 6. The number of migrated $\mathrm{BMMt}_{\mathrm{n}}$ and $\mathrm{BNMt}_{\mathrm{x}}$ are presented in columns 4 and 7. Percentages of migrated extrema, relative to their initial 4-year average count, are given in columns 5 and 8 .

Table 4. Migration counts of the Before Midnight Minima $\left(B M M t_{n}\right)$ to After Midnight Minima $\left(\mathrm{AMMt}_{\mathrm{n}}\right)$ and of the Before Noon Maxima $\left(\mathrm{BNMt}_{\mathrm{x}}\right)$ to After Noon Maxima $\left(\mathrm{ANMt}_{\mathrm{x}}\right)$ between the examined 4-year averages at the beginning (1953-1956) and ending of the data range (2015-2018). Migration is expressed as counts, as well as percentages, of total populations.

\begin{tabular}{|c|c|c|c|c|c|c|c|}
\hline \multirow[t]{2}{*}{ Provinces \& Territories } & \multirow[t]{2}{*}{ Location } & \multirow{2}{*}{$\begin{array}{c}\text { Total BMMt } \\
\text { (n) }\end{array}$} & \multicolumn{2}{|c|}{${\text { Migrated } B M M t_{n}}$} & \multirow{2}{*}{$\begin{array}{c}\text { Total BNMt } \\
\text { (n) }\end{array}$} & \multicolumn{2}{|c|}{ Migrated $\mathrm{BNMt}_{\mathrm{x}}$} \\
\hline & & & (n) & $(\%)$ & & (n) & $(\%)$ \\
\hline \multirow[t]{3}{*}{ Alberta } & Calgary & 270 & -120 & 44.4 & 146 & -42 & 28.8 \\
\hline & Cold Lake & 174 & -7 & 9.5 & 141 & -34 & 24.1 \\
\hline & Fort McMurray & 219 & -40 & 18.3 & 123 & -26 & 21.1 \\
\hline \multirow[t]{2}{*}{ British Columbia } & Vancouver & 311 & -111 & 35.7 & 220 & -93 & 42.3 \\
\hline & Victoria & 390 & -149 & 38.2 & 242 & -123 & 50.8 \\
\hline \multirow[t]{2}{*}{ Manitoba } & Churchill & 453 & -140 & 30.9 & 431 & -106 & 24.6 \\
\hline & Winnipeg & 224 & -45 & 20.1 & 159 & -18 & 11.3 \\
\hline \multirow[t]{2}{*}{ New Brunswick } & Fredericton & 232 & -13 & 5.6 & 162 & -46 & 28.4 \\
\hline & Moncton & 298 & -55 & 18.5 & 236 & -70 & 29.7 \\
\hline \multirow[t]{2}{*}{ Newfoundland \& Labrador } & Goose & 281 & -71 & 25.3 & 196 & -28 & 14.3 \\
\hline & St. John's & 589 & -120 & 20.4 & 508 & -97 & 19.1 \\
\hline \multirow[t]{2}{*}{ Nova Scotia } & Greenwood & 337 & -102 & 30.3 & 280 & -100 & 35.1 \\
\hline & Yarmouth & 498 & -130 & 26.1 & 465 & -176 & 37.8 \\
\hline \multirow[t]{3}{*}{ Ontario } & Ottawa & 261 & -58 & 22.2 & 174 & -47 & 27.0 \\
\hline & Toronto & 284 & -72 & 25.4 & 235 & -79 & 31.9 \\
\hline & Trenton & 271 & -30 & 11.1 & 250 & -69 & 27.6 \\
\hline Prince Edward Island & Charlottetown & 460 & -108 & 23.5 & 382 & -124 & 32.5 \\
\hline \multirow[t]{2}{*}{ Quebec } & Bagotville & 333 & -77 & 23.1 & 283 & -120 & 42.4 \\
\hline & Montreal & 246 & -61 & 24.8 & 212 & -66 & 31.1 \\
\hline \multirow[t]{2}{*}{ Saskatchewan } & Estevan & 228 & -79 & 34.6 & 149 & -56 & 37.6 \\
\hline & Saskatoon & 214 & -37 & 17.3 & 159 & -68 & 42.8 \\
\hline Northwest Territories & Yellowknife & 339 & -47 & 13.9 & 214 & -47 & 22.0 \\
\hline Nunavut & Baker Lake & 560 & -176 & 31.4 & 406 & -113 & 27.8 \\
\hline Yukon & Whitehorse & 279 & -80 & 28.7 & 181 & -104 & 57.5 \\
\hline Canadian Averages & & 323 & -80 & 24.1 & 248 & -77 & 31.2 \\
\hline
\end{tabular}

The most intense migration of $\mathrm{BMMt}_{\mathrm{n}}$ counts, among all climatic regions, is observed at the Arctic Tundra location of Baker Lake (176 BMMt $)$, followed by the Pacific Coast, North British Columbia Mountains/Yukon Territory, Atlantic Canada, and Hudson Bay stations. While the Northwestern Forest, the Mackenzie District, and the Prairies display the lowest $\mathrm{BNMt}_{\mathrm{x}}$ migration counts among Canadian climate regions, Northeastern Forest and other Canadian eastern continental locations exhibit large BNMt $\mathrm{B}_{\mathrm{x}}$ migration counts. The most intense migration of the $\mathrm{BNMt}_{\mathrm{x}}$ counts is observed at Atlantic Canada locations of Yarmouth (176 BNMt $\mathrm{B}_{\mathrm{x}}$ ) and Charlottetown (123 BNMt $\mathrm{BN}_{\mathrm{x}}$ ). The largest overall migrations are observed at Calgary $\left(44.4 \% \mathrm{BMMt}_{\mathrm{n}}\right)$ and Saskatoon $\left(42.8 \% \mathrm{BNMt}_{\mathrm{x}}\right)$. 


\subsection{Analysis of Diurnal Extrema Timing Subpopulation Trends and Time Shifts}

This section presents linear trends and calculated delays of annually averaged $\mathrm{AMMt}_{n}$ and $\mathrm{ANMt}_{\mathrm{x}}$ subpopulations. The MK test for detecting trends in annual timing subpopulation data was employed using the "Kendal" package in R code to answer the question of whether or not the DET is systematically changing through time. Time shifts of annual $\mathrm{AMMt}_{\mathrm{n}}$ and $\mathrm{ANMt}_{\mathrm{x}}$ subpopulations were calculated as a product of linear slope and the period of slope increase. Subsequently, locally estimated scatterplot smoothing (LOESS) was used in regression analysis to demonstrate the digression from linearity in the DET parameter over the study range. LOESS curves fitted to $\mathrm{AMMt}_{\mathrm{n}}$ and $\mathrm{ANMt}_{\mathrm{x}}$ subpopulations are presented in Figures 10 and 11 to emphasize the complexities of the overall change in the DET parameter.

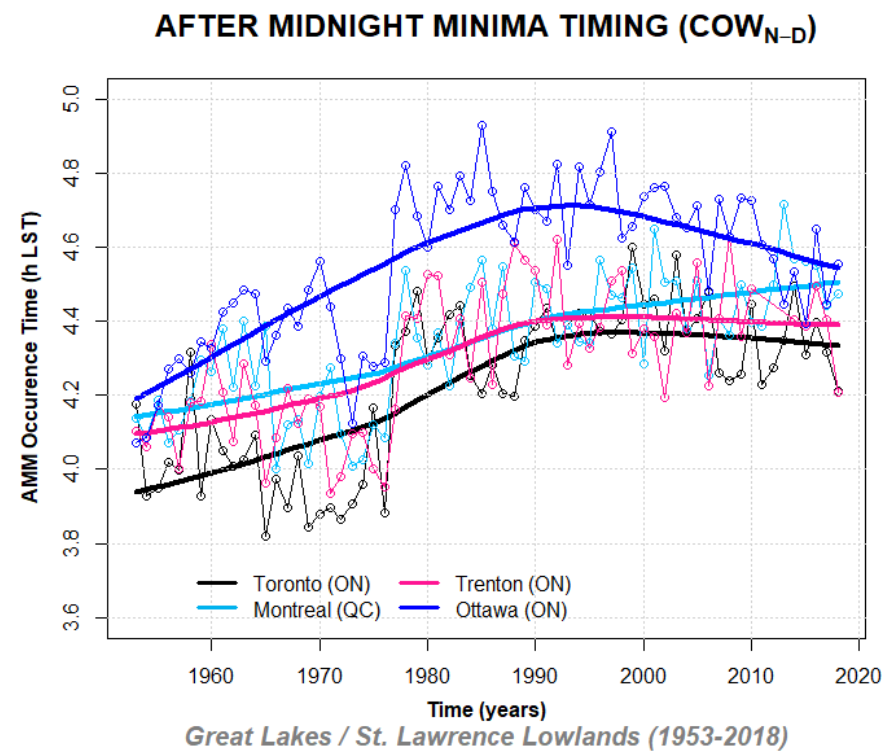

Figure 10. Annually averaged DET AMMt $t_{n}$ trends of the Great Lakes/St. Lawrence Lowlands climate region with notable LOESS trends, indicating positive shifts in the After Midnight Minima timing occurrence.

\section{AFTER NOON MAXIMA TIMING $\left(\operatorname{COW}_{\mathrm{N}-\mathrm{D}}\right)$}

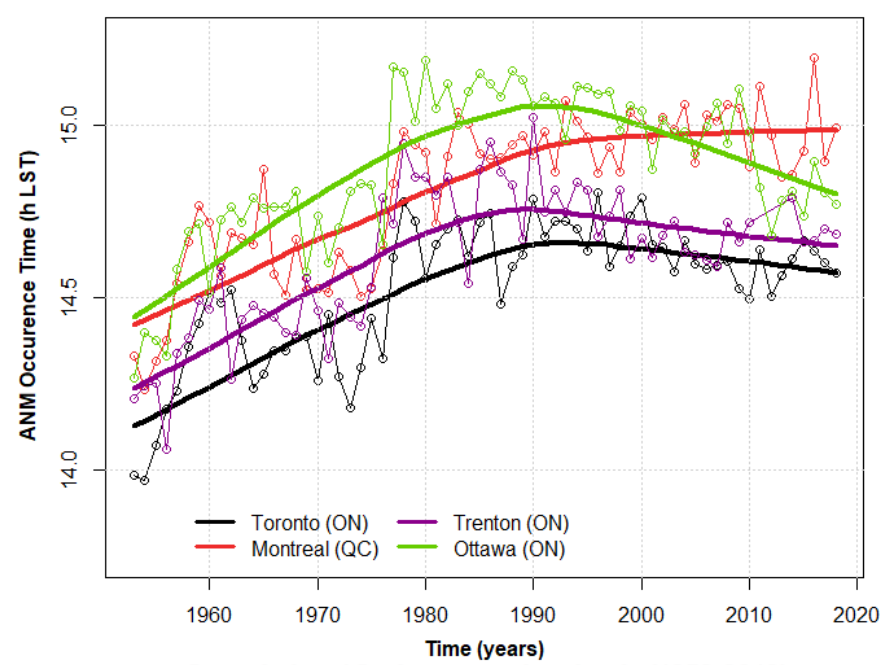

Great Lakes / St. Lawrence Lowlands (1953-2018)

Figure 11. Annually averaged DET ANMt trends of the Great Lakes/St. Lawrence Lowlands climate region with variable positive shifts in After Noon Maxima timing occurrence. 
Table 5 presents Canadian $\mathrm{AMMt}_{\mathrm{n}}$ and $\mathrm{ANMt}_{\mathrm{x}}$ subpopulations trends and estimates of their time shifts expressed as time increments accrued to the minima and maxima DET parameters over the 66-year study range. Delays in $\mathrm{AMMt}_{\mathrm{n}}$ and $\mathrm{ANMt}_{\mathrm{x}}$ extrema timing subpopulations, calculated as the product of the linear slope of annually averaged timing and the time span of the study range, are denoted as linearly projected DETt $\mathrm{n}_{\mathrm{n}}$ and DETt time shifts in hours (columns 4 and 6 of Table 5).

Table 5. Annually averaged timing trends of the After Midnight Minima (AMMt ${ }_{n}$ ) and After Noon Maxima $\left(\mathrm{ANMt}_{\mathrm{x}}\right)$ subpopulations and linearly projected time shifts $\left(\mathrm{DETt}_{\mathrm{n}}\right.$ and $\left.\mathrm{DETt}_{\mathrm{x}}\right)$ calculated as the product of the linear slope and the time span of the study range.

\begin{tabular}{|c|c|c|c|c|c|}
\hline Provinces \& Territories & Location & AMMt $_{n}$ Slopes & DETt $_{n}$ & ANMt $_{X}$ Slopes & $\operatorname{DETt}_{x}$ \\
\hline & & $(\mathrm{h} / \mathrm{y})$ & (h) & $(h / y)$ & (h) \\
\hline \multirow[t]{3}{*}{ Alberta } & Calgary & $6.6 \times 10^{-3}$ & 0.44 & $5.5 \times 10^{-3}$ & 0.36 \\
\hline & Cold Lake & $9.5 \times 10^{-3}$ & 0.61 & $9.3 \times 10^{-3}$ & 0.60 \\
\hline & Fort McMurray & $6.3 \times 10^{-3}$ & 0.42 & $6.7 \times 10^{-3}$ & 0.44 \\
\hline \multirow[t]{2}{*}{ British Columbia } & Vancouver & $8.1 \times 10^{-3}$ & 0.53 & $7.2 \times 10^{-3}$ & 0.48 \\
\hline & Victoria & $7.1 \times 10^{-3}$ & 0.47 & $9.3 \times 10^{-3}$ & 0.61 \\
\hline \multirow[t]{2}{*}{ Manitoba } & Churchill & $8.0 \times 10^{-3}$ & 0.53 & $2.8 \times 10^{-3}$ & 0.18 \\
\hline & Winnipeg & $3.6 \times 10^{-3}$ & 0.24 & $5.3 \times 10^{-3}$ & 0.35 \\
\hline \multirow[t]{2}{*}{ New Brunswick } & Fredericton & $6.8 \times 10^{-3}$ & 0.38 & $6.3 \times 10^{-3}$ & 0.42 \\
\hline & Moncton & $8.5 \times 10^{-3}$ & 0.56 & $6.7 \times 10^{-3}$ & 0.38 \\
\hline \multirow[t]{2}{*}{ Newfoundland \& Labrador } & Goose & $8.4 \times 10^{-3}$ & 0.55 & $9.5 \times 10^{-3}$ & 0.63 \\
\hline & St. John's & $6.1 \times 10^{-3}$ & 0.40 & $2.3 \times 10^{-3}$ & 0.14 \\
\hline \multirow[t]{2}{*}{ Nova Scotia } & Greenwood & $9.3 \times 10^{-3}$ & 0.61 & $9.2 \times 10^{-3}$ & 0.61 \\
\hline & Yarmouth & $9.3 \times 10^{-3}$ & 0.61 & $7.6 \times 10^{-3}$ & 0.50 \\
\hline \multirow[t]{3}{*}{ Ontario } & Ottawa & $6.3 \times 10^{-3}$ & 0.42 & $6.0 \times 10^{-3}$ & 0.40 \\
\hline & Toronto & $7.5 \times 10^{-3}$ & 0.50 & $6.9 \times 10^{-3}$ & 0.46 \\
\hline & Trenton & $6.1 \times 10^{-3}$ & 0.38 & $6.7 \times 10^{-3}$ & 0.42 \\
\hline Prince Edward Island & Charlottetown & $8.9 \times 10^{-3}$ & 0.59 & $5.7 \times 10^{-3}$ & 0.38 \\
\hline \multirow[t]{2}{*}{ Quebec } & Bagotville & $7.0 \times 10^{-3}$ & 0.46 & $9.6 \times 10^{-3}$ & 0.63 \\
\hline & Montreal & $6.4 \times 10^{-3}$ & 0.42 & $9.1 \times 10^{-3}$ & 0.60 \\
\hline \multirow[t]{2}{*}{ Saskatchewan } & Estevan & $5.3 \times 10^{-3}$ & 0.35 & $5.1 \times 10^{-3}$ & 0.34 \\
\hline & Saskatoon & $6.7 \times 10^{-3}$ & 0.44 & $2.1 \times 10^{-2}$ & 1.39 \\
\hline Northwest Territories & Yellowknife & $5.5 \times 10^{-3}$ & 0.36 & $8.5 \times 10^{-3}$ & 0.56 \\
\hline Nunavut & Baker Lake & $8.0 \times 10^{-3}$ & 0.44 & $1.3 \times 10^{-3}$ & 0.09 \\
\hline Yukon & Whitehorse & $1.0 \times 10^{-3}$ & 0.69 & $2.2 \times 10^{-2}$ & 1.44 \\
\hline Canadian Averages & & & 0.48 & & 0.52 \\
\hline
\end{tabular}

The average delay of all $\mathrm{AMMt}_{\mathrm{n}}$ subpopulations of the Great Lakes/St. Lawrence Lowlands region is estimated to be $\sim 0.43 \mathrm{~h}$ and $\sim 0.47 \mathrm{~h}$ for $\mathrm{ANMt}_{\mathrm{x}}$ subpopulations over the 66-year study range. The most considerable $\mathrm{ANMt}_{\mathrm{x}}$ delay observed at Whitehorse $(1.44 \mathrm{~h})$ data stands in contrast with the smallest delay observed at Churchill $(0.18 \mathrm{~h})$. The overall timing of the $\mathrm{AMMt}_{\mathrm{n}}$ subpopulations has shifted $\sim 29$ min later in the day, while the timing of the $\mathrm{ANMt}_{\mathrm{x}}$ subpopulations has been delayed by $\sim 31 \mathrm{~min}$, on average, throughout Canada. All slopes of $\mathrm{AMMt}_{\mathrm{n}}$ and $\mathrm{ANMt}_{\mathrm{x}}$ subpopulations are statistically significant according to low Mann-Kendall $p$-values that are less than 0.01 , and many are much smaller $\left(10^{-6}\right)$.

Local polynomial regression trends of the annually averaged "after" subpopulations of diurnal minima $\left(\mathrm{AMMt}_{\mathrm{n}}\right)$ and maxima $\left(\mathrm{ANMt}_{\mathrm{x}}\right)$ timing subpopulations of the Great Lakes/St. Lawrence Lowlands climate region are presented in Figures 10 and 11.

Figures of minima (DET AMMt $)$ and maxima (DET ANMt $)$ time shifts of other study locations are presented in Appendix D. The time evolution of $\mathrm{AMMt}_{\mathrm{n}}$ subpopulation trends at Toronto, Trenton, and Montreal are similar and in contrast with the trend changes observed in Ottawa data that exhibit a faster and more considerable shift in the DET AMMt parameter. The time evolution of the DET ANMt $\mathrm{A}_{\mathrm{x}}$ subpopulation trends in the Great 
Lakes/St Lawrence Lowlands climate region shows a latitudinal spread at the beginning of the data range. A similar pattern of abrupt trend increases, observed in Ottawa DET $\mathrm{AMMt}_{\mathrm{n}}$, also emerges in DET ANMt $\mathrm{t}_{\mathrm{x}}$, achieving its maximum value in the mid-1990s and a sudden decrease afterward. A simultaneous mid-1990s maximum observed in all Great

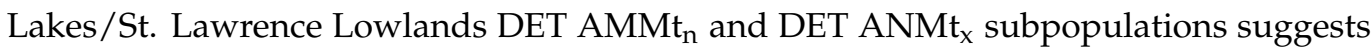
an intensification of large-scale climatic influences affecting the entire region. A sudden DET positive shift, starting in the early 1970s and continuing through 1978, is observed in all examined data sets. The most prominent DET shift is registered in the DET AMMt at Saskatoon, Whitehorse, and Cold Lake stations, as well as at Vancouver and St. John's. One possible explanation of this Canada-wide timing shift is the amplification of Canada's climate trends under the influence of large-scale teleconnections on air temperature. Most of the stations that exhibit intense temperature and timing changes are located within the range of overlapping teleconnection influences [33]. While the interannual variability in the DET parameter seems to be reflective of minor climate variation the departure of the DET trends from the linearity after a phase of intensification in Figures 10 and 11 suggests a strong correlation with the periodicity of the teleconnection phases.

\subsection{Climate Parameter Sensitivity Index (CPSI) Ranking}

The values of the CPSI for temperature minima $\left(\mathrm{NT}_{\mathrm{n}}\right)$, temperature maxima $\left(\mathrm{DT}_{\mathrm{x}}\right)$, After Midnight Minima timing (DET AMMt $\mathrm{n}_{\mathrm{n}}$ ), and After Noon Maxima timing (DET $\mathrm{ANMt}_{\mathrm{x}}$ ) are calculated using Equations (1)-(6) in Section 2.6. and presented in Table 6 for a comparison of the sensitivity of the parameters to climate change (see Appendix $\mathrm{E}$ for sample calculations).

Table 6. Climate parameter sensitivity indices for diurnal temperature and timing parameters.

\begin{tabular}{|c|c|c|c|c|c|}
\hline Provinces \& Territories & Location & $N T_{n}$ & $A M M t_{n}$ & $\mathrm{DT}_{\mathrm{x}}$ & $\mathrm{ANMt}_{\mathrm{x}}$ \\
\hline & & $(\%)$ & $(\%)$ & $(\%)$ & $(\%)$ \\
\hline \multirow[t]{3}{*}{ Alberta } & Calgary & 3.06 & 5.48 & 2.44 & 5.14 \\
\hline & Cold Lake & 2.99 & 7.62 & 2.42 & 8.49 \\
\hline & Fort McMurray & 3.55 & 4.60 & 3.11 & 7.34 \\
\hline \multirow[t]{2}{*}{ British Columbia } & Vancouver & 3.36 & 6.68 & 2.05 & 11.81 \\
\hline & Victoria & 2.93 & 5.89 & 2.57 & 15.27 \\
\hline \multirow[t]{2}{*}{ Manitoba } & Churchill & 2.87 & 5.83 & 2.94 & 2.67 \\
\hline & Winnipeg & 1.64 & 2.99 & 1.93 & 5.88 \\
\hline \multirow{2}{*}{ New Brunswick } & Fredericton & 1.77 & 4.70 & 1.51 & 13.69 \\
\hline & Moncton & 2.02 & 7.02 & 1.91 & 6.00 \\
\hline \multirow[t]{2}{*}{ Newfoundland \& Labrador } & Goose & 0.76 & 7.01 & 1.26 & 8.91 \\
\hline & St. John's & 2.10 & 4.57 & 2.61 & 1.95 \\
\hline \multirow[t]{2}{*}{ Nova Scotia } & Greenwood & 2.36 & 7.64 & 2.09 & 8.63 \\
\hline & Yarmouth & 2.43 & 8.02 & 2.54 & 10.00 \\
\hline \multirow[t]{3}{*}{ Ontario } & Ottawa & 2.07 & 5.22 & 2.08 & 5.68 \\
\hline & Toronto & 5.00 & 6.19 & 2.24 & 7.54 \\
\hline & Trenton & 1.26 & 4.78 & 1.52 & 7.04 \\
\hline Prince Edward Island & Charlottetown & 1.80 & 7.39 & 2.12 & 5.34 \\
\hline \multirow[t]{2}{*}{ Quebec } & Bagotville & 2.62 & 4.62 & 1.79 & 7.96 \\
\hline & Montreal & 2.83 & 5.25 & 1.97 & 8.59 \\
\hline \multirow[t]{2}{*}{ Saskatchewan } & Estevan & -1.08 & 4.37 & 0.51 & 6.70 \\
\hline & Saskatoon & 1.78 & 5.56 & 1.84 & 27.75 \\
\hline Northwest Territories & Yellowknife & 3.63 & 3.65 & 3.34 & 6.23 \\
\hline Nunavut & Baker Lake & 3.34 & 4.45 & 3.28 & 4.71 \\
\hline Yukon & Whitehorse & 3.27 & 7.66 & 2.43 & 20.63 \\
\hline Canadian Averages & & 2.43 & 5.72 & 2.19 & 8.91 \\
\hline
\end{tabular}

The CPSI values of air temperature minima $\left(\mathrm{AMM} \mathrm{NT}_{\mathrm{n}}\right)$ and maxima $\left(\mathrm{AMM} \mathrm{DT}_{\mathrm{x}}\right)$ are presented on the map of Canada with coinciding climatic patterns for identification of specific teleconnection influences on individual temperature time series (Figure 12). 


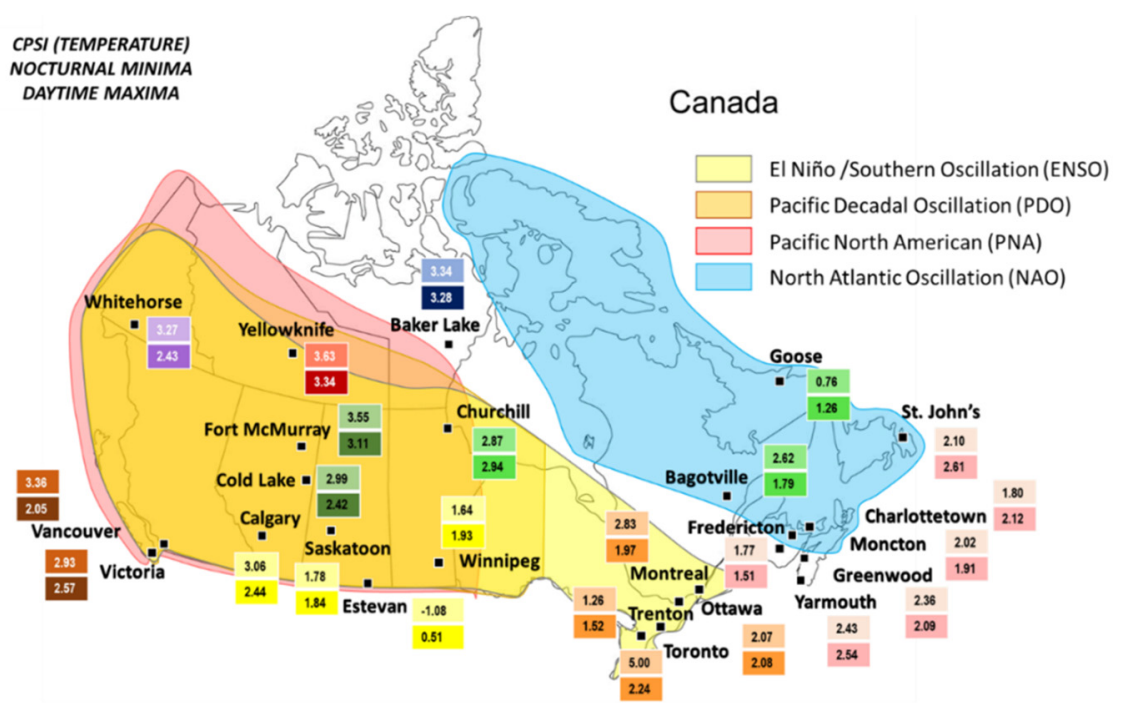

Figure 12. The CPSI of temperature minima (upper row values) and maxima (lower row values) of study locations within the range of influence of large-scale teleconnections affecting the climate of Canada. The CPSI indices are expressed in percentages and presented on color-coded fields corresponding to the colors of shading selected for identifying Canadian climate regions from Figure 3. The map of Canada with regions impacted by large climatic patterns (Adapted from Large-Scale Climate Oscillations Influencing Canada, 1900-2008 by Bonsal and Shabbar, 2011. Copyright 2011 by Her Majesty the Queen in Right of Canada).

The CPSI indices are expressed in percentages and presented on color-coded fields that correspond to the colors of shading selected for identifying Canadian climate regions from Figure 3.

The western and northwestern regions of Canada are found within the range of influence of the El Nino/Southern Oscillation (ENSO), Pacific Decadal Oscillation (PDO), and Pacific North American (PNA) oscillations, while the North Atlantic (NAO) Oscillation influences the northeastern Canada. The El Nino/Southern Oscillation (ENSO) is known to exert a large influence over climatic conditions in Canada. Furthermore, the PNA climate variability frequently coincides with ENSO and PDO phases [33].

The highest value of the CPSI for air temperature minima $\left(\mathrm{NT}_{\mathrm{n}}=5 \%\right)$ is observed in Toronto temperature records, indicating the strong effects of the urban heat island altering the air temperature minimum. The $\mathrm{NT}_{\mathrm{n}} \mathrm{CPSI}$ values of the other locations within the Great Lakes and St. Lawrence Lowlands climate region range between $1.26 \%$ at Trenton and $2.83 \%$ at Montreal. High values of $\mathrm{NT}_{\mathrm{n}}$ CPSI are identified at Canadian northwesternnorthern locations of Yellowknife (3.63\%), Vancouver (3.36\%), Baker Lake (3.34\%), and Calgary $(3.06 \%)$. The findings of high $\mathrm{NT}_{\mathrm{n}}$ CPSI at these locations are consistent with the most considerable change in annual averages of diurnal air temperature extrema across Canada found within the overlapping influence of major teleconnections. The lowest $\mathrm{NT}_{\mathrm{n}}$ CPSI is observed at Goose $(0.76 \%)$, pointing to the moderating effect of cold waters of the Labrador Current on the coastal lands in its path. Lower $\mathrm{NT}_{\mathrm{n}}$ CPSI values are characteristic of Prairies, while a midrange $\mathrm{NT}_{\mathrm{n}} \mathrm{CPSI}$ is typical for Atlantic Canada and Northeastern Forest climate regions. A negative $\mathrm{NT}_{\mathrm{n}} \mathrm{CPSI}$ is identified at Estevan $(-1.08 \%)$, indicating a locally strong cooling temperature trend over the 66-year study range.

The highest value of the CPSI for daytime temperature maxima $\left(\mathrm{DT}_{\mathrm{x}}=3.34 \%\right)$ is found at Yellowknife. Higher values of $\mathrm{DT}_{\mathrm{x}} \mathrm{CPSI}$ are identified at Canadian northwesternnorthern locations of Fort McMurray (3.11\%) and Churchill (2.94\%). Lower DT $\mathrm{x}$ CPSI is observed in Prairies, while higher midrange values of maxima CPSI are characteristic for the Atlantic Canada climate region. The $\mathrm{DT}_{\mathrm{x}} \mathrm{CPSI}$ for the Great Lakes and St. Lawrence Lowlands climate region ranges from $1.97 \%$ at Montreal to $2.24 \%$ at Toronto. The lowest $\mathrm{DT}_{\mathrm{x}} \mathrm{CPSI}$ value is observed at Estevan (0.51\%). 
Figure 13 displays the CPSI timing indices of the $\mathrm{AMMt}_{\mathrm{n}}$ and $\mathrm{ANMt} \mathrm{t}_{\mathrm{x}}$ DET subpopulations.

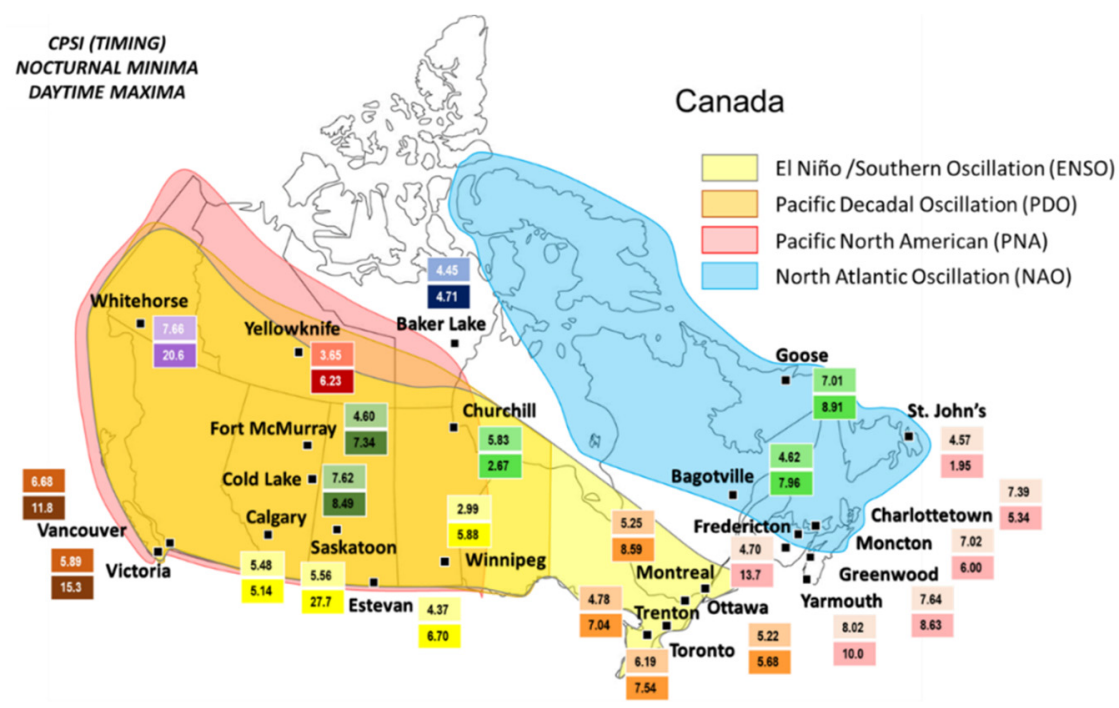

Figure 13. The CPSI of Diurnal Extrema Timing (DET) for minima (upper row values) and maxima (lower row values) indices of study locations within the range of Canadian climatic patterns. The map of Canada with regions impacted by large climatic patterns (Adapted from Large-Scale Climate Oscillations Influencing Canada, 1900-2008 by Bonsal and Shabbar, 2011. Copyright 2011 by Her Majesty the Queen in Right of Canada).

The timing CPSI is expressed as the ratio of external changes relative to the DET's range of variability. A broad range of CPSI values, identifying the susceptibility of the DET of the After Midnight Minima (DET AMMt ${ }_{n}$ ), and the After Noon Maxima (DET $\mathrm{ANMt}_{\mathrm{x}}$ ) subpopulations, is presented on color-coded fields corresponding to different climate regions from Figure 3.

The timing element of diurnal temperature extrema appears overall more susceptible to climate change than temperature extrema alone.

Ranges of the CPSI values for the DET of maxima $\left(\mathrm{ANMt}_{\mathrm{x}}\right)$ are much larger than the ranges of the CPSI values for the DET minima (DET AMMt ${ }_{n}$ ). The largest $\mathrm{AMMt}_{n}$ CPSI is observed at Yarmouth (8.02\%). In addition to a large AMMt $\mathrm{A}_{\mathrm{n}}$ CPSI at Whitehorse (7.66\%), all other large $\mathrm{AMMt}_{\mathrm{n}} \mathrm{CPSI}$ values can be associated with Pacific or Atlantic maritime locations. Anomalously large ANMt ${ }_{\mathrm{x}} \mathrm{CPSI}$ values are observed at Saskatoon $(27.75 \%)$ and Whitehorse (20.63\%). Substantially large ANMt $x_{x}$ CPSI values are identified at Pacific and Atlantic maritime locations, such as Victoria $(15.27 \%)$, Fredericton (13.69\%), Vancouver (11.81\%), and Yarmouth (10.0\%).

Anomalously low ANMt $\mathrm{x}_{\mathrm{x}} \mathrm{CPSI}$ indices were observed at fog-prone locations of Saint John's (1.95\%) and Churchill (2.67\%), pointing to a low value of a numerator in the CPSI estimation equation usually suggesting extensive external changes to the system, or a greater denominator often caused by a larger time span of parameter's own variability (Equation (4)). Anomalously low ANMt $t_{x}$ CPSI at the St. John's location seems to result from a small linear trend of change in the ANMt $t_{x}$, while a small CPSI value at Churchill station indicates a larger span of $\mathrm{ANMt}_{\mathrm{x}}$ variability.

According to the CPSI analysis of Canadian temperature and timing indices, when external changes in climate and parameters' variability are considered, the DET ANMt parameter is the most susceptible to climate change.

A decadal-scale change in atmosphere-ocean conditions over western North America has caused a large shift in the mid-1970s, inducing longer and more intense ENSO episodes, as well as affecting the PDO [33]. The most intense ENSO episodes in the 1970s and 1980s that coincided with positive PDO and PNA phases are the probable cause of extensive time shifts in the DET parameter. 


\section{Discussion}

The potential for use of diurnal extrema timing as a climate parameter was examined. This study analyzed 66 year-long hourly data sets from twenty-four Canadian stations to determine the impact of the observing window on the daily identification of mathematical extrema and evaluate annual shifts in daily extrema timing. A new index for assessing the strength of the climate change signal exhibited by a parameter has been introduced.

Since discrete search methods for extrema identification require a specified base time interval that involves inherent biases, we quantitatively evaluated differences between two observing windows using linear temperature tracking. The success in linear tracking of Climatological Observing Window Night and Day indicated the lack of the extrema timing parameter for the correct identification of the turning points of air temperature function. Diurnal errors in linear temperature tracking and their propagation to annual averaging were evaluated. Results indicate that attention to the extrema timing parameter improves the characterization of diurnal air temperature minima and amends the cold bias associated with the traditional observing window [5]. Attention to the extrema timing parameter furthermore facilitates the determination of air temperature patterns utilized in the identification of thermal drivers behind diurnal air temperature variability [8].

The applicability of Diurnal Extrema Timing as a possible parameter of relevance to climatological analysis was evaluated by examining the time evolution of nighttime and daytime extrema timing and annual averaging of diurnal extrema timing subpopulations. Application of Climatological Observing Window Night and Day for the identification of diurnal extrema generated populations of nighttime minima and daytime maxima for the analysis of air temperature and extrema timing trends. The nighttime timing population was subdivided into Before Midnight Minima and After Midnight Minima, while the daytime maxima timing population was further divided into Before Noon Maxima and After Noon Maxima for the evaluation of the timing shifts. Mann-Kendall analysis revealed statistically significant positive trends in annual averages of the After Midnight Minima and After Noon Maxima subpopulations, further supported by the migration of the Before Midnight Minima and Before Noon Maxima subpopulations across midnight and noon delineation points.

This study revealed that an improved characterization of diurnal air temperature minima and identification of extrema timing is essential for gaining insight into the timing shifts of nighttime and daytime extrema populations. Our findings suggest that shifts in annually averaged extrema timing, consistent with temperature shifts, reveal changes to the climate system when daily extrema are identified using Climatological Observing Window Night and Day.

Climate Parameter Sensitivity Index used to assess the susceptibility of temperature and timing parameters, identified the timing parameter as more prone to climate change than the temperature itself.

Apart from positive trends in the timing parameter referring to temperature increase, the abrupt changes in this parameter point to the intensification of large-scale oscillation phases influencing temperature and timing trends.

An in-depth evaluation of seasonal trends, time shifts, and sensitivity of the diurnal extrema timing parameter is recommended. Additional research is necessary to expand on the correlation of interannual variation of the timing parameter with low-frequency modes of atmospheric-oceanic variability influencing the Canadian climate [33,34]. A study of the variability of diurnal extrema timing parameter with fog frequency is also suggested. In view of the fact that a variation in observing window significantly affects temperature minima, further study of diurnal temperature asymmetries [35] and changes in air mass frequency [36] would be beneficial.

Given the necessity of extrema timing for the analysis of air temperature patterns, the systematic recording of this parameter is highly encouraged [8]. 


\section{Conclusions}

In this work, we turn the attention to a potentially new climate parameter that is, at present, systematically overlooked in routine air temperature observations and analysis.

Systematic bias in air temperature extrema, associated with the traditional observing window, is identified across all examined temperature extrema series. Further, substantial positive time shifts in annual averages of Diurnal Extrema Timing parameter are observed at all stations. Lastly, the Climate Parameter Sensitivity Index analysis ranks the annual After Noon Maxima timing as the most vulnerable to climate change among temperature and timing indices.

The results of this study indicate that turning points of daily air temperature function carry vital climatological information. Therefore, we propose a change in the observing window for the identification of daily mathematical extrema with temperature and time coordinates. The information on daily minima and maxima timing are fundamental for the analysis of extrema time series and the development of algorithmic tools in climate analysis. We stress that the lack in reporting of daily extrema timing leaves crucial spatial information to speculation. To this end, we emphasize the importance of the systematic recording of the timing of daily air temperature extrema, alongside the actual temperatures.

Author Contributions: Conceptualization, methodology, formal analysis, writing-original draft preparation, visualization, A.Ž.Ć., writing — review and editing, supervision, funding acquisition, W.A.G. All authors have read and agreed to the published version of the manuscript.

Funding: The research was supported by NSERC RGPIN-2018-06801.

Institutional Review Board Statement: Not applicable.

Informed Consent Statement: Not applicable.

Data Availability Statement: Publicly available datasets were analyzed in this study. This data can be found here: [https:// climate.weather.gc.ca/ accessed on 15 September 2021]. The DET data in form of $\mathrm{COW}_{\mathrm{N}-\mathrm{D}}$ chronologically ordered sequences of mathematical air temperature extrema are available from the authors upon request.

Conflicts of Interest: The authors declare no conflict of interest.

\section{Appendix A. Histograms of Errors in Air Temperature Tracking}

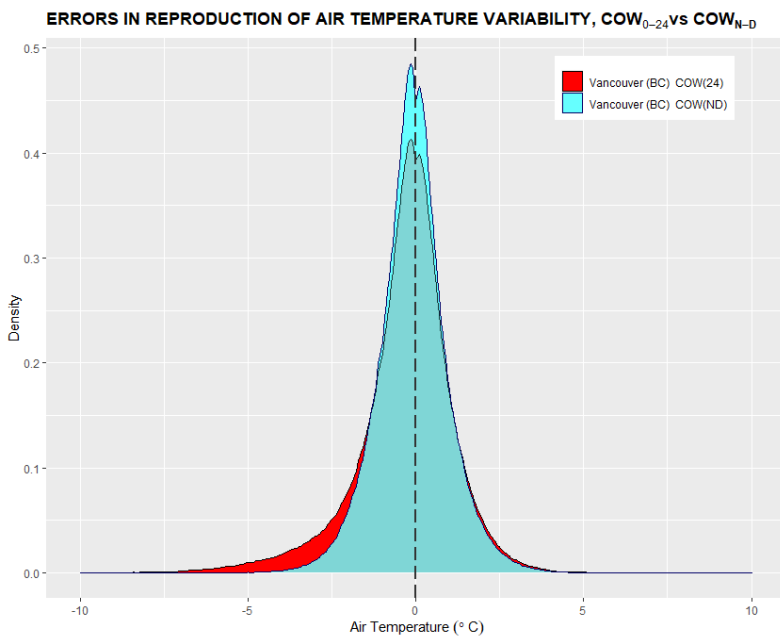

(a)

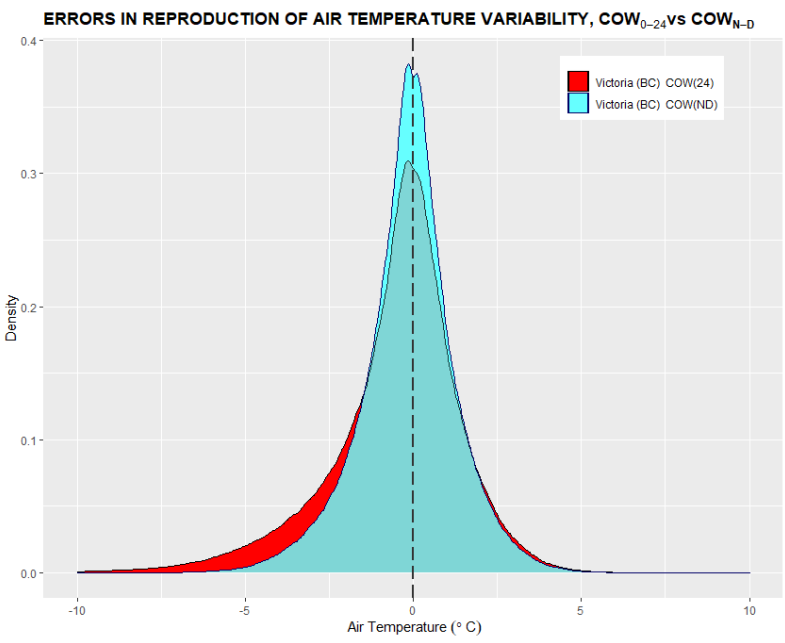

(b)

Figure A1. Pacific Coast climate region. Histograms of conformity of $\mathrm{COW}_{0-24}$ and $\mathrm{COW}_{\mathrm{N}-\mathrm{D}}$ reproduced temperature with observed hourly temperature data for the 1953-2018 data period at Vancouver (a) and Victoria (b) stations. 


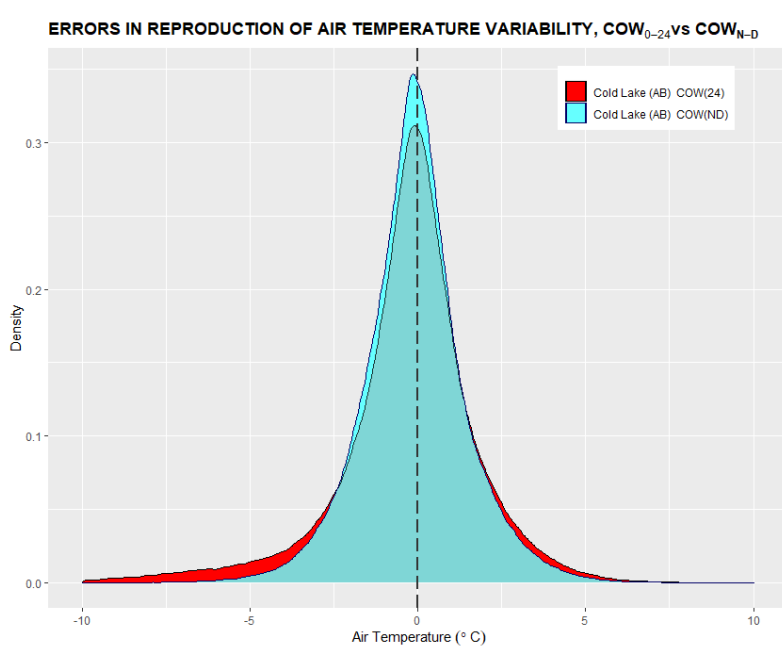

(a)

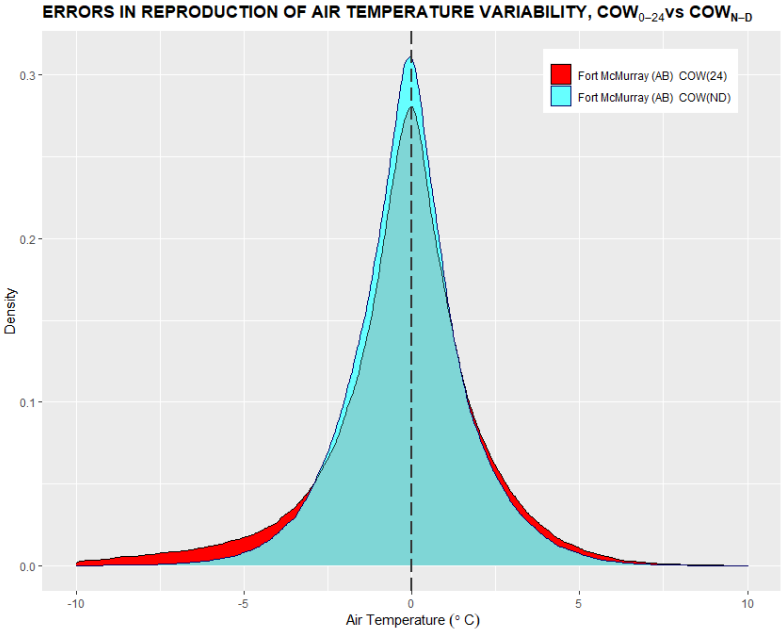

(b)

Figure A2. Northwestern Forest climate region. Histograms of conformity of $\mathrm{COW}_{0-24}$ and $\mathrm{COW}_{\mathrm{N}-\mathrm{D}}$ reproduced temperature with observed hourly temperature data for the 1955-2018 data period at Cold Lake (a) and the 1953-2018 data period at Fort McMurry (b) stations.

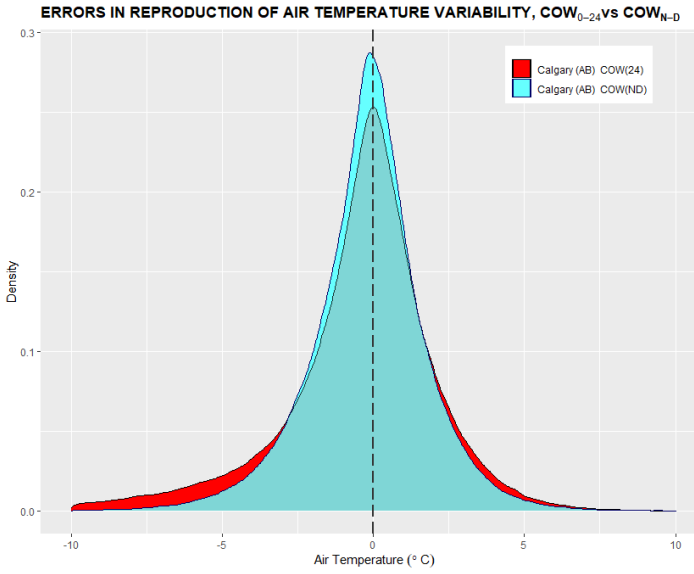

(a)

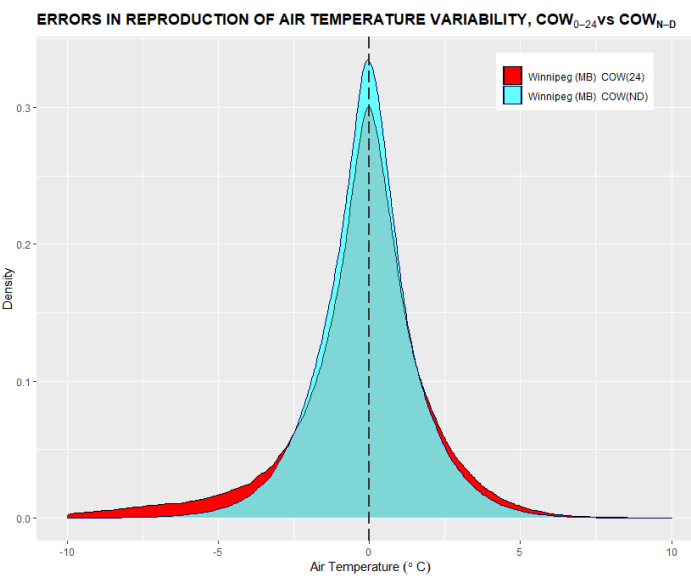

(c)

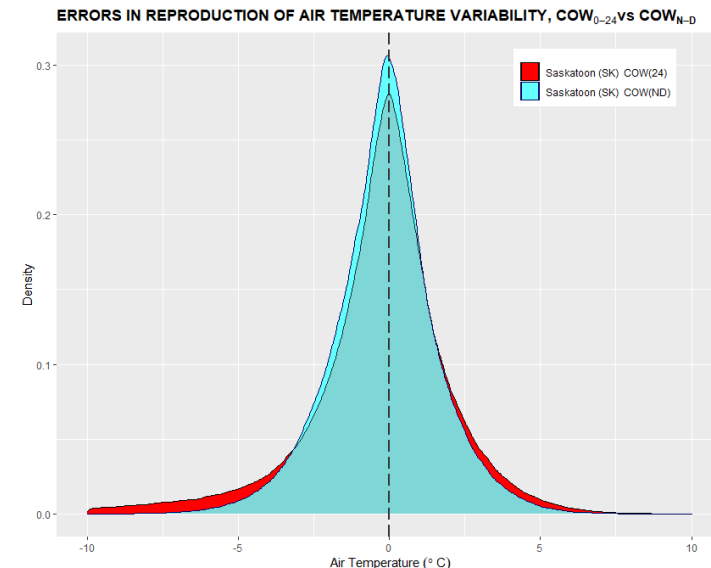

(b)

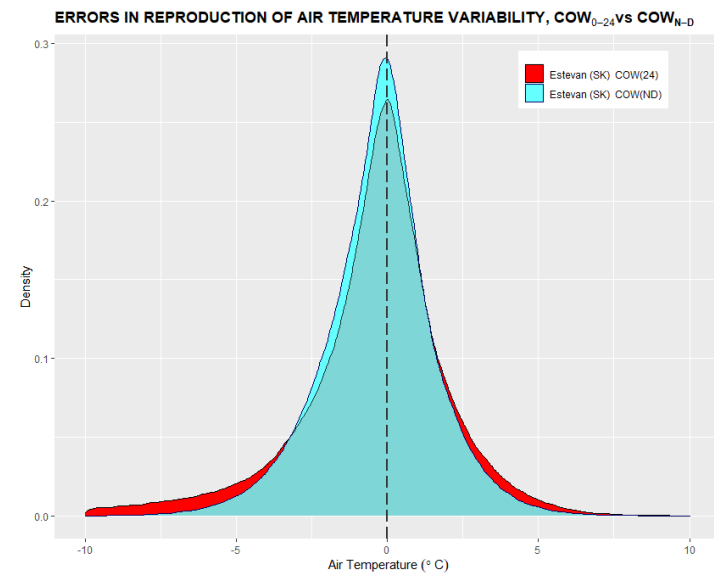

(d)

Figure A3. Prairies climate region. Histograms of conformity of $\mathrm{COW}_{0-24}$ and $\mathrm{COW}_{\mathrm{N}-\mathrm{D}}$ reproduced temperature with observed hourly temperature data for the 1953-2018 data period at Calgary (a), Saskatoon (b), Winnipeg (c), and Estevan (d) stations. 


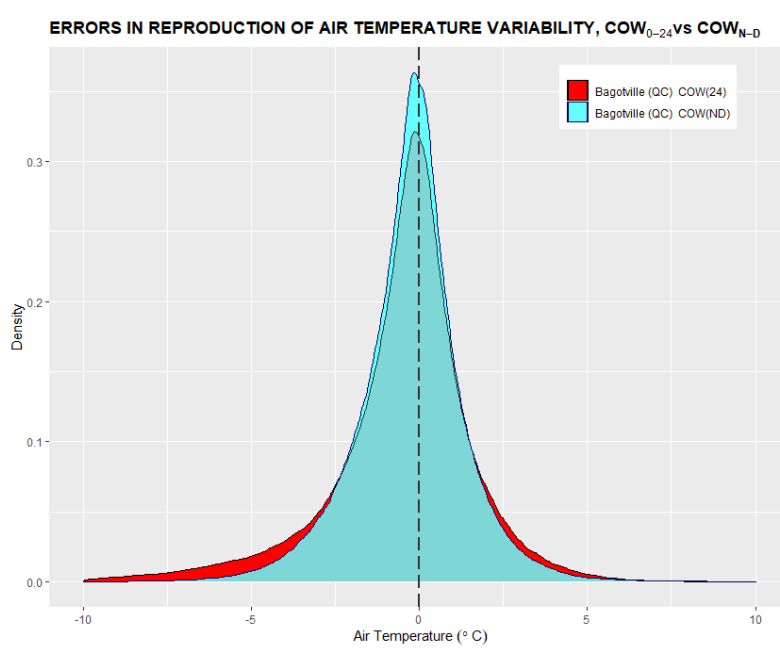

(a)

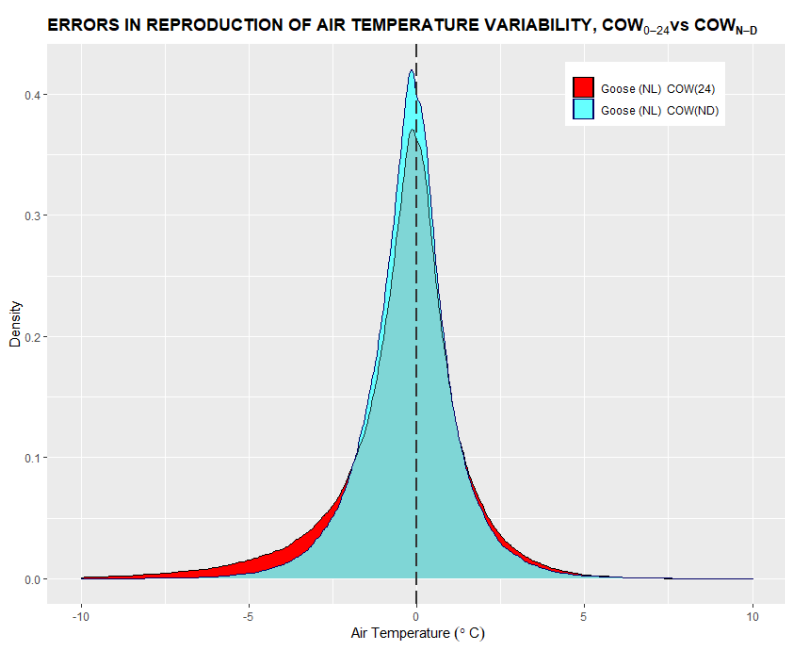

(b)

Figure A4. Northeastern Forest climate region. Histograms of conformity of $\mathrm{COW}_{0-24}$ and $\mathrm{COW}_{\mathrm{N}-\mathrm{D}}$ reproduced temperature with observed hourly temperature data for the 1953-2018 data period at Bagotville (a) and Goose (b) stations.

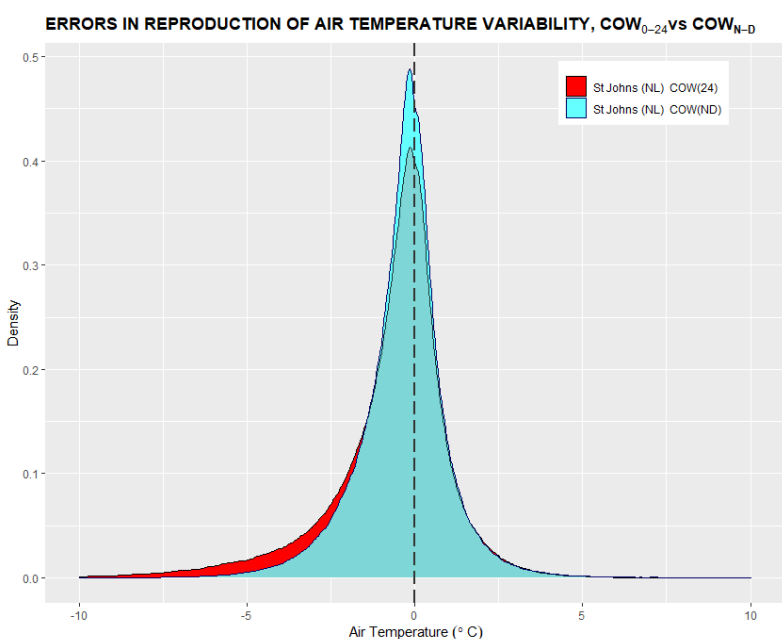

(a)

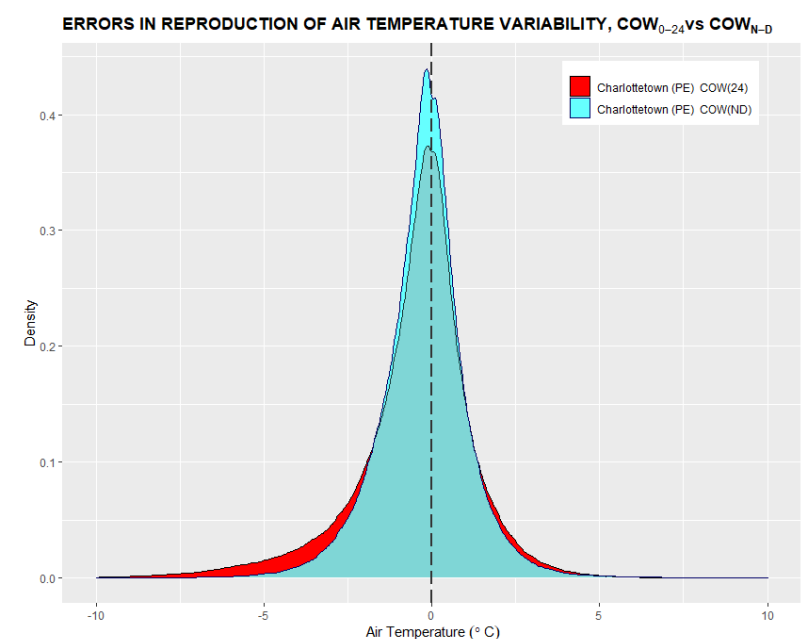

(b)

Figure A5. Cont. 


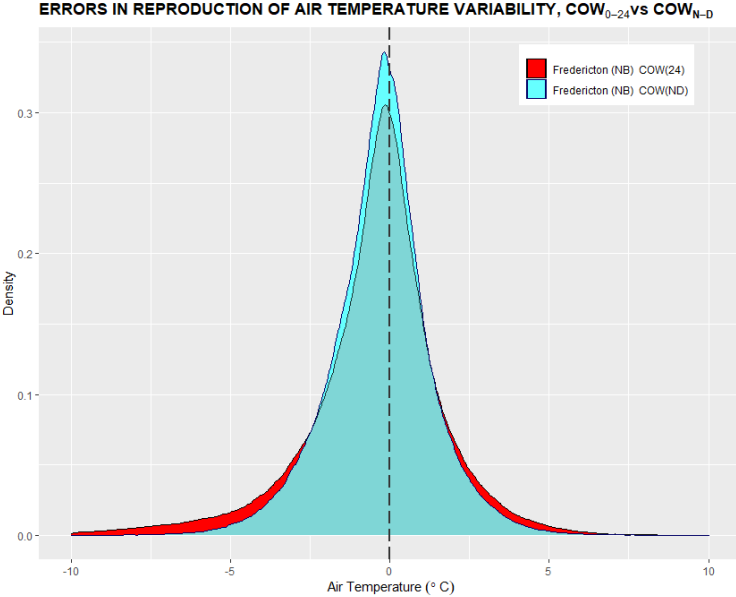

(c)

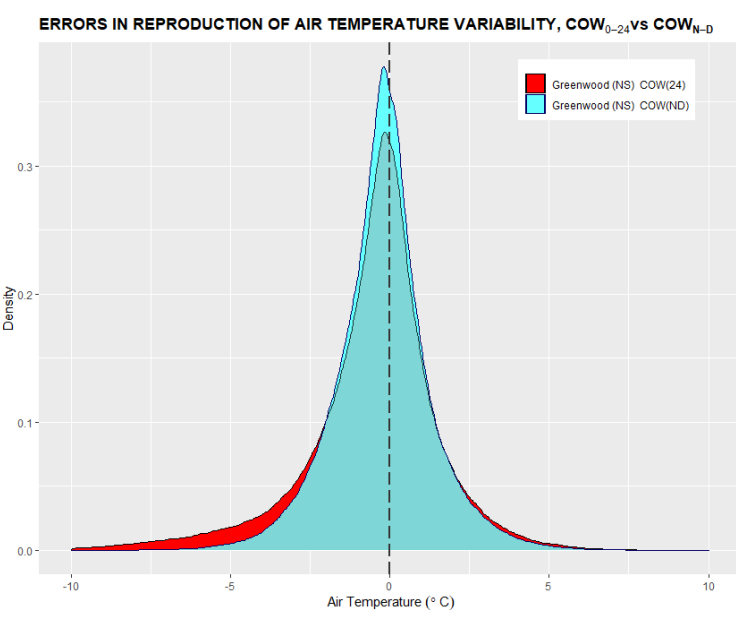

(e)

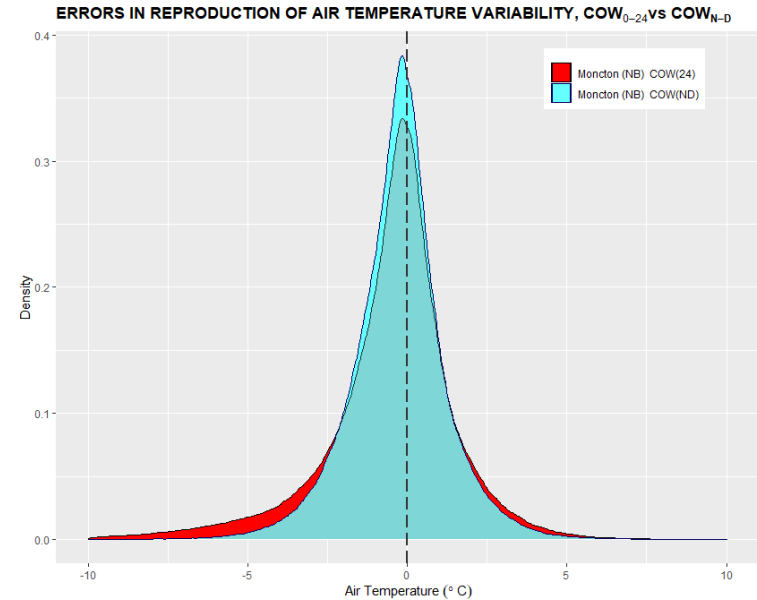

(d)

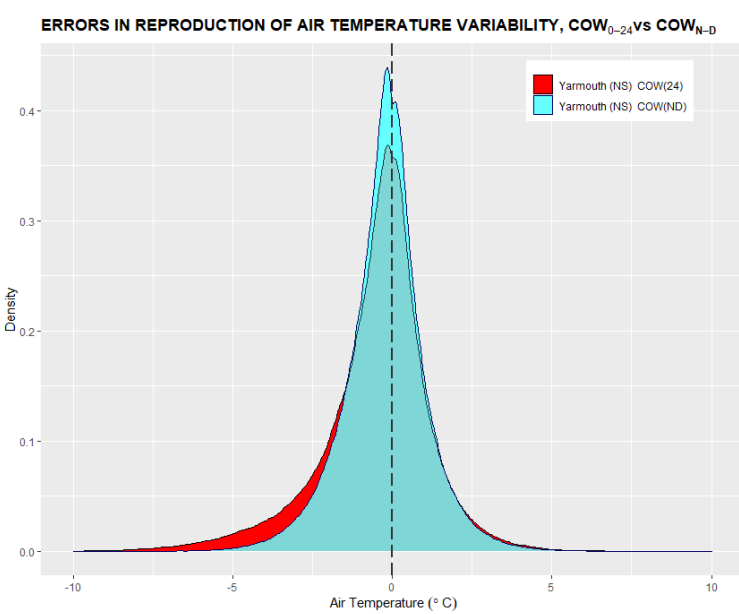

(f)

Figure A5. Atlantic Canada climate region. Histograms of conformity of $\mathrm{COW}_{0-24}$ and $\mathrm{COW}_{\mathrm{N}-\mathrm{D}}$ reproduced temperature with observed hourly temperature data for the 1959-2018 data period at St John's (a) and 1953-2018 at Charlottetown (b), Fredericton (c), Moncton (d), Greenwood (e), and Yarmouth (f) stations.

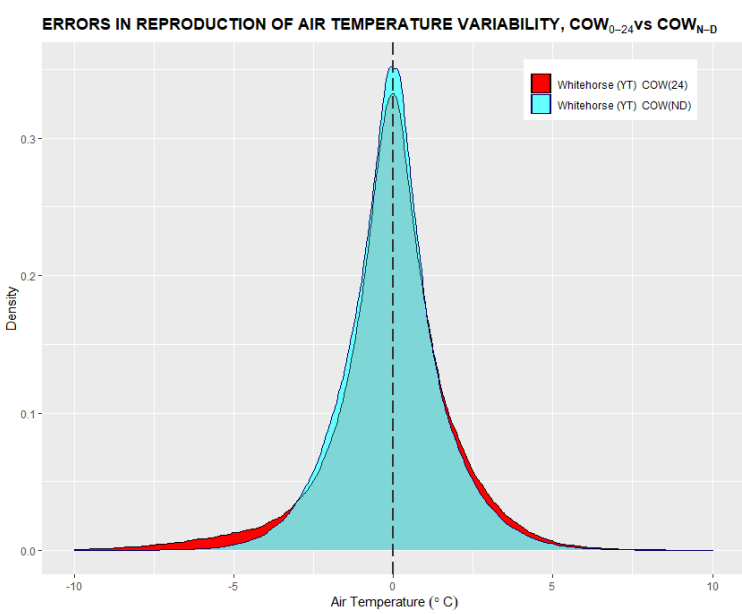

(a)

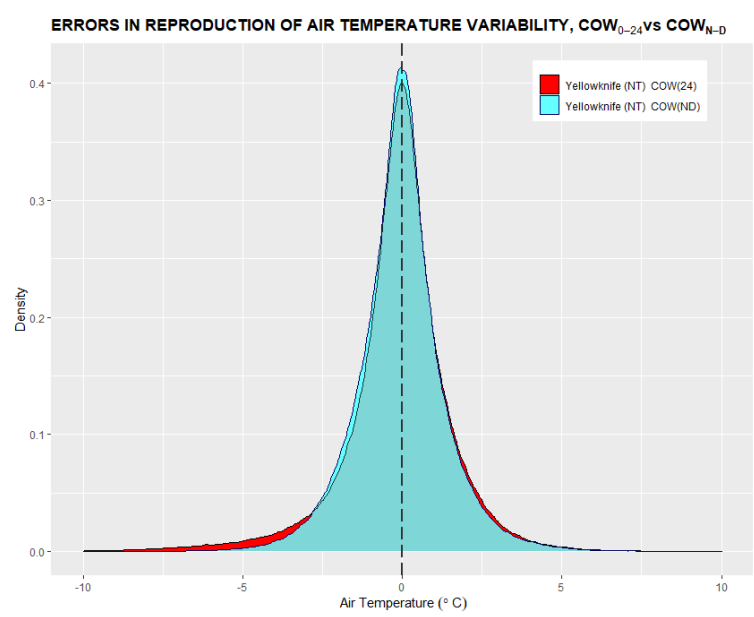

(b)

Figure A6. Cont. 


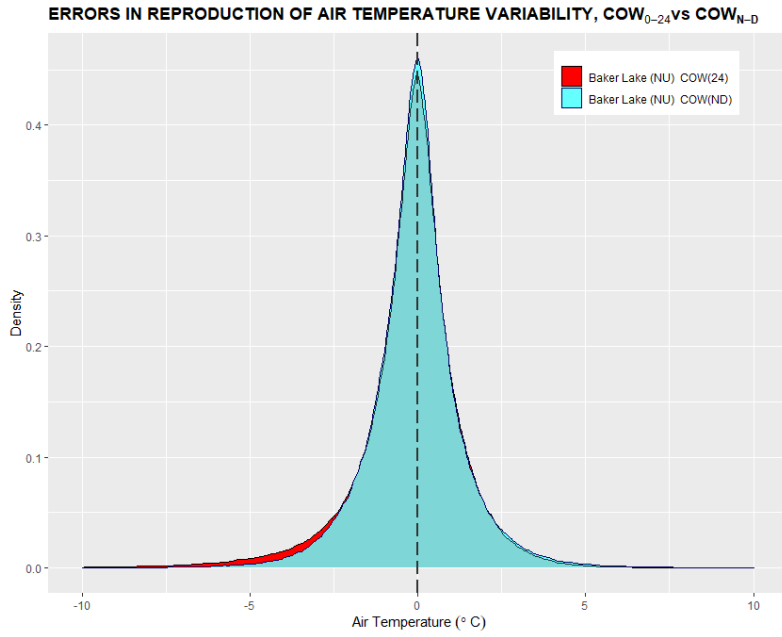

(c)

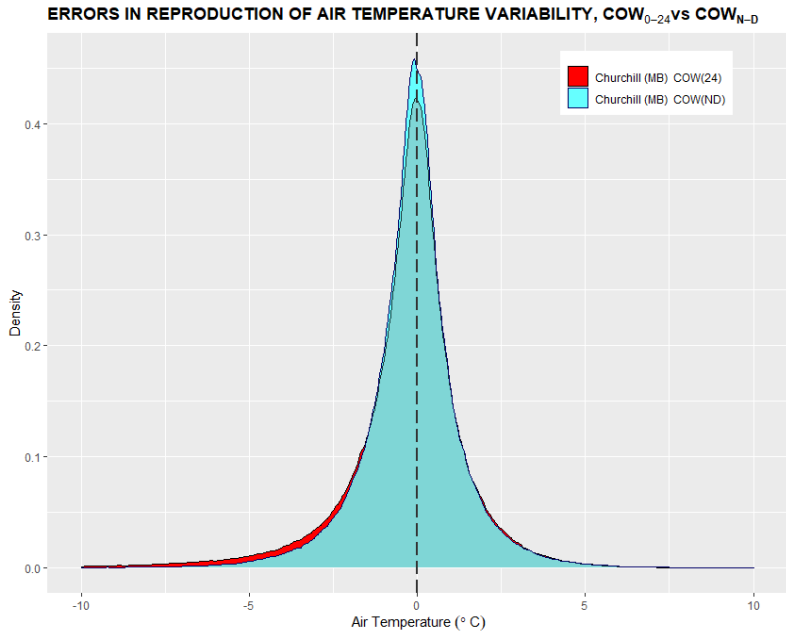

(d)

Figure A6. Northern Canada climate region. Histograms of conformity of $\mathrm{COW}_{0-24}$ and $\mathrm{COW}_{\mathrm{N}-\mathrm{D}}$ reproduced temperature with observed hourly temperature data for the 1953-2018 data period at Whitehorse (a), Yellowknife (b), and Churchill (d) and 1963-2018 period at Baker Lake (c) stations within Northern Canada.

Appendix B. Annual Trends of Daily Air Temperature Minima, Maxima, and Min-Max Averages

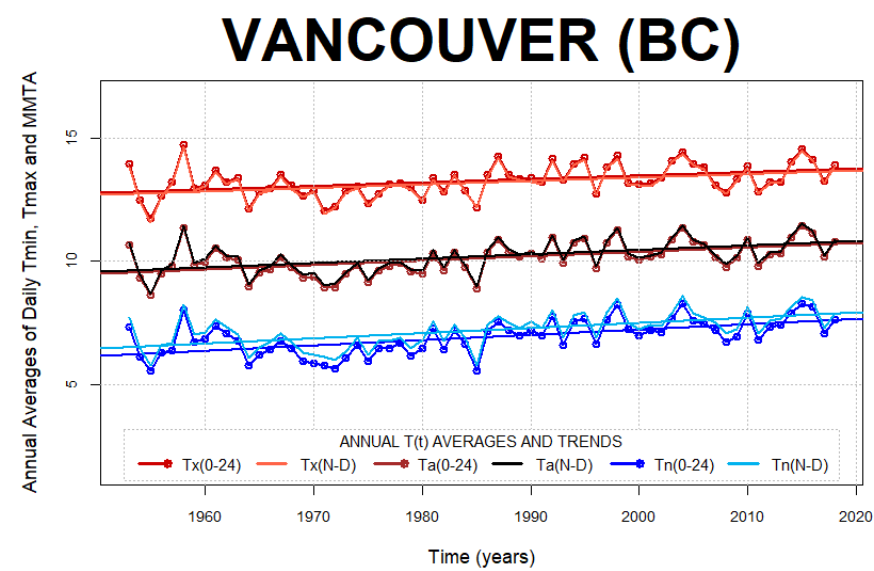

(a)

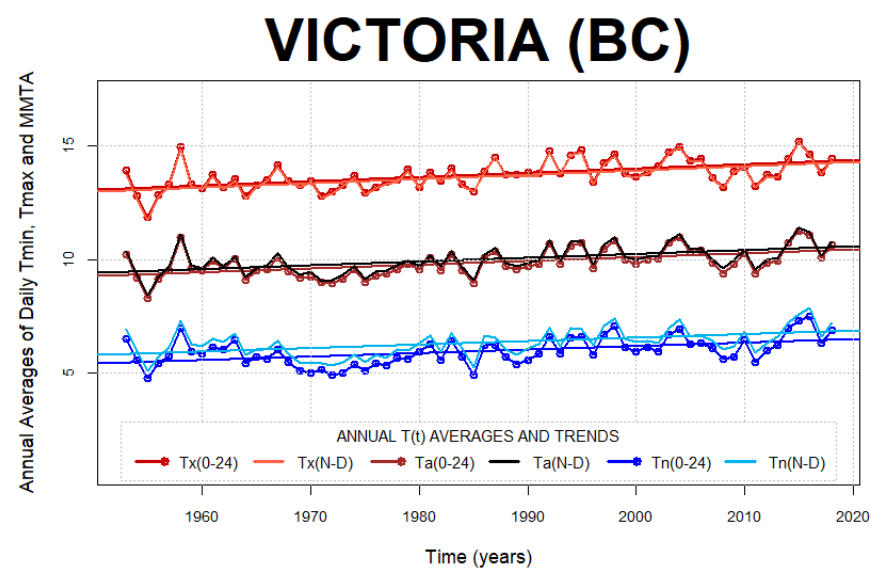

(b)

Figure A7. Pacific Coast climate region. Effect of the observing window on long-term air temperature averaging at Vancouver (a) and Victoria (b) stations. Annually averaged diurnal air temperature minima, maxima, and Min-Max averages obtained with $\mathrm{COW}_{0-24}$ and $\mathrm{COW}_{\mathrm{N}-\mathrm{D}}$ air temperature approximating methods. 
COLDLAKE (AB)

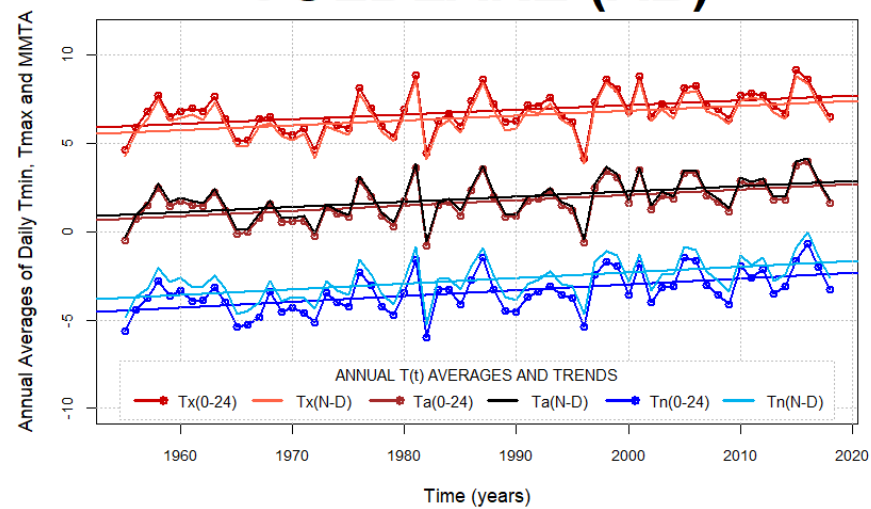

(a)
FORT MCMURRAY (AB)

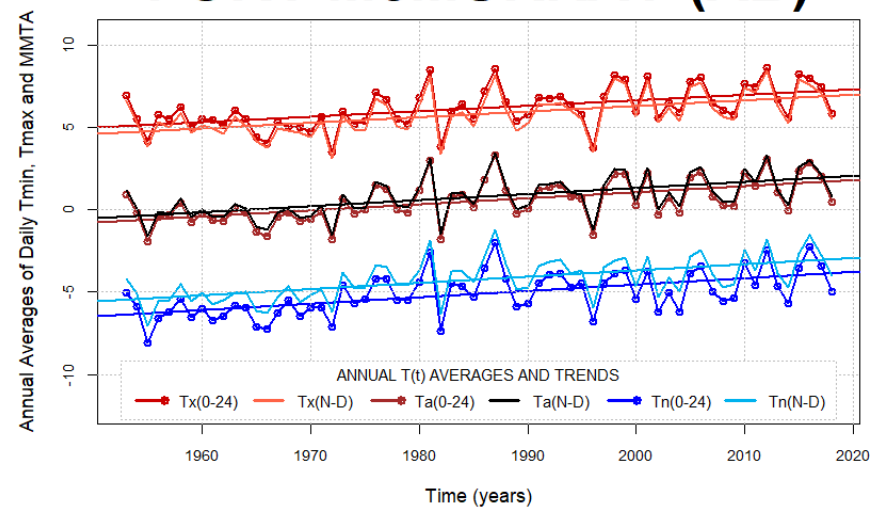

(b)

Figure A8. Northwestern Forest climate region. Effect of the observing window on long-term air temperature averaging at Cold Lake (a) and Fort McMurray (b) stations. Annually averaged diurnal air temperature minima, maxima, and Min-Max averages obtained with $\mathrm{COW}_{0-24}$ and $\mathrm{COW}_{\mathrm{N}-\mathrm{D}}$ air temperature approximating methods.

CALGARY (AB)

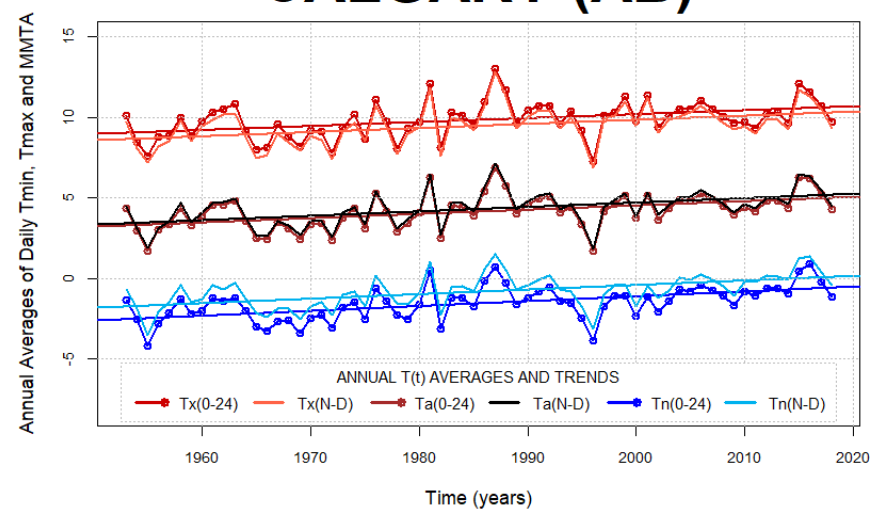

(a)

WINNIPEG (MB)

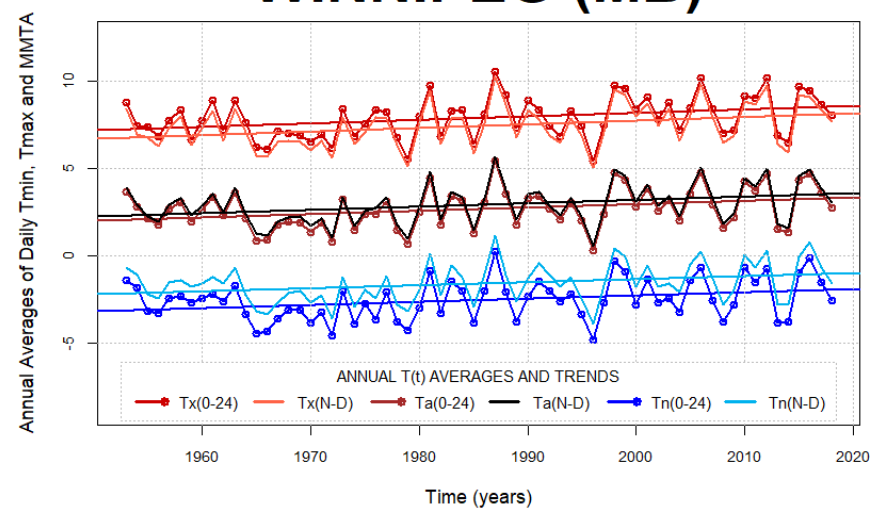

(c)
SASKATOON (SK)

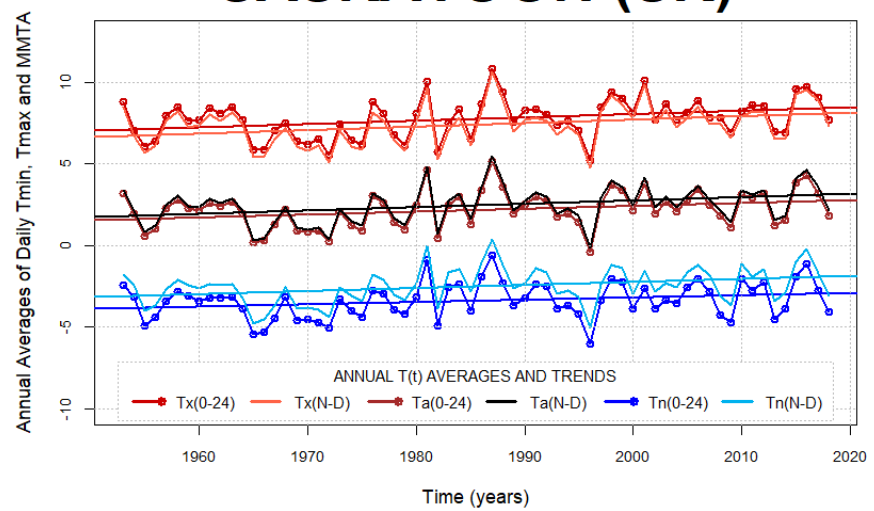

(b)

ESTEVAN (SK)

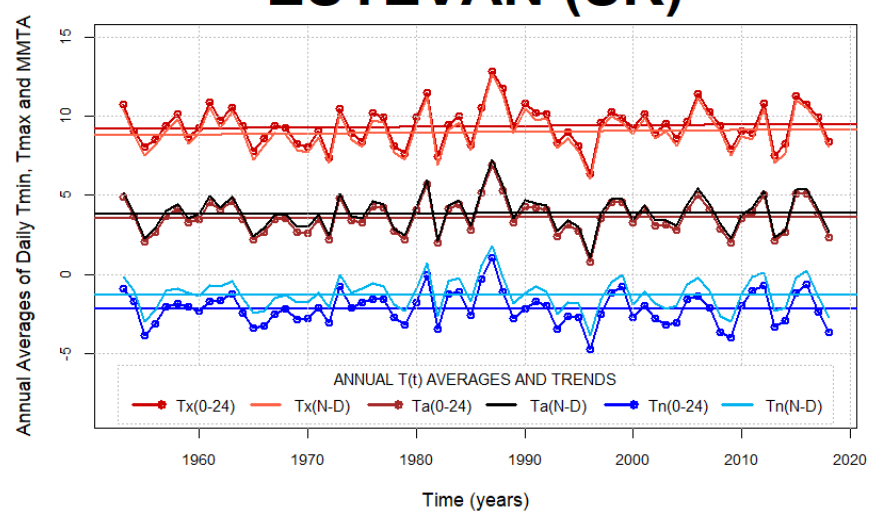

(d)

Figure A9. Prairies climate region. Effect of the observing window on long-term air temperature averaging at Calgary (a), Saskatoon (b), Winnipeg (c), and Estevan (d) stations. Annually averaged diurnal air temperature minima, maxima, and Min-Max averages obtained with $\mathrm{COW}_{0-24}$ and $\mathrm{COW}_{\mathrm{N}-\mathrm{D}}$ air temperature approximating methods. 
BAGOTVILLE (QC)

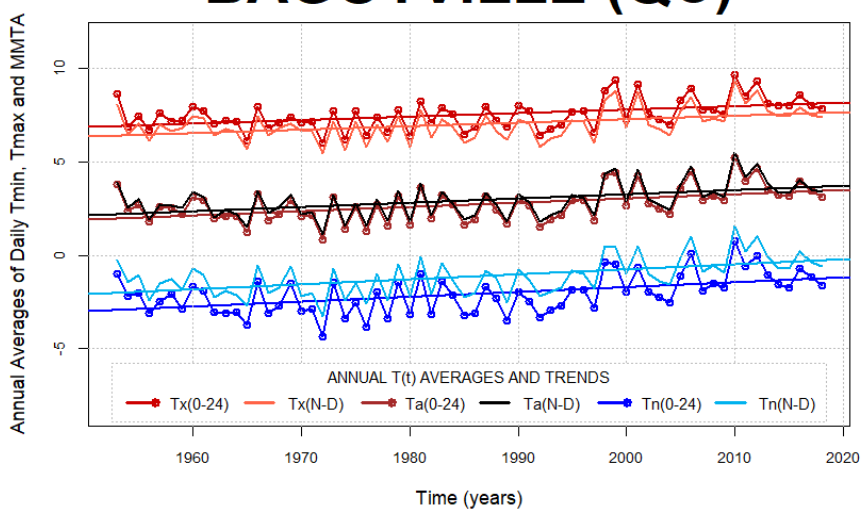

(a)
GOOSE BAY (NL)

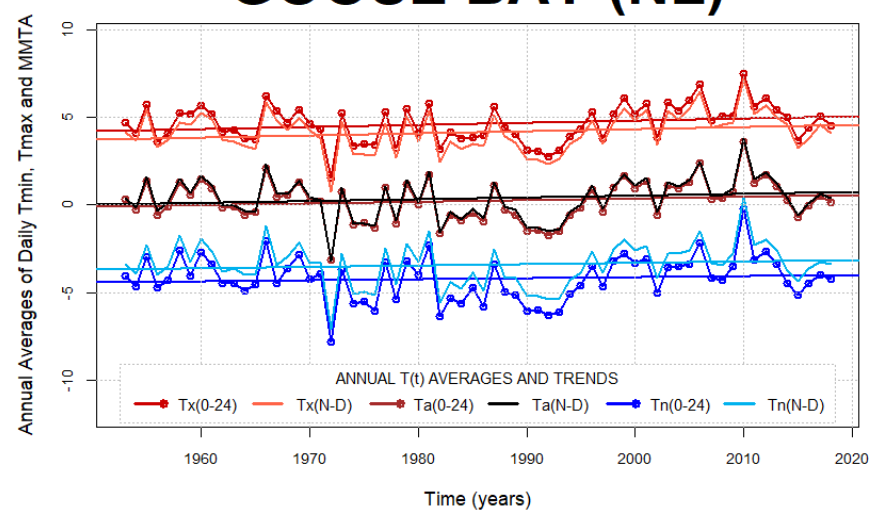

(b)

Figure A10. Northeastern Forest climate region. Effect of the observing window on long-term air temperature averaging at Bagotville (a) and Goose (b) stations. Annually averaged diurnal air temperature minima, maxima, and Min-Max averages obtained with $\mathrm{COW}_{0-24}$ and $\mathrm{COW}_{\mathrm{N}-\mathrm{D}}$ air temperature approximating methods.

\section{St JOHNS (NL)}

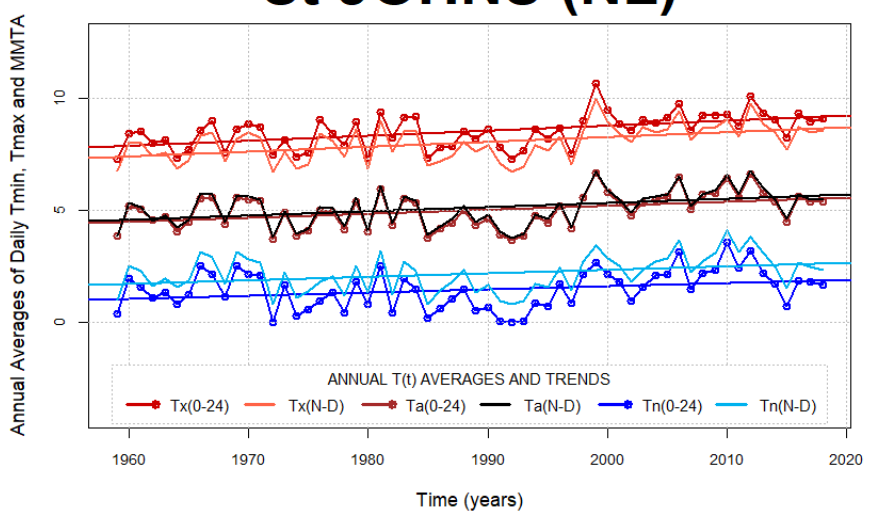

(a)

\section{FREDERICTON (NB)}

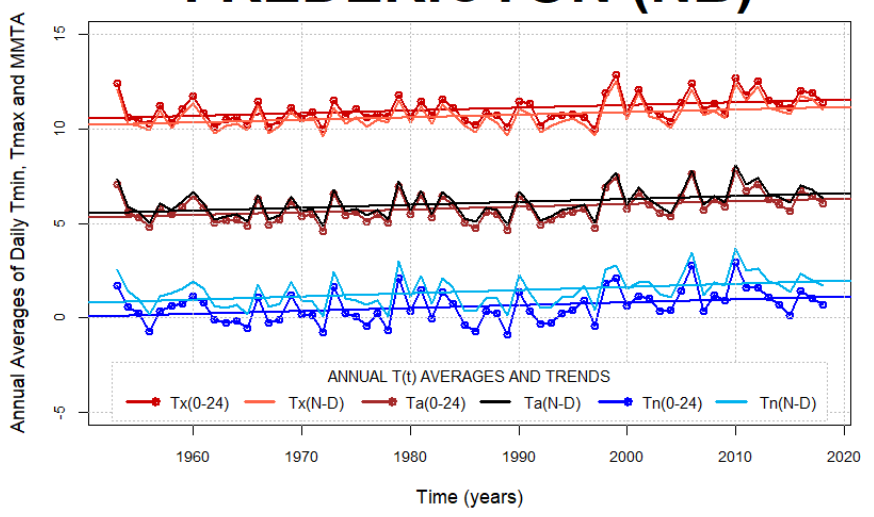

(c)

\section{CHARLOTTETOWN (PE)}

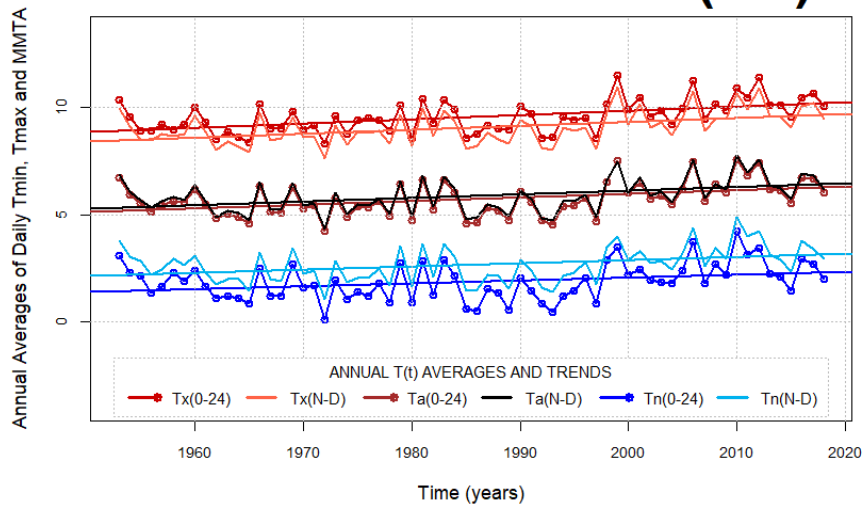

(b)

\section{MONCTON (NB)}

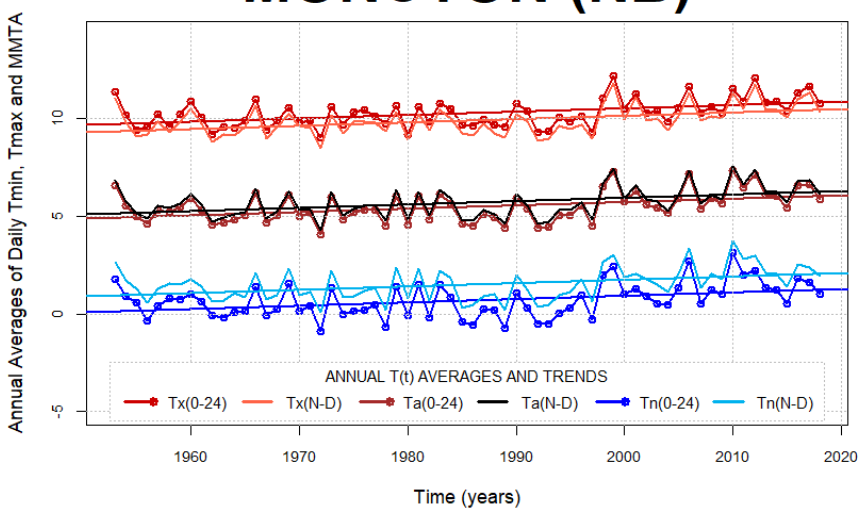

(d)

Figure A11. Cont. 
GREENWOOD (NS)

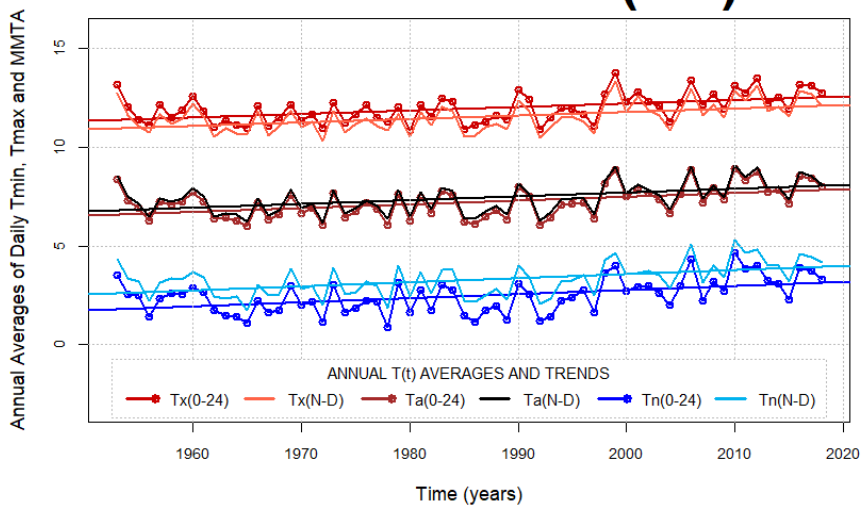

(e)
YARMOUTH (NS)

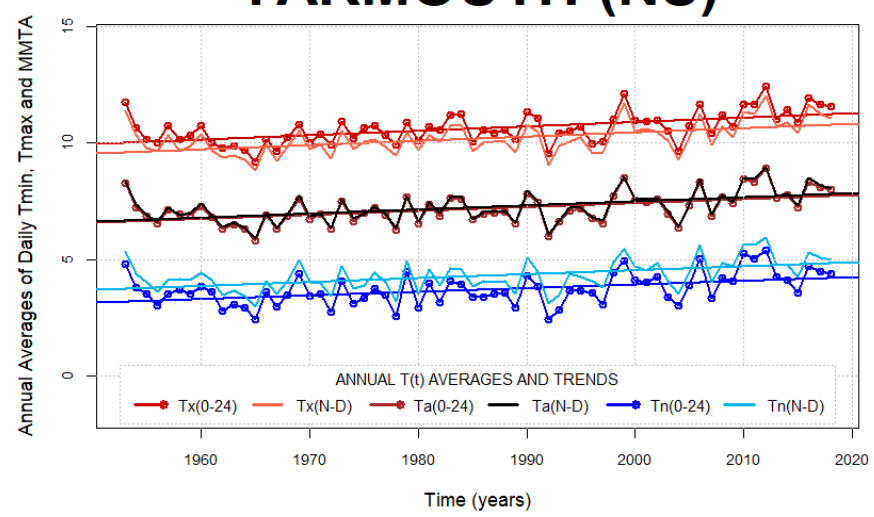

(f)

Figure A11. Atlantic Canada climate region. Effect of the observing window on long-term air temperature averaging at St John's (a), Charlottetown (b), Fredericton (c), Moncton (d), Greenwood (e), and Yarmouth (f) stations. Annually averaged diurnal air temperature minima, maxima, and Min-Max averages obtained with $\mathrm{COW}_{0-24}$ and $\mathrm{COW}_{\mathrm{N}-\mathrm{D}}$ air temperature approximating methods.

WHITEHORSE (YT)

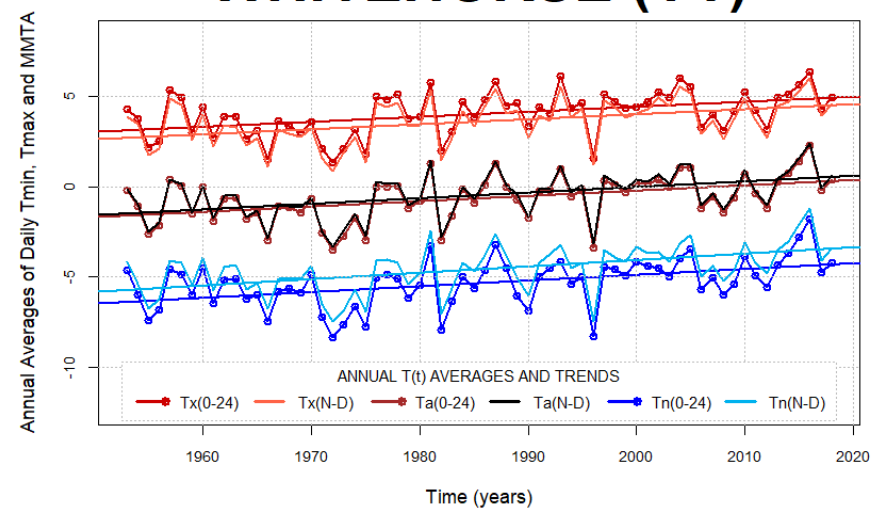

(a)

\section{BAKER LAKE (NU)}

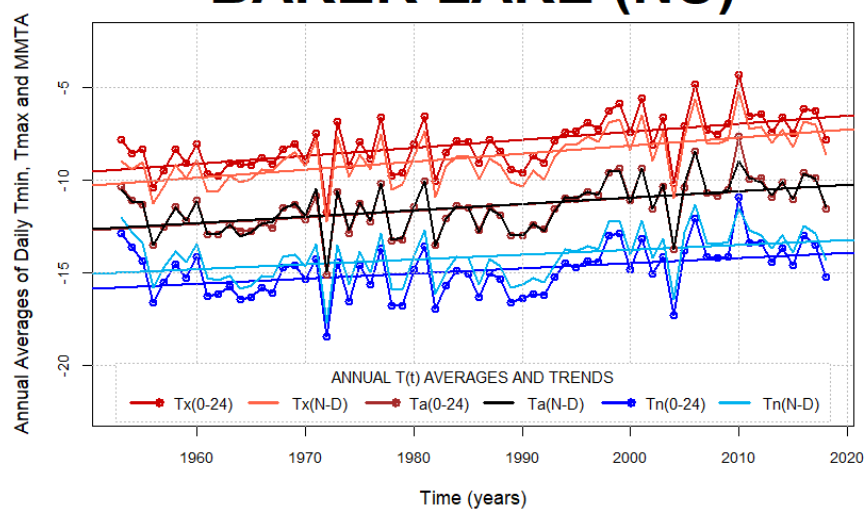

(c)
YELLOWKNIFE (NT)

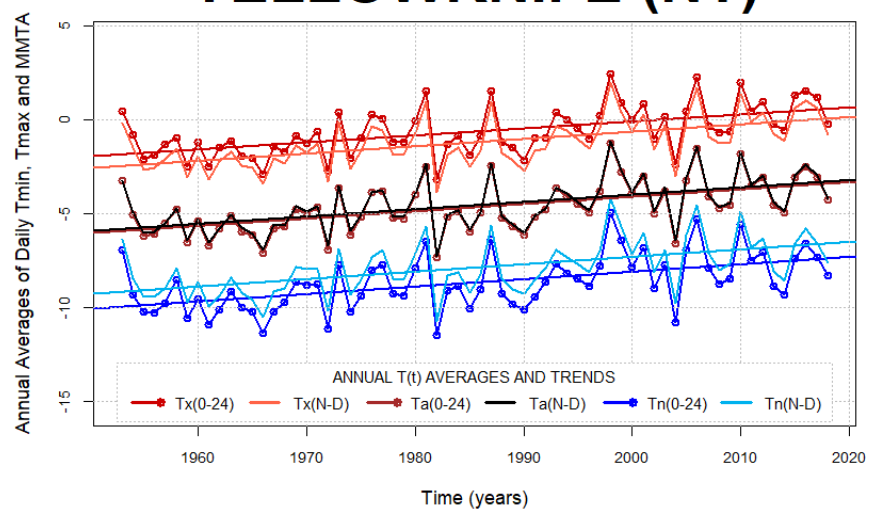

(b)

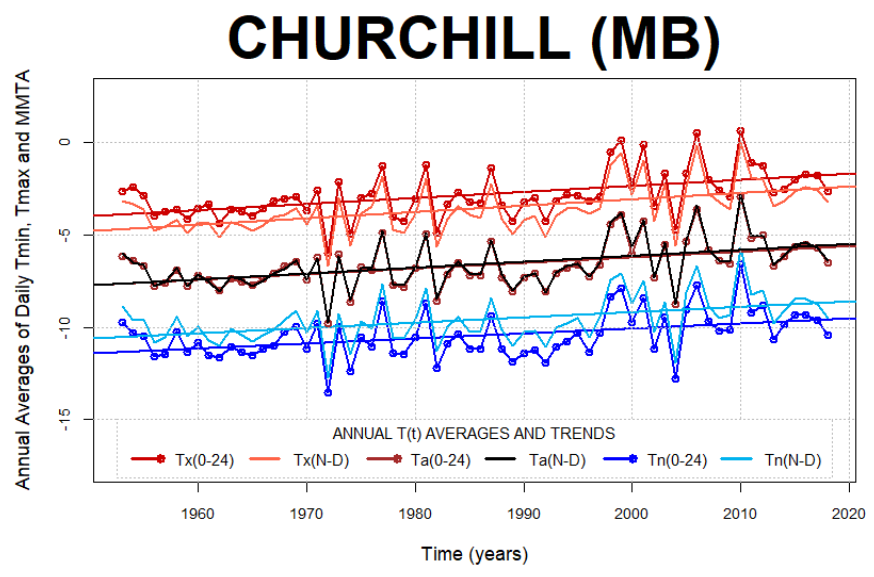

(d)

Figure A12. Northern Canada climate region. Effect of the observing window on long-term air temperature averaging at Whitehorse (a), Yellowknife (b), Baker Lake (c), and Churchill (d) stations. Annually averaged diurnal air temperature minima, maxima, and Min-Max averages obtained with $\mathrm{COW}_{0-24}$ and $\mathrm{COW}_{\mathrm{N}-\mathrm{D}}$ air temperature approximating methods. 


\section{Appendix C. Histograms of Minima and Maxima Timing Migration}

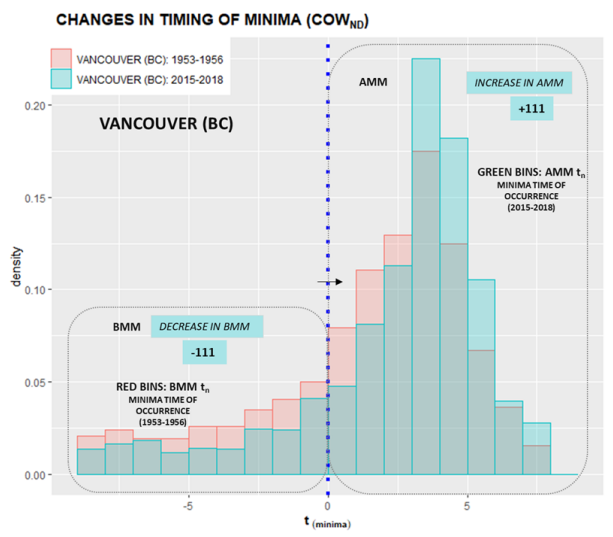

(a)

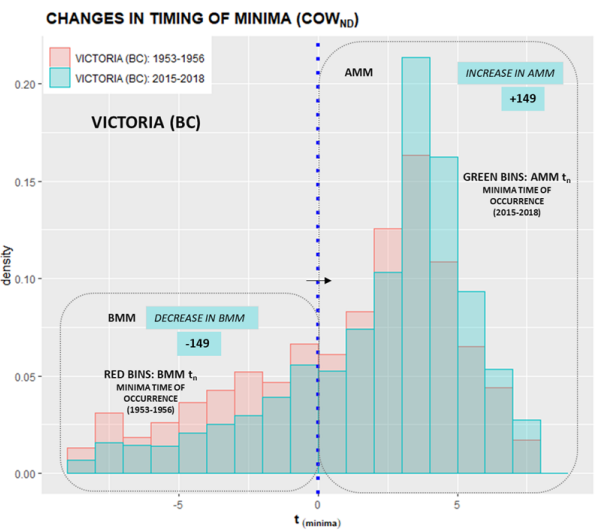

(c)

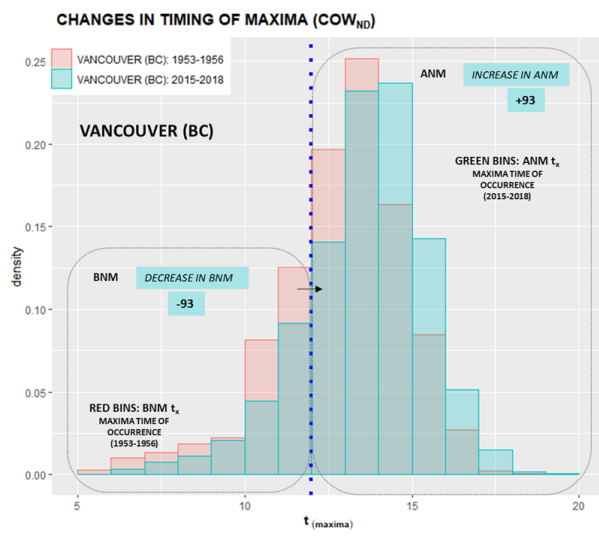

(b)

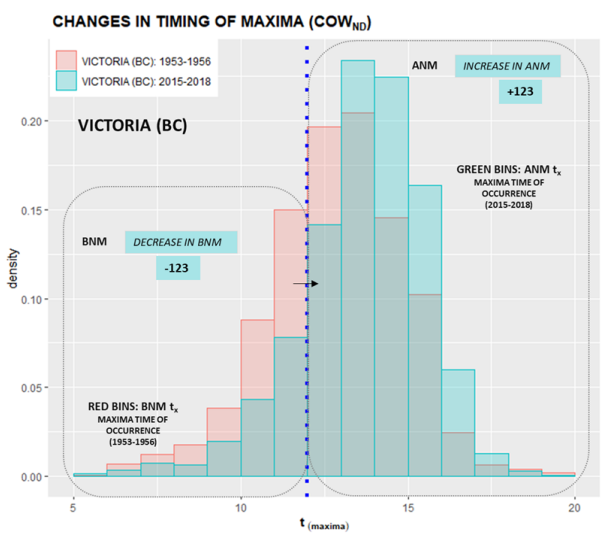

(d)

Figure A13. Pacific Coast climate region: Vancouver (BC) and Victoria (BC). Time evolution of the Diurnal Extrema Timing (DET) histograms at Vancouver $(\mathbf{a}, \mathbf{b})$, and Victoria (c,d) stations. Migration of the Before Midnight Minima (BMM) to After Midnight Minima (AMM) and migration of the Before Noon Maxima (BNM) to After Noon Maxima (ANM) between four-year averages at the beginning (1953-1956) and ending (2015-2018) of data ranges. The blue dotted line represents midnight delineation (left) and noon delineation (right).

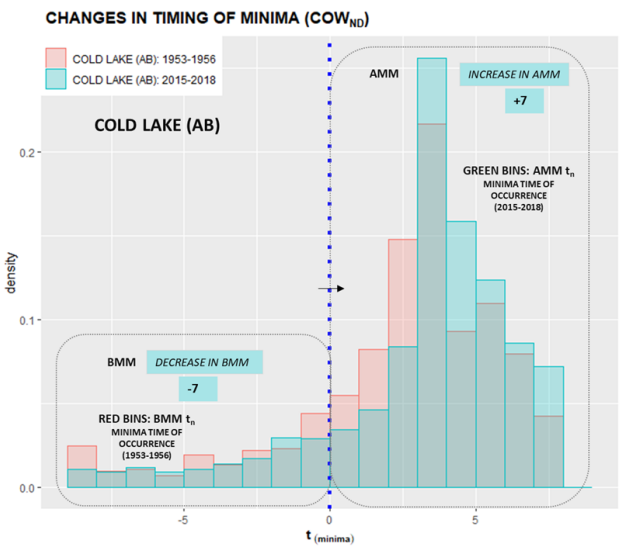

(a)

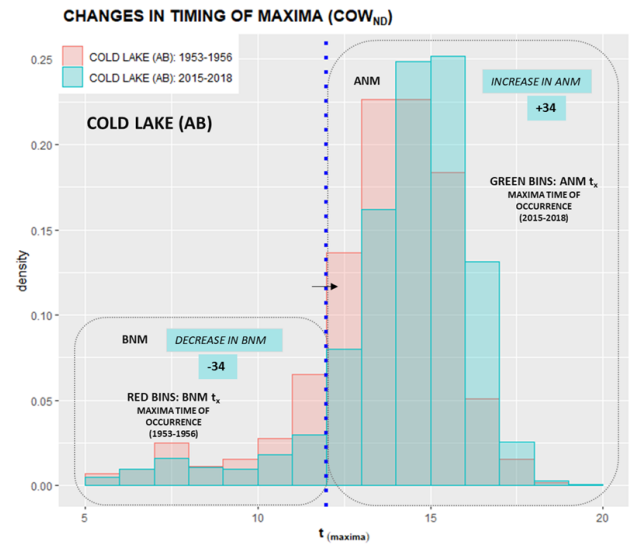

(b)

Figure A14. Cont. 


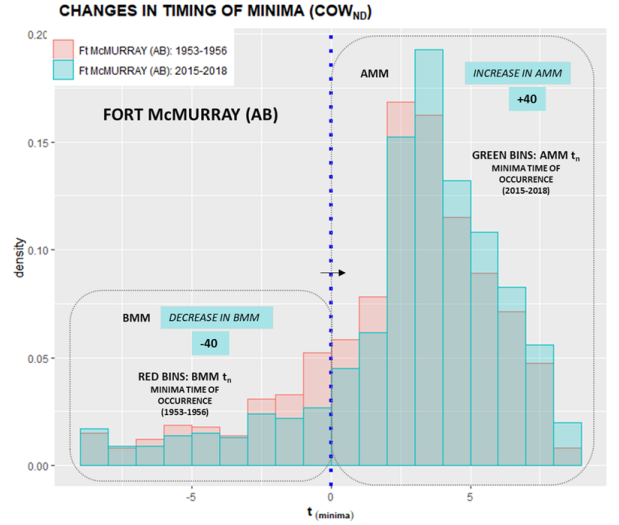

(c)

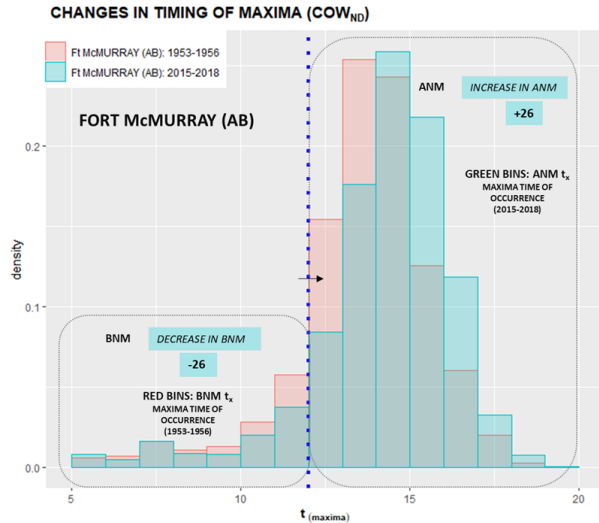

(d)

Figure A14. Northwestern Forest climate region: Cold Lake (AB) and Fort McMurray (AB). Time evolution of the Diurnal Extrema Timing (DET) histograms at Cold Lake (a,b), and Fort McMurray (c,d) stations. Migration of the Before Midnight Minima (BMM) to After Midnight Minima (AMM) and migration of the Before Noon Maxima (BNM) to After Noon Maxima (ANM) between four-year averages at the beginning (1953-1956) and ending (2015-2018) of data ranges. The blue dotted line represents midnight delineation (left) and noon delineation (right).

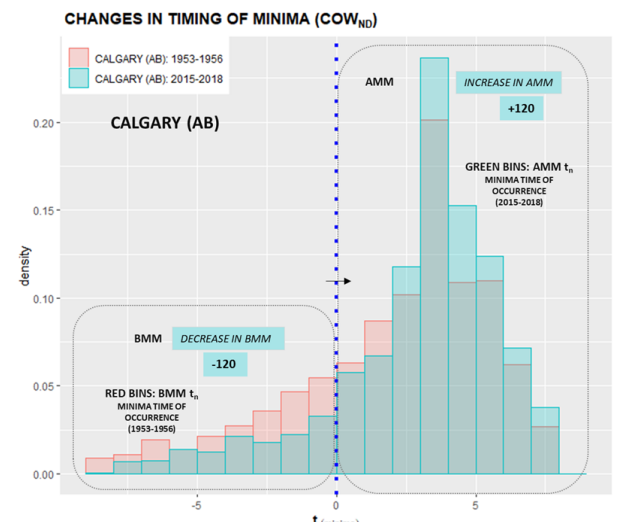

(a)

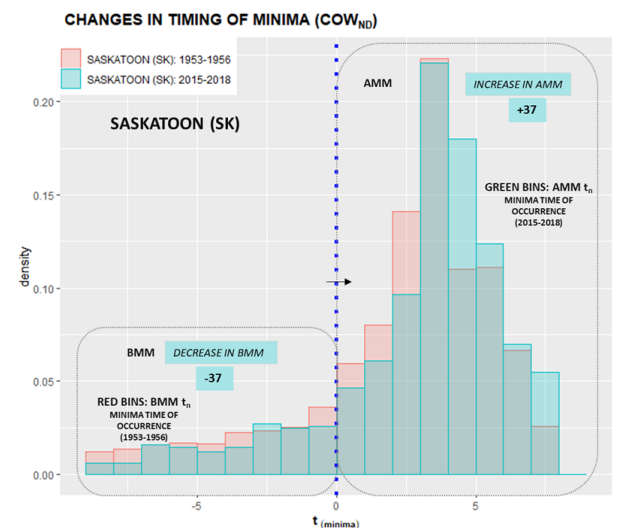

(c)

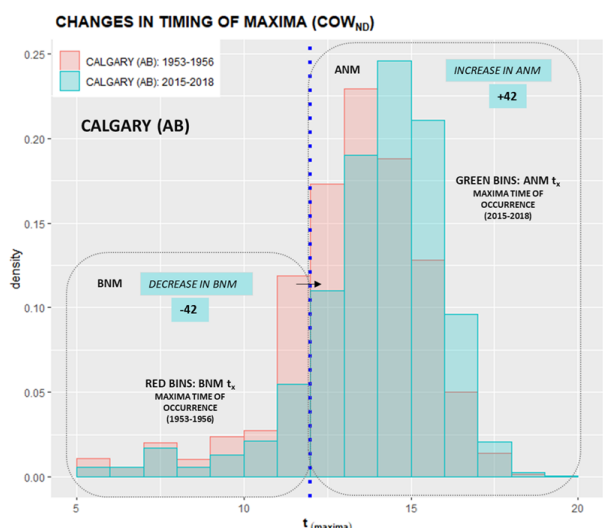

(b)

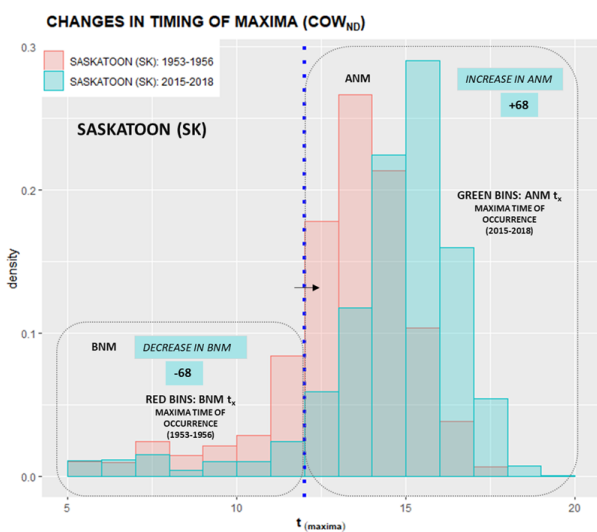

(d)

Figure A15. Prairies climate region: Calgary (AB) and Saskatoon (SK). Time evolution of the Diurnal Extrema Timing (DET) histograms at Calgary $(\mathbf{a}, \mathbf{b})$, and Saskatoon $(\mathbf{c}, \mathbf{d})$ stations. Migration of the Before Midnight Minima (BMM) to After Midnight Minima (AMM) and migration of the Before Noon Maxima (BNM) to After Noon Maxima (ANM) between four-year averages at the beginning (19531956) and ending (2015-2018) of data ranges. The blue dotted line represents midnight delineation (left) and noon delineation (right). 


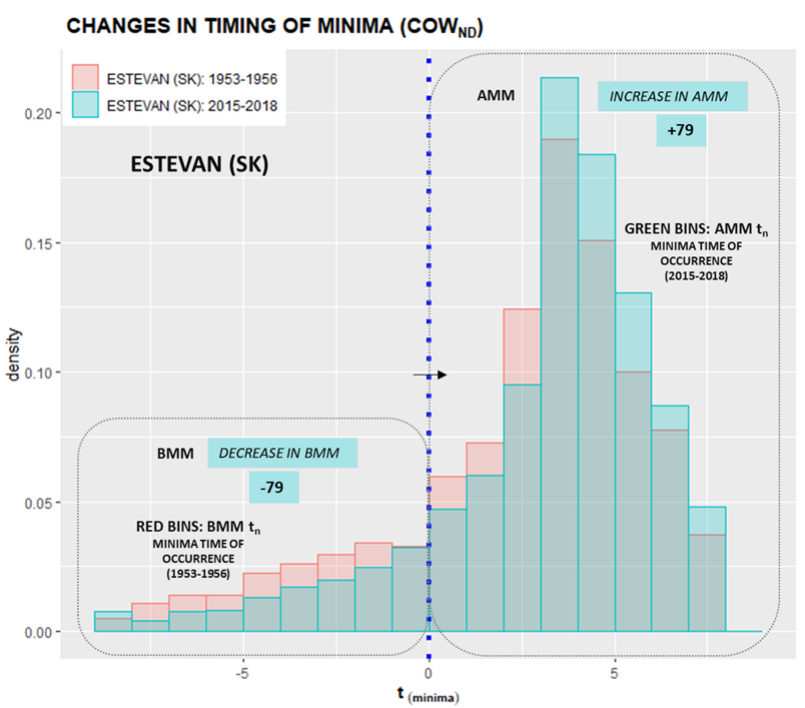

(a)

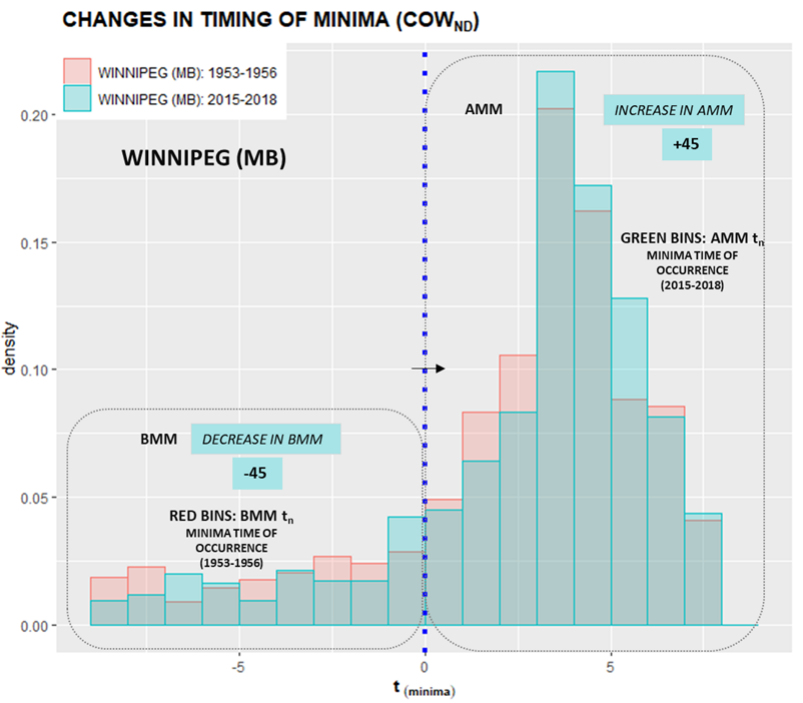

(c)

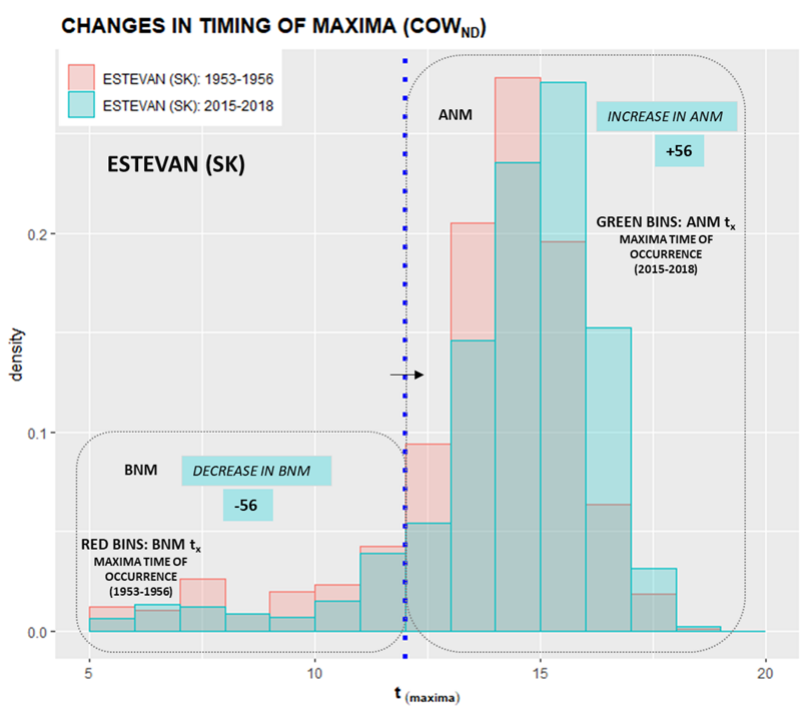

(b)

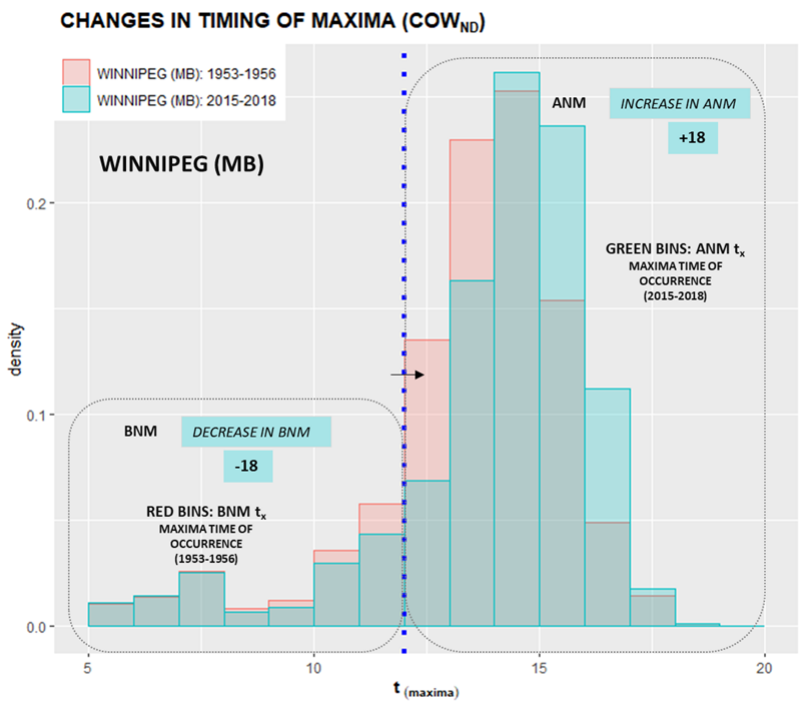

(d)

Figure A16. Prairies climate region: Estevan (SK) and Winnipeg (MB). Time evolution of the Diurnal Extrema Timing (DET) histograms at Estevan $(\mathbf{a}, \mathbf{b})$, and Winnipeg $(\mathbf{c}, \mathbf{d})$ stations. Migration of the Before Midnight Minima (BMM) to After Midnight Minima (AMM) and migration of the Before Noon Maxima (BNM) to After Noon Maxima (ANM) between four-year averages at the beginning (19531956) and ending (2015-2018) of data ranges. The blue dotted line represents midnight delineation (left) and noon delineation (right). 


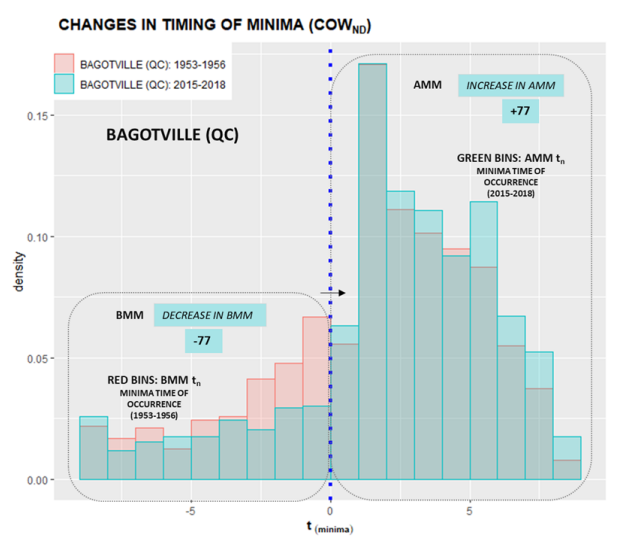

(a)

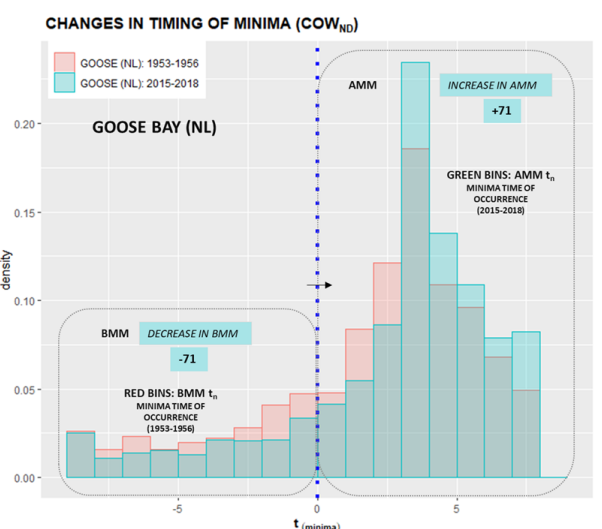

(c)

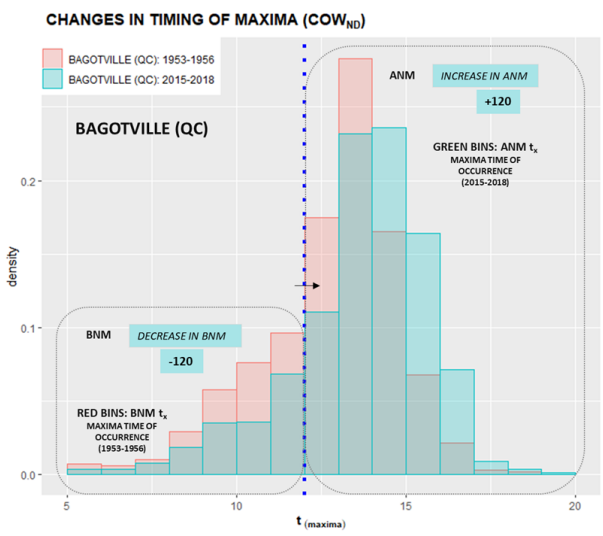

(b)

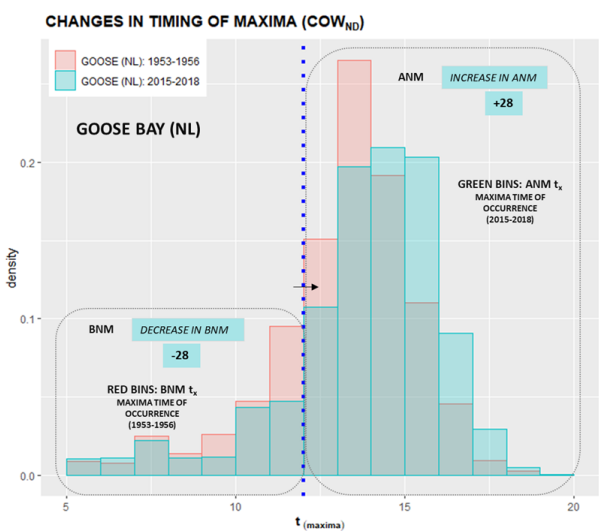

(d)

Figure A17. Northeastern Forest climate region: Bagotville (QC) and Goose (NL). Time evolution of the Diurnal Extrema Timing (DET) histograms at Bagotville (a,b), and Goose (c,d) stations. Migration of the Before Midnight Minima (BMM) to After Midnight Minima (AMM) and migration of the Before Noon Maxima (BNM) to After Noon Maxima (ANM) between four-year averages at the beginning (1953-1956) and ending (2015-2018) of data ranges. The blue dotted line represents midnight delineation (left) and noon delineation (right).

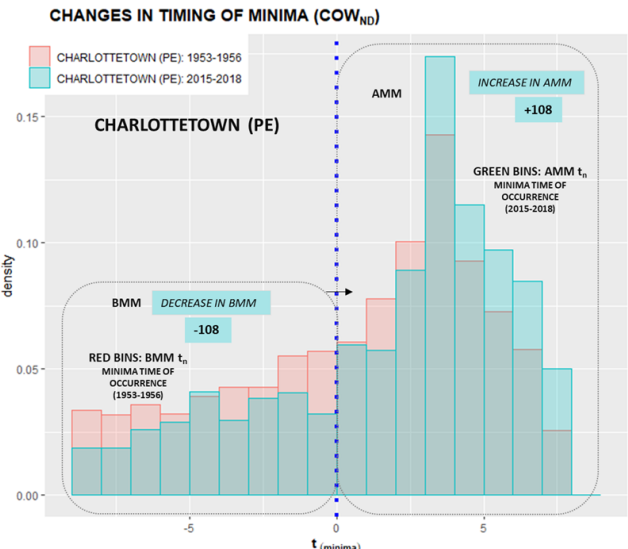

(a)

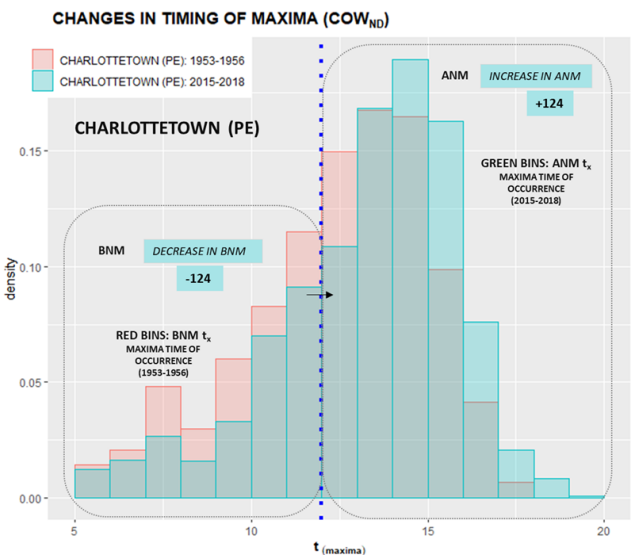

(b)

Figure A18. Cont. 


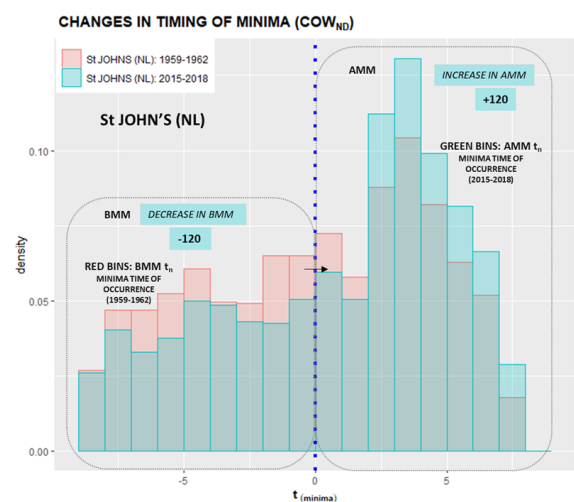

(c)

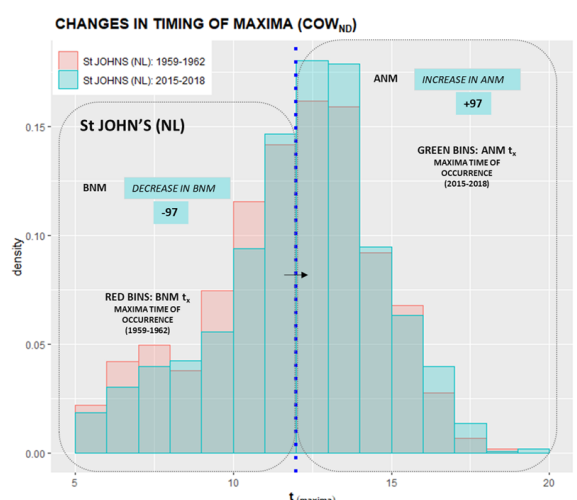

(d)

Figure A18. Atlantic Canada climate region: Charlottetown (PE) and St. John's (NL). Time evolution of the Diurnal Extrema Timing (DET) histograms at Charlottetown (a,b), and St John's (c,d) stations. Migration of the Before Midnight Minima (BMM) to After Midnight Minima (AMM) and migration of the Before Noon Maxima (BNM) to After Noon Maxima (ANM) between four-year averages at the beginning (1953-1956) and ending (2015-2018) of data ranges at Charlottetown (PE) and between (1959-1962) and (2015-2018) of data ranges at St. John's (NL) station. The blue dotted line represents midnight delineation (left) and noon delineation (right).

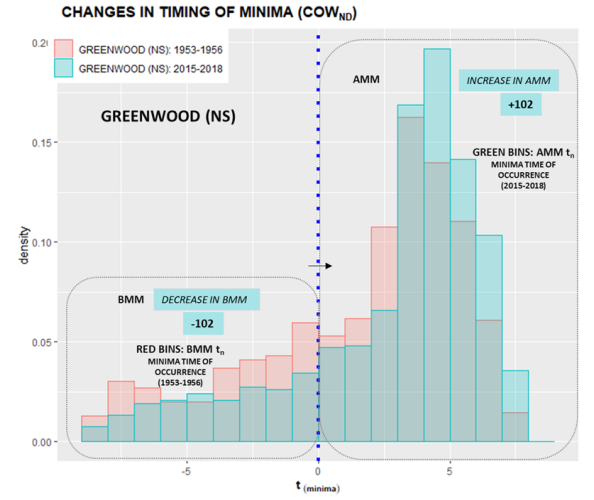

(a)

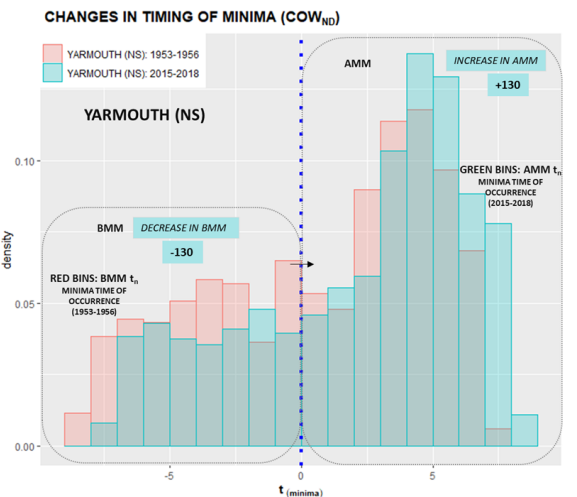

(c)

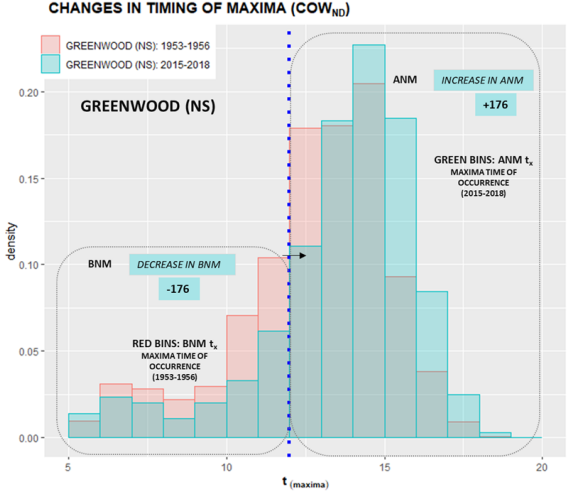

(b)

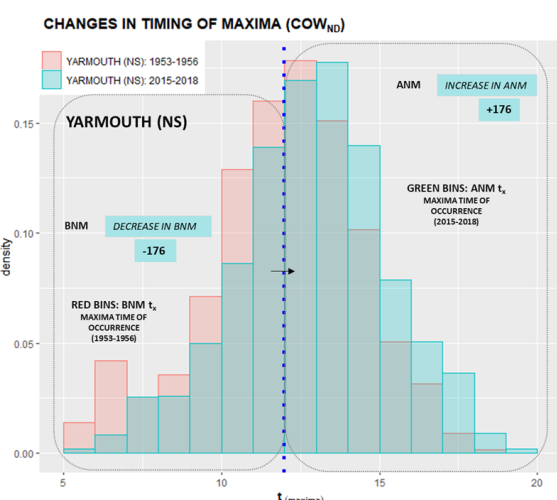

(d)

Figure A19. Atlantic Canada climate region: Greenwood (NS) and Yarmouth (NS). Time evolution of the Diurnal Extrema Timing (DET) histograms at Greenwood (a,b), and Yarmouth (c,d) stations. Migration of the Before Midnight Minima (BMM) to After Midnight Minima (AMM) and migration of the Before Noon Maxima (BNM) to After Noon Maxima (ANM) between four-year averages at the beginning (1953-1956) and ending (2015-2018) of data ranges. The blue dotted line represents midnight delineation (left) and noon delineation (right). 


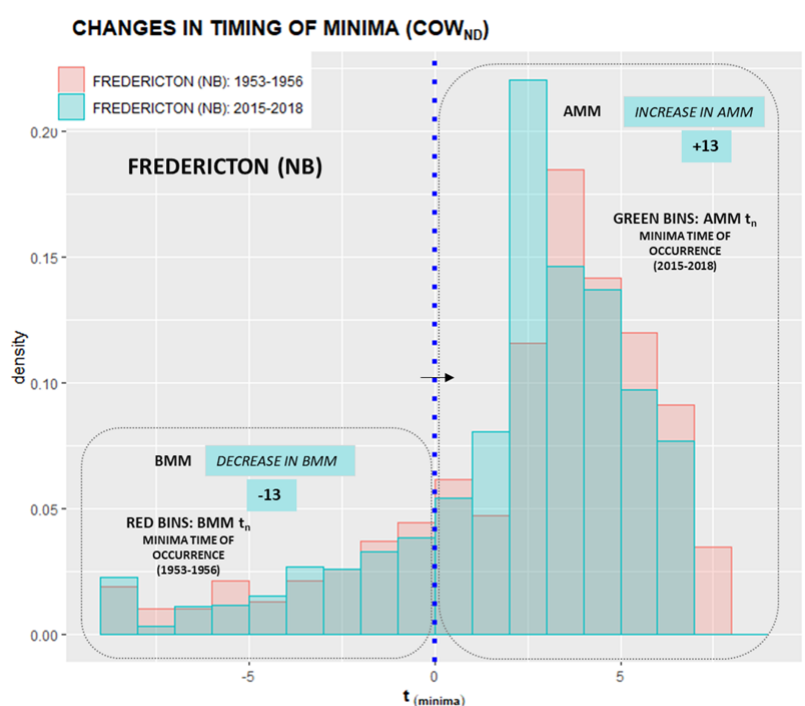

(a)

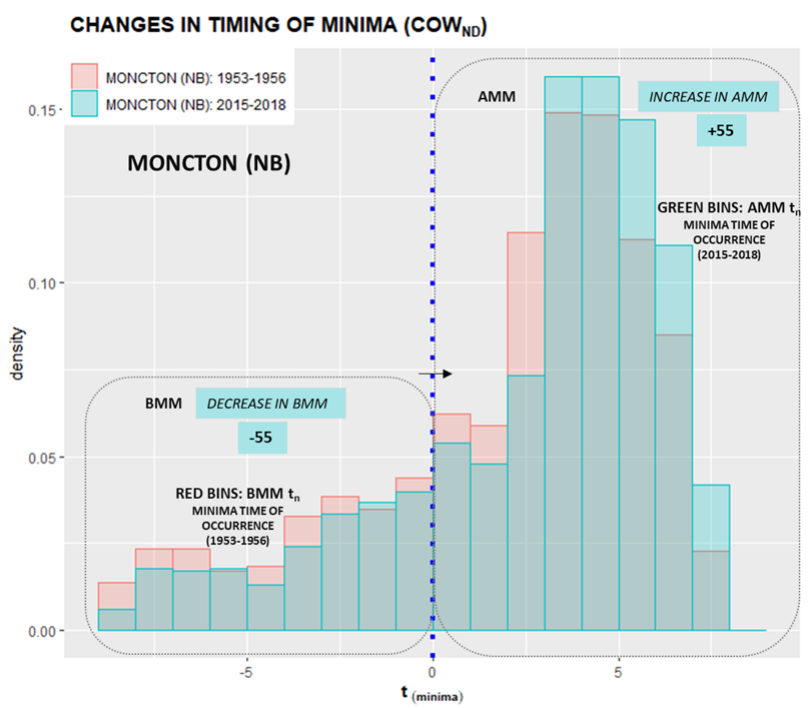

(c)

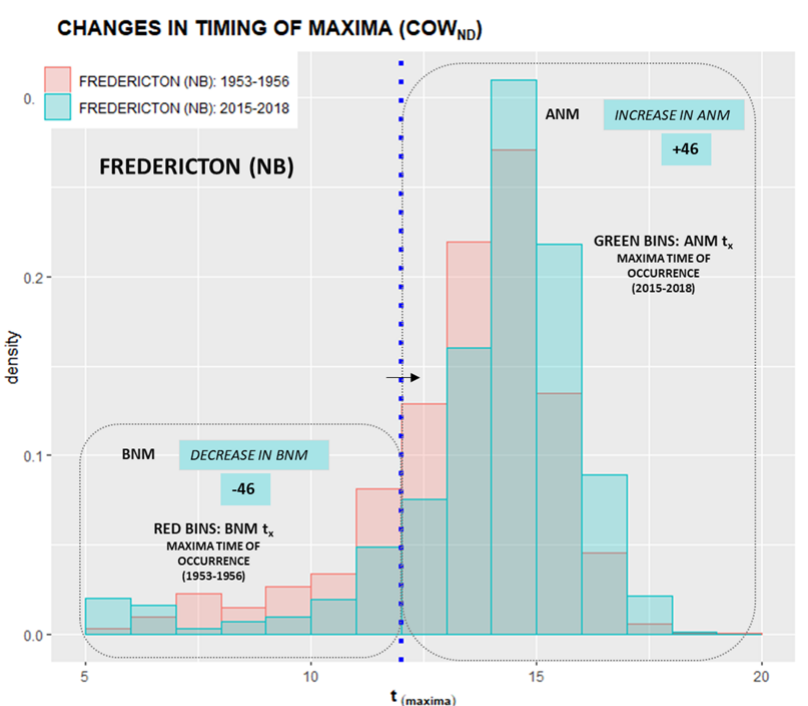

(b)

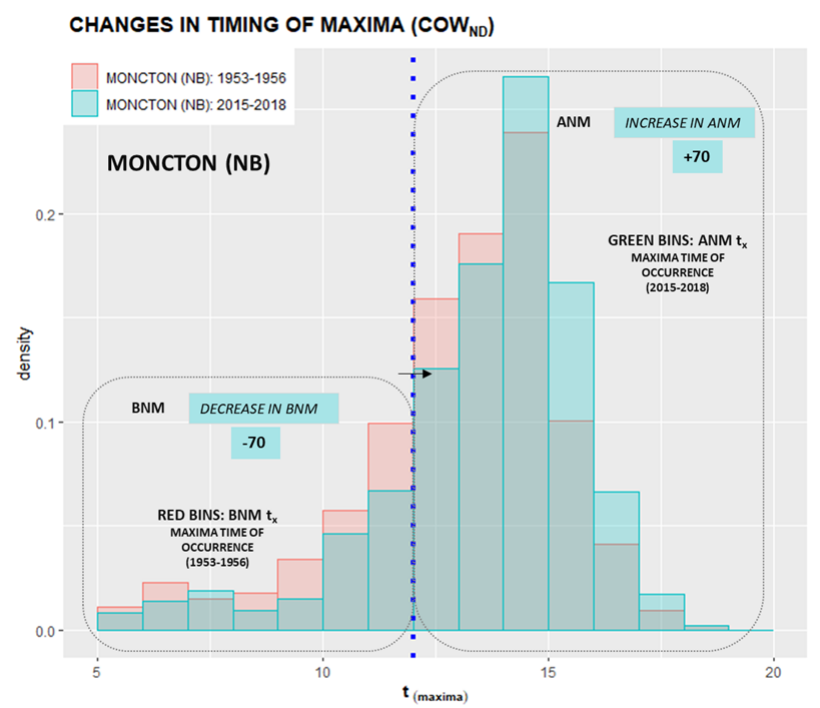

(d)

Figure A20. Atlantic Canada climate region: Fredericton (NB) and Moncton (NB). Time evolution of the Diurnal Extrema Timing (DET) histograms at Fredericton (a,b), and Moncton (c,d) stations. Migration of the Before Midnight Minima (BMM) to After Midnight Minima (AMM) and migration of the Before Noon Maxima (BNM) to After Noon Maxima (ANM) between four-year averages at the beginning (1953-1956) and ending (2015-2018) of data ranges. The blue dotted line represents midnight delineation (left) and noon delineation (right). 


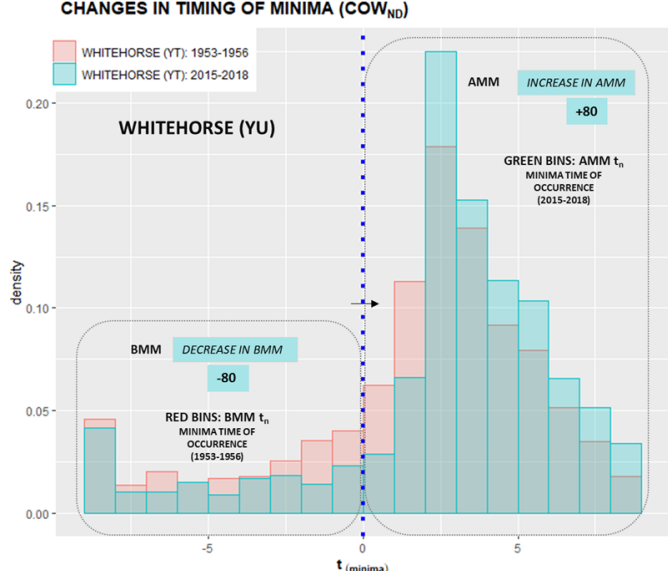

(a)

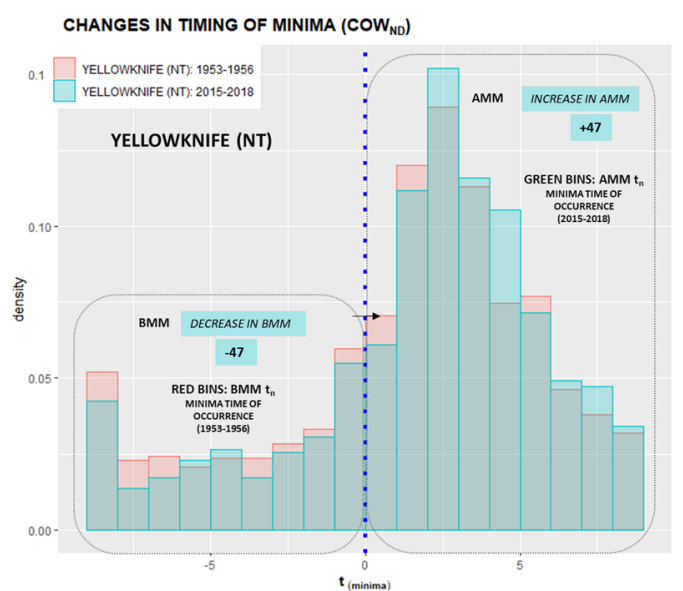

(c)

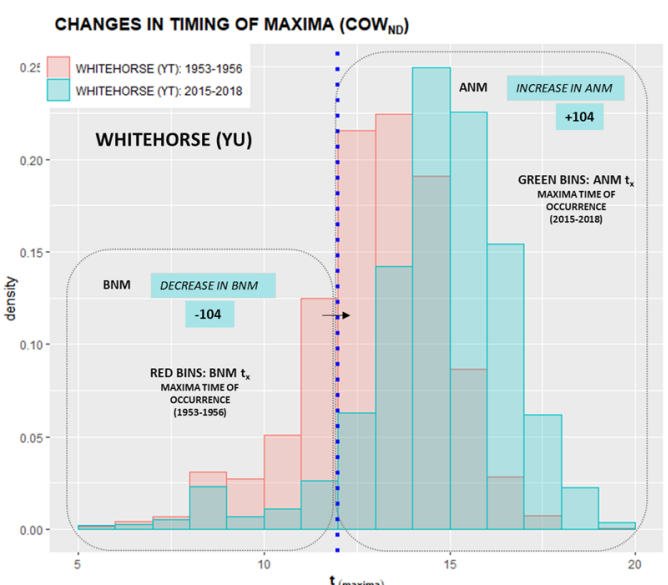

(b)

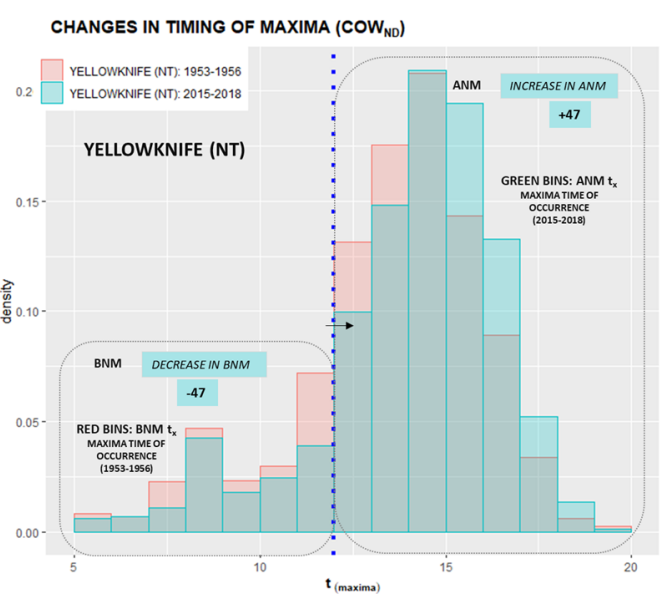

(d)

Figure A21. Northern Canada climate region: Whitehorse (YU) and Yellowknife (NT). Time evolution of the Diurnal Extrema Timing (DET) histograms at Whitehorse $(\mathbf{a}, \mathbf{b})$, and Yellowknife (c,d) stations. Migration of the Before Midnight Minima (BMM) to After Midnight Minima (AMM) and migration of the Before Noon Maxima (BNM) to After Noon Maxima (ANM) between four-year averages at the beginning (1953-1956) and ending (2015-2018) of data ranges. The blue dotted line represents midnight delineation (left) and noon delineation (right).

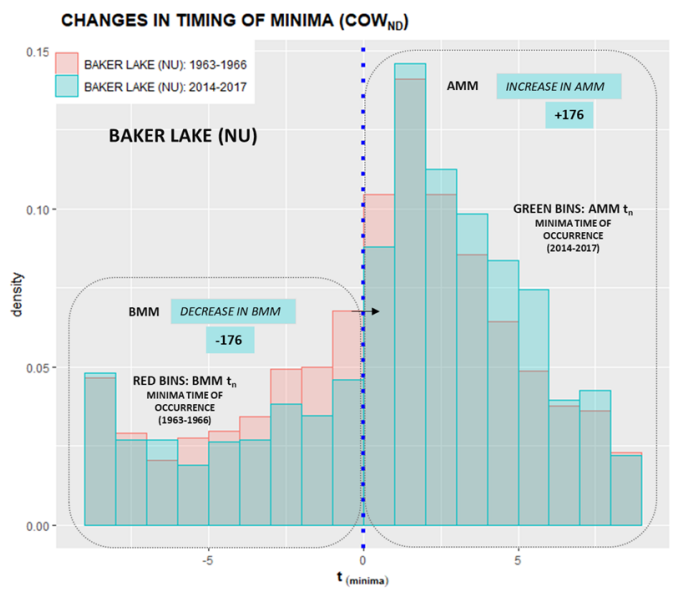

(a)

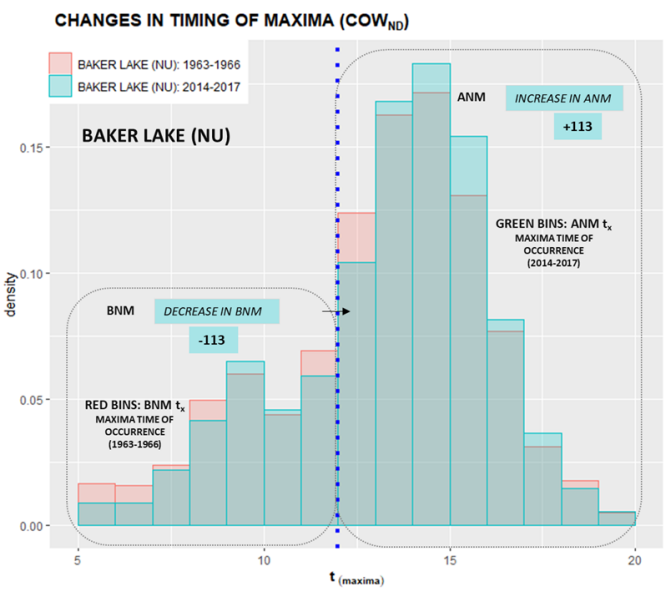

(b)

Figure A22. Cont. 


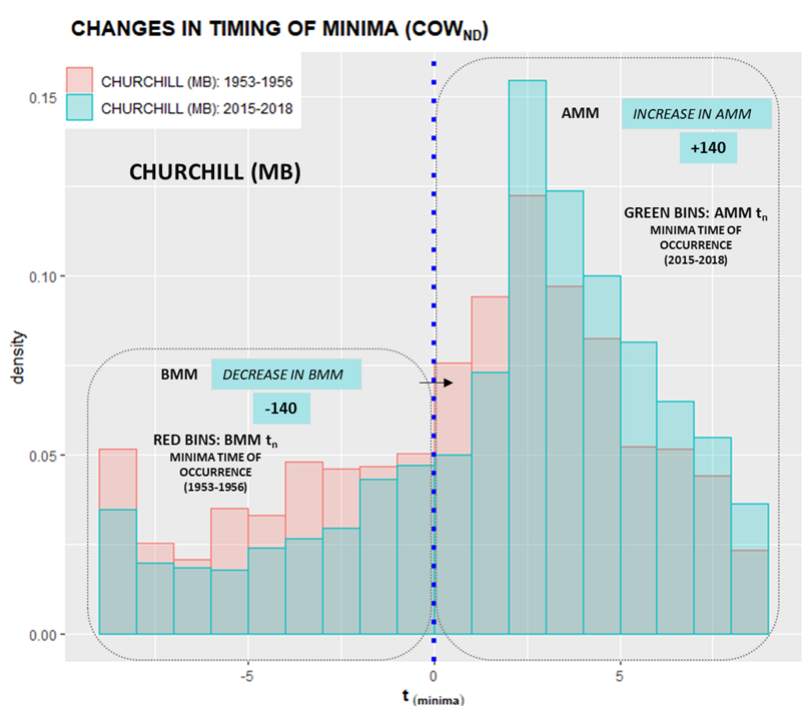

(c)

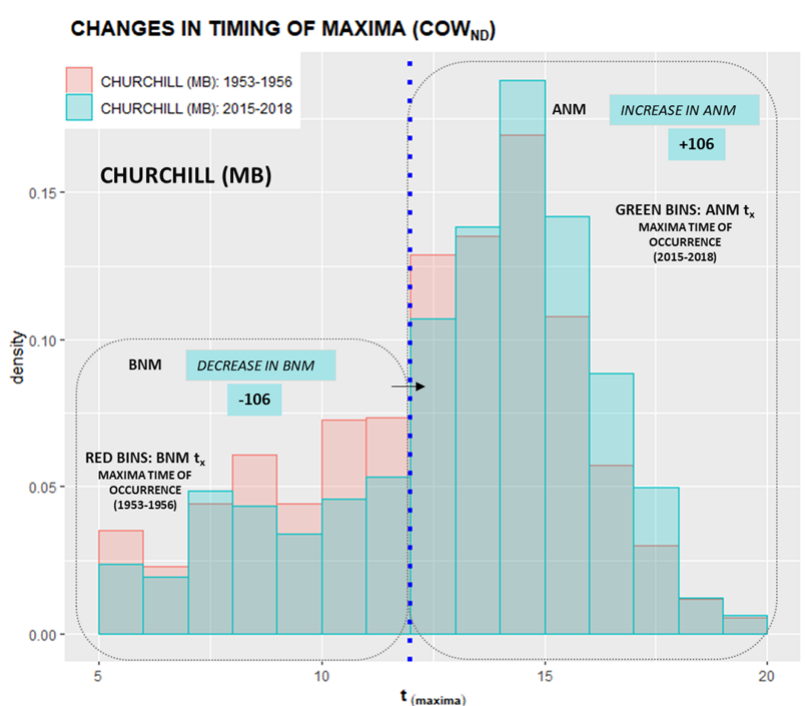

(d)

Figure A22. Northern Canada climate region: Baker Lake (NU) and Churchill (MB). Time evolution of the Diurnal Extrema Timing (DET) histograms at Baker Lake (a,b), and Churchill $(\mathbf{c}, \mathbf{d})$ stations. Migration of the Before Midnight Minima (BMM) to After Midnight Minima (AMM) and migration of the Before Noon Maxima (BNM) to After Noon Maxima (ANM) between four-year averages at the beginning (1953-1956) and ending (2015-2018) of data ranges. The blue dotted line represents midnight delineation (left) and noon delineation (right).

\section{Appendix D. Annually Averaged After Midnight Minima (AMM) and After Noon Maxima (ANM) Timing Shifts}

AFTER MIDNIGHT MINIMA TIMING $\left(\mathrm{COW}_{\mathrm{N}-\mathrm{D}}\right)$

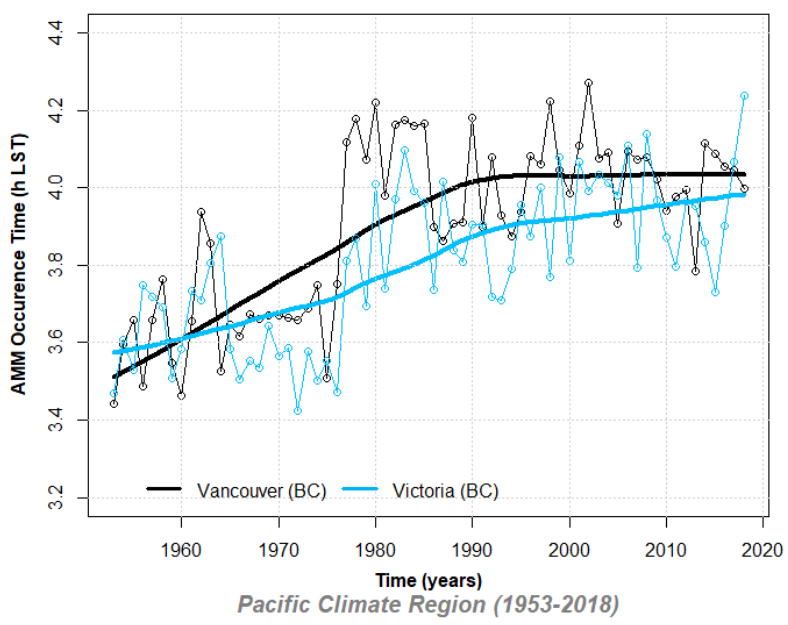

(a)

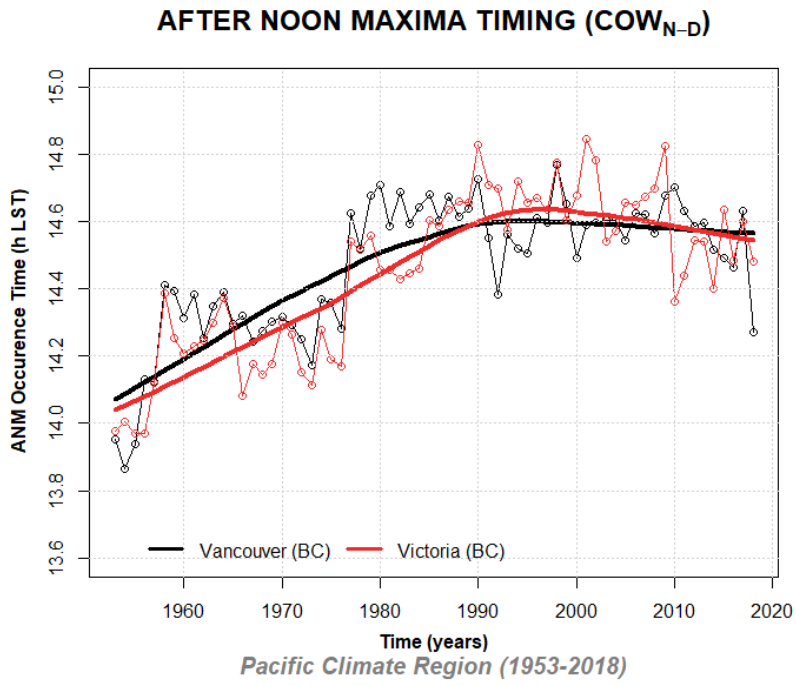

(b)

Figure A23. Annually averaged After Midnight Minima (a) and After Noon Maxima timing shifts (b) and LOESS fit curves for Vancouver (BC) and Victoria (BC) temperature time series, Pacific Coast climate region. 


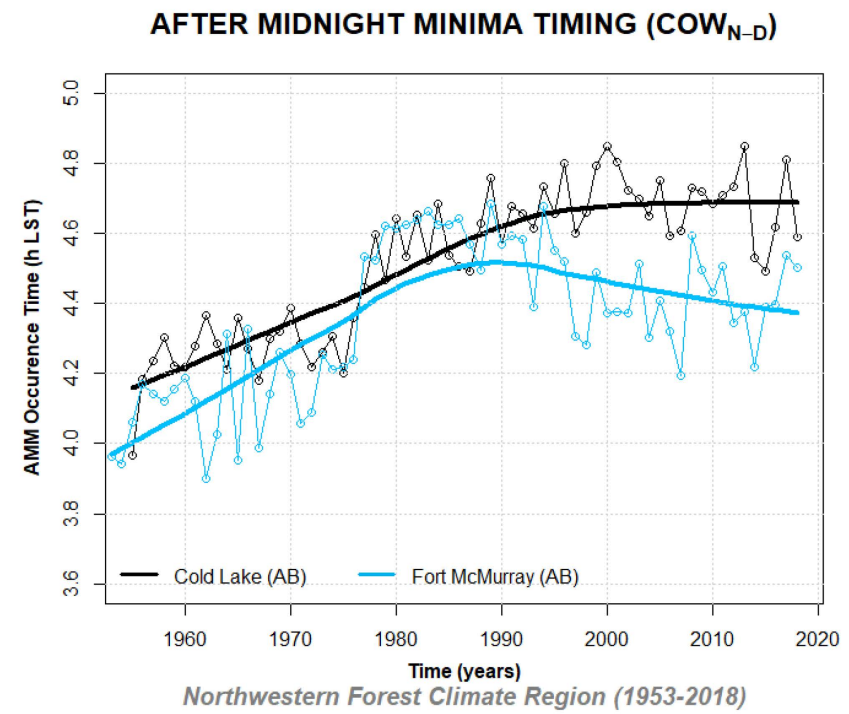

(a)

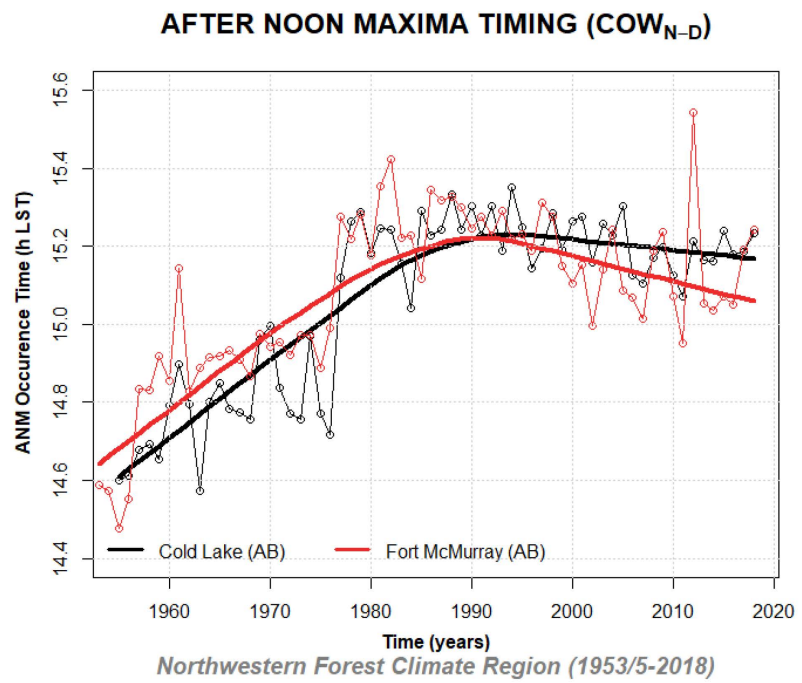

(b)

Figure A24. Annually averaged After Midnight Minima (a) and After Noon Maxima timing shifts (b) and LOESS fit curves for Cold Lake (AB) and Ft McMurray (BC) temperature time series, Northwestern Forest climate region.

AFTER MIDNIGHT MINIMA TIMING $\left(\operatorname{COW}_{\mathrm{N}-\mathrm{D}}\right)$

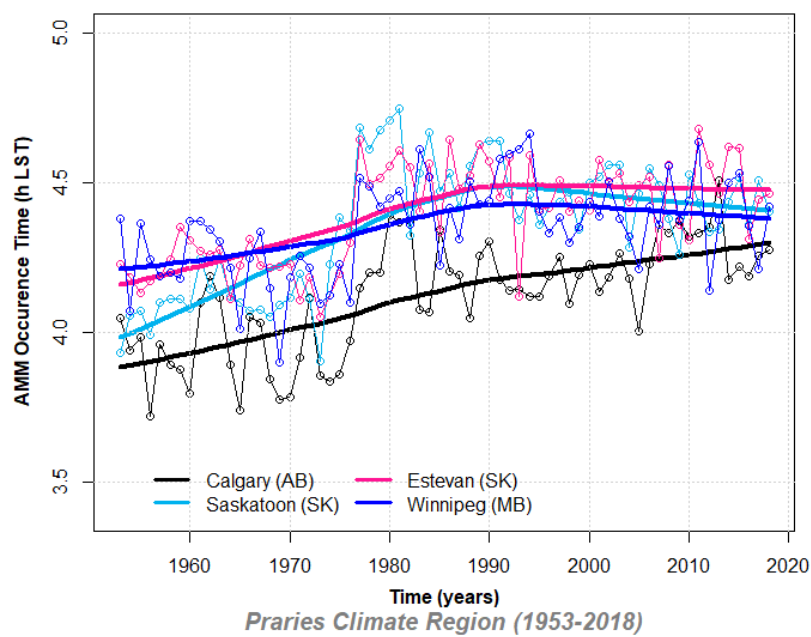

(a)

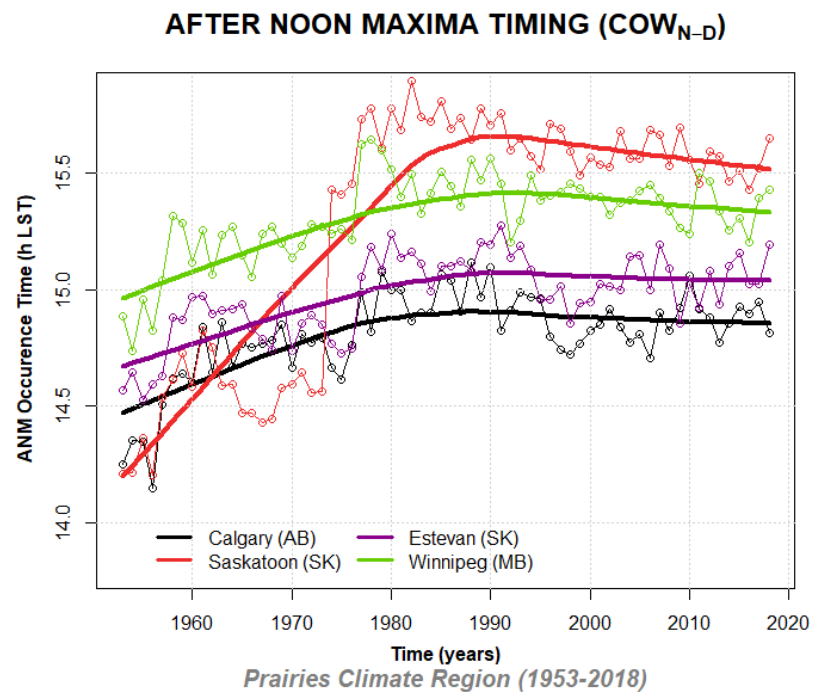

(b)

Figure A25. Annually averaged After Midnight Minima (a) and After Noon Maxima timing shifts (b) and LOESS fit curves for Calgary (AB), Saskatoon (SK), Estevan (SK), and Winnipeg (MB) temperature time series, Prairies climate region. 


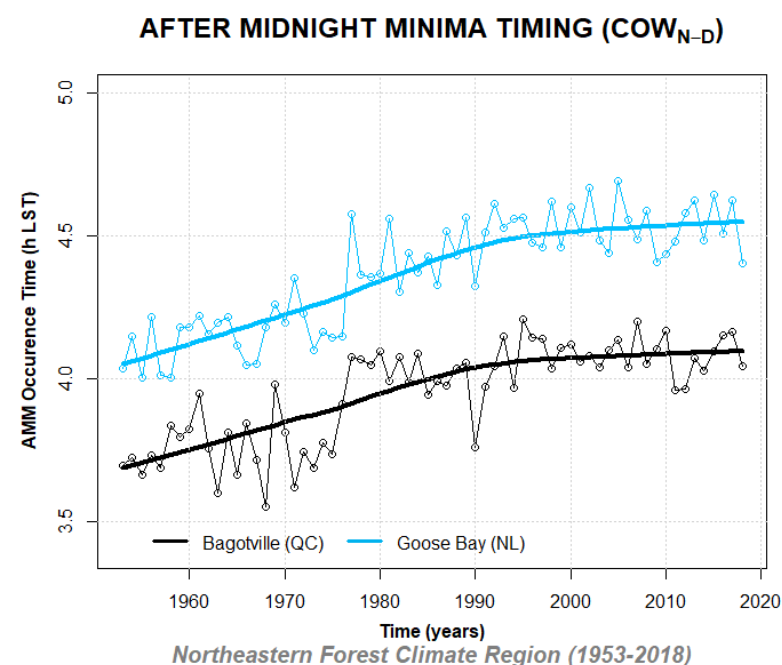

(a)

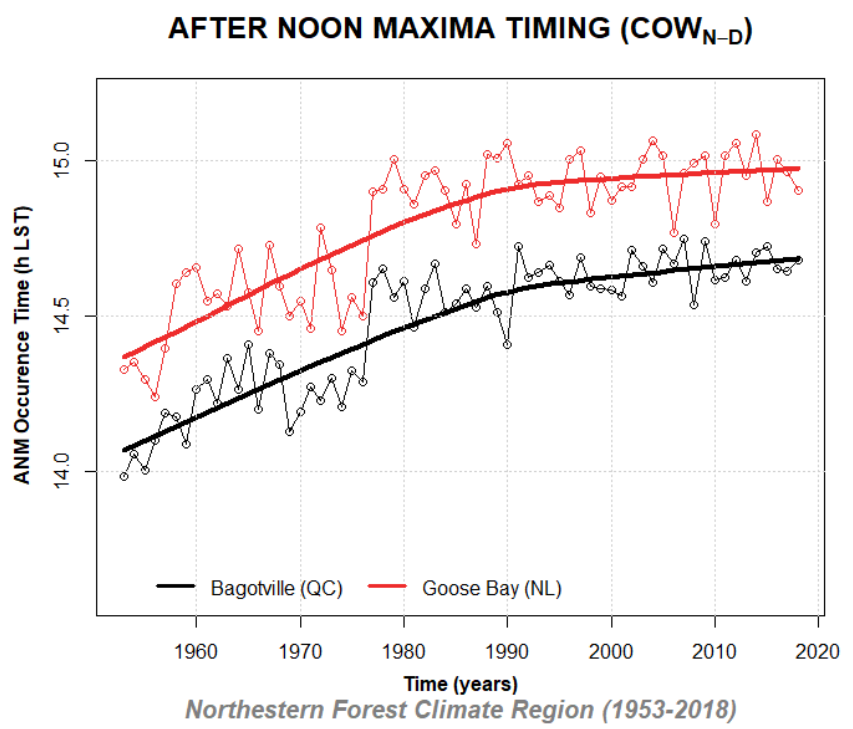

(b)

Figure A26. Annually averaged After Midnight Minima (a) and After Noon Maxima timing shifts (b) and LOESS fit curves for Bagotville (QC) and Goose (NL) temperature time series, Northeastern Forest climate region.

\section{AFTER MIDNIGHT MINIMA TIMING $\left(\mathrm{COW}_{\mathrm{N}-\mathrm{D}}\right)$}

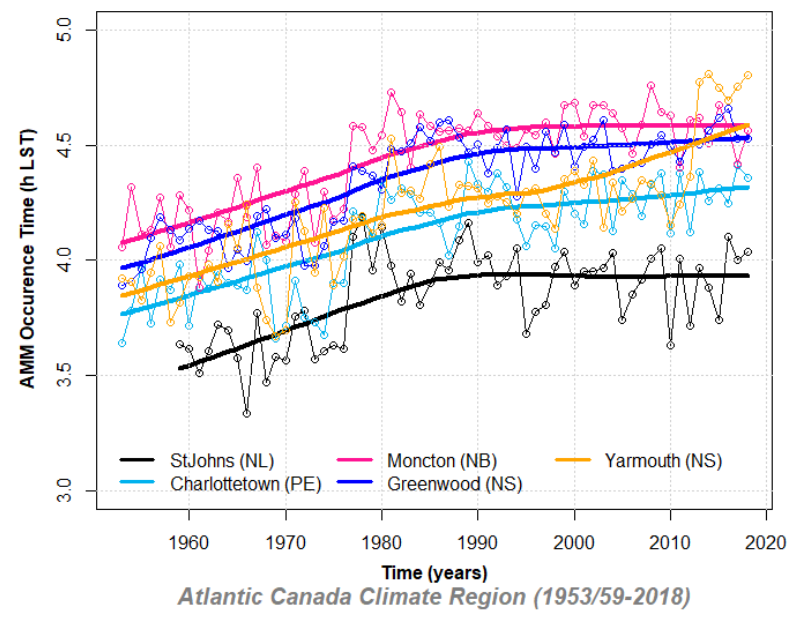

(a)

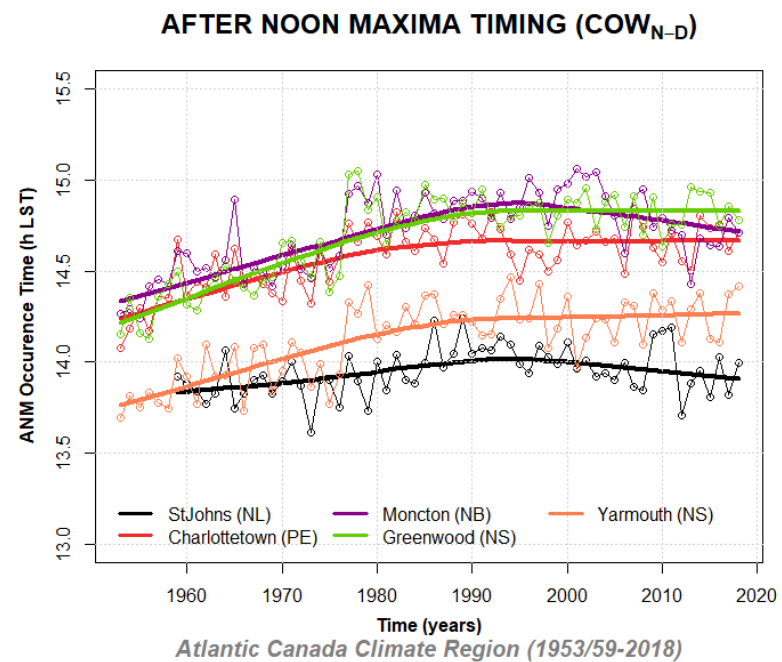

(b)

Figure A27. Annually averaged After Midnight Minima (a) and After Noon Maxima timing shifts (b) and LOESS fit curves for St. John's (NL), Charlottetown (PE), Moncton (NB), Greenwood (NS), and Yarmouth (NS) temperature time series, Atlantic Canada climate region. 


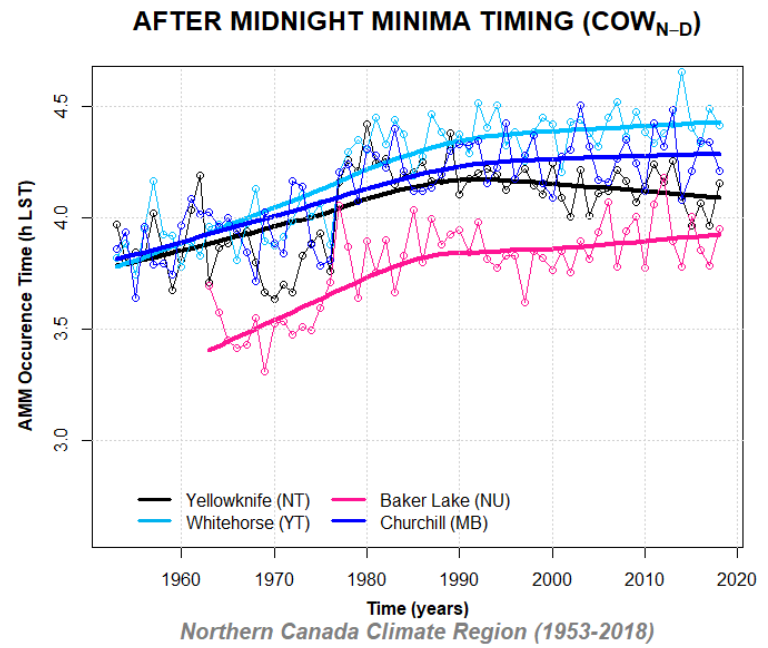

(a)

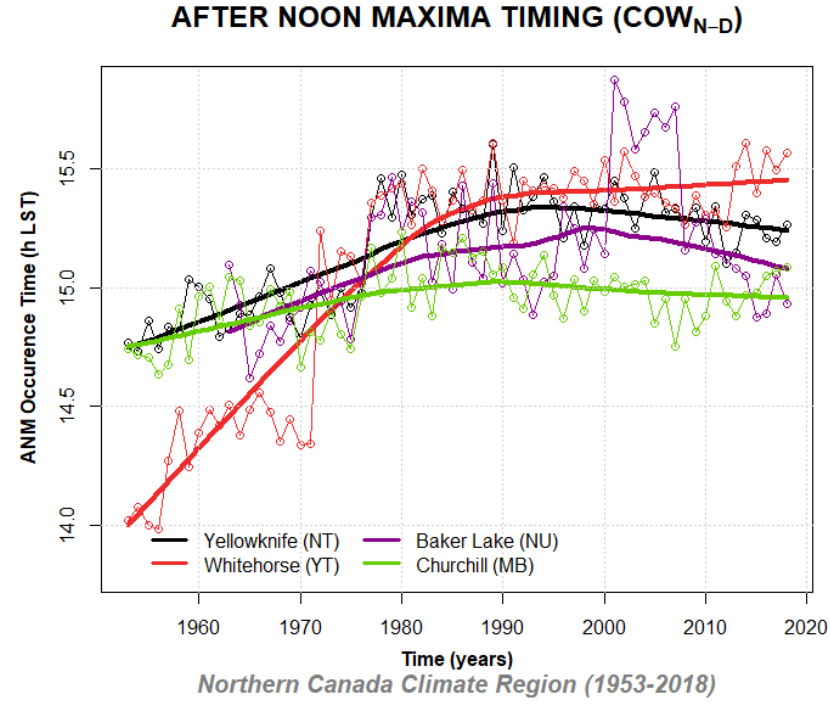

(b)

Figure A28. Annually averaged After Midnight Minima (a) and After Noon Maxima timing shifts (b) and LOESS fit curves for Yellowknife (NT), Whitehorse (YT), Baker Lake (NU), and Churchill (MB) temperature time series, from Northern Canada, including North British Columbia Mountains/Yukon, Mackenzie District, Arctic Tundra, and part of Northeastern Forest climate region.

\section{Appendix E. Example Calculations of Temperature and Timing Sensitivity Indices}

Example calculations of Toronto Nighttime Temperature Minima $\left(N T_{n}\right)$ and After Midnight Minima timing $\left(A M M t_{n}\right)$ are presented here using Equations (1)-(6) from Section 2.6.

Climate Parameter Sensitivity Index for the nighttime temperature minima, CPSI $\left(N T_{n}\right)$ is the ratio of the nighttime minima variability due to climate change $\left(\Delta N T_{n}\right)$ and the overall variability of the nighttime minima $\left(\delta N T_{n}\right)$ within the selected temperature data set.

The CPSI for the nighttime temperature minima of the Toronto 1953-2018 data set is estimated to be $5.0 \%$ (Equation (A1)).

$$
\operatorname{CPSI}\left(N T_{n}\right)=\frac{\Delta N T_{n}}{\delta N T_{n}} \cdot 100 \%=\frac{2.9^{\circ} \mathrm{C}}{58{ }^{\circ} \mathrm{C}} \cdot 100 \%=5.0 \% .
$$

The variability of the Toronto nighttime temperature minima due to climate change is estimated to be $2.9^{\circ} \mathrm{C}$ obtained by multiplying the slope of the linear trend of the $N T_{n}$ with the length of the study range (Equation (A2)):

$$
\Delta N T_{n}=m_{\text {lin }}\left(N T_{n}\right) \cdot(\text { time range })=0.044 \frac{{ }^{\circ} \mathrm{C}}{y} * 66 y=2.9^{\circ} \mathrm{C} .
$$

The overall variability of the nighttime minima within the Toronto data set is estimated to be $58^{\circ} \mathrm{C}$ based on the temperature span between the largest and the smallest recorded nighttime minimum (Equation (A3)):

$$
\delta N T_{n}=\max \left(N T_{n}\right)-\min \left(N T_{n}\right)=26.9^{\circ} \mathrm{C}-\left(-31.1{ }^{\circ} \mathrm{C}\right)=58{ }^{\circ} \mathrm{C} .
$$

Climate Parameter Sensitivity Index for the timing of the AMM subpopulation, $\operatorname{CPSI}\left(A M M t_{n}\right)$, is the ratio of the variability in the AMM timing due to climate change $\left(\triangle A M M t_{n}\right)$ and the overall variability in the AMM timing $\left(\delta A M M t_{n}\right)$ within the selected data set. 
The CPSI for the After Midnight Minima timing of the Toronto 1953-2018 data set is estimated to be $6.2 \%$ (Equation (A4)).

$$
\operatorname{CPSI}\left(A M M t_{n}\right)=\frac{\Delta A M M t_{n}}{\sigma A M M t_{n}} \cdot 100 \%=\frac{0.49 h}{8 h}=6.2 \% .
$$

The variability of the Toronto AMM timing parameter due to climate change is estimated to be $0.49 \mathrm{~h}$ obtained by multiplying the slope of the linear trend of the $A M M t_{n}$ with the length of the study range (Equation (A5)):

$$
\Delta A M M t_{n}=m_{\text {lin }}\left(A M M t_{n}\right) \cdot(\text { time range })=0.0075 \mathrm{~h} / \mathrm{y} * 66 \mathrm{y}=0.49 \mathrm{~h} .
$$

The overall variability of the AMM timing parameter within the Toronto data set is estimated to be $8 \mathrm{~h}$ based on the timing span between the largest and the smallest recorded AMM timing (Equation (A6)):

$$
\delta A M M t_{n}=\max \left(A M M t_{n}\right)-\min \left(A M M t_{n}\right)=8 h-0 h=8 h .
$$

\section{References}

1. Bonacci, O.; Željković, I.; Trogrlić, R.Š.; Milković, J. Differences between true mean, daily, monthly and annual air temperatures and air temperatures calculated with three equations: A case from three Croatian stations. Theor. Appl. Clim. 2013, 114, $271-279$. [CrossRef]

2. Allen, S.M.J.; Gough, W.A.; Mohsin, T. Changes in the frequency of extreme temperature records for Toronto, Ontario, Canada. Theor. Appl. Clim. 2015, 119, 481-491. [CrossRef]

3. Wang, K.C. Sampling biases in datasets of historical mean air temperature over land. Sci. Rep. 2014, 4, 4637. [CrossRef]

4. Schaal, L.A.; Dale, R.F. Time of observation temperature bias and "climatic change". J. Appl. Meteorol. 1977, 16, 215-222. [CrossRef]

5. Žaknić-Ćatović, A.; Gough, W.A. A comparison of climatological observing windows and their impact on detecting daily temperature extrema. Theor. Appl. Clim. 2018, 132, 41-54. [CrossRef]

6. Gough, W.A.; Žaknić-Ćatović, A.; Zajch, A. Sampling frequency of climate data for the determination of daily temperature and daily temperature extrema. Int. J. Clim. 2020, 40, 5451-5463. [CrossRef]

7. Lin, X.; Hubbard, K.G. What are daily maximum and minimum temperatures in observed climatology? Int. J. Clim. 2008, 28, 283-294. [CrossRef]

8. Žaknić-Ćatović, A.; Gough, W.A. Identification of radiative and advective populations in Canadian temperature time series using the Linear Pattern Discrimination algorithm. Int. J. Clim. 2021, 41, 5100-5124. [CrossRef]

9. Žaknić-Ćatović, A.; Howard, K.W.F.; Ćatović, Z. Modification of the degree-day formula for diurnal meltwater generation and refreezing. Theor. Appl. Clim. 2018, 131, 1157-1171. [CrossRef]

10. Chow, D.H.C.; Levermore, G.J. New algorithm for generating hourly temperature values using daily maximum, minimum and average values from climate models. Build. Serv. Eng. Res. Technol. 2007, 28, 237-248. [CrossRef]

11. Magnano, L.; Boland, J.W.; Hyndman, R.J. Generation of synthetic sequences of half-hourly temperatures. Environmetrics 2008, 19, 818-835. [CrossRef]

12. Parton, W.J.; Logan, J.A. A model for diurnal variation in soil and air temperature. Agric. Meteorol. 1981, 23, 205-216. [CrossRef]

13. Watanabe, N. An improved method for computing heat accumulation from daily maximum and minimum temperatures. Appl. Entomol. Zool. 1978, 13, 44-46. [CrossRef]

14. Floyd, B.R.; Braddock, R.D. A simple method for fitting average diurnal temperature curves. Agric. For. Meteorol. 1984, 32, 107-1194. [CrossRef]

15. Wann, M.; Yen, D.; Gold, H.J. Evaluation and calibration of three models for daily cycle of air temperature. Agric. For. Meteorol. 1985, 34, 121-128. [CrossRef]

16. Linvill, D.E. Calculating chilling hours and chill units from daily maximum and minimum temperature observations. Hort Sci. 1990, 25, 14-16. [CrossRef]

17. Sadler, J.E.; Schroll, R.E. An empirical model of diurnal temperature patterns. Agron. J. 1997, 89, 542-548. [CrossRef]

18. Dall'Amico, M.; Hornsteiner, M. A simple method for estimating daily and monthly mean temperatures from daily minima and maxima. Int. J. Clim. 2006, 26, 1929-1936. [CrossRef]

19. Besson, F.; Bazile, E.; Soci, C.; Soubeyroux, J.-M.; Ouzeau, G.; Perrin, M. Diurnal temperature cycle deduced from extreme daily temperatures and impact over a surface reanalysis system. Adv. Sci. Res. 2015, 12, 137-140. [CrossRef]

20. Hansen, J.E. A mathematical model for the generation of hourly temperatures. J. Appl. Meteorol. 1962, 16, 935-948. [CrossRef]

21. Allen, J.C. A modified sine wave method for calculating degree-days. Environ. Entomol. 1976, 5, 388-396. [CrossRef]

22. Reicosky, D.C.; Winkelman, L.J.; Baker, D.G. Accuracy of hourly air temperatures calculated from daily minima and maxima. Agric. For. Meteorol. 1989, 46, 193-209. [CrossRef] 
23. Schaub, W.R., Jr. A Method for Estimating Missing Hourly Temperatures Using Daily Maximum and Minimum Temperatures; USAF Environmental Technical Applications Center, Scott Air Force Base: St. Louis, IL, USA, 1991; USAFETAC/PR-91/017.

24. Žaknić-Ćatović, A.; Howard, K.W.F.; Gough, W.A.; Catovic, Z. A modified degree-day method for volume and timing estimation of snowmelt and refreezing. In Proceedings of the 34th Conference on Hydrology, American Meteorological Society, Boston, MA, USA, 15 January 2020; p. 368200. [CrossRef]

25. Žaknić-Ćatović, A.; Gough, W.A. A new approach to air temperature analysis. In Proceedings of the 32nd Conference on Climate Variability and Change, American Meteorological Society, Phoenix, AZ, USA, 7 January 2019; p. 352891. [CrossRef]

26. Vincent, L.A.; Milewska, E.J.; Hopkinson, R.; Malone, L. Bias in minimum temperature introduced by a redefinition of the climatological day at the Canadian synoptic stations. J. Appl. Meteorol. Clim. 2009, 48, 2160-2168. [CrossRef]

27. Hopkinson, R.F.; McKenney, D.W.; Daniel, W.; Milewska, E.J.; Hutchinson, M.F.; Papadopol, P.; Vincent, L.A. Impact of aligning climatological day on gridding daily maximum-minimum temperatures and precipitation over Canada. J. Appl. Meteorol. Clim. 2011, 50, 1654-1665. [CrossRef]

28. Nichols, E.S. Time limits of the day affecting records of minimum temperature. Mon. Weather Rev. 1934, 62, 337-343. [CrossRef]

29. Janis, M.J. Observation-time-dependent biases and departures for daily minimum and maximum air temperatures. J. Appl. Meteorol. 2001, 41, 588-603. [CrossRef]

30. Government of Canada. About the Data. Available online: https://climate.weather.gc.ca/about_the_data_index_e.html (accessed on 15 September 2021).

31. Government of Canada. Historical Climate Data. Available online: https://climate.weather.gc.ca/historical_data/search_ historic_data_e.html (accessed on 15 September 2021).

32. Core Team, R. A Language and Environment for Statistical Computing; R Foundation for Statistical Computing: Vienna, Austria, 2021.

33. Bonsal, B.; Shabbar, A. Large-Scale Climate Oscillations Influencing Canada, 1900-2008. Canadian Biodiversity: Ecosystem Status and Trends 2010. Technical Thematic Report No.4; Canadian Councils of Resource Ministers: Ottawa, ON, Canada, 2011; Available online: http:/ / www.biodivcanada.ca/ default.asp?lang=En\&n=137E1147-0 (accessed on 15 September 2021).

34. Vincent, L.A.; Zhang, X.; Brown, R.D.; Feng, Y.; Mekis, E.; Milewska, E.J.; Wan, H.; Wang, X.L. Observed trends in Canada's climate and influence of low-frequency variability modes. J. Clim. 2015, 28, 4545-4560. [CrossRef]

35. Gough, W.A.; He, D. Diurnal temperature asymmetries and fog at Churchill, Manitoba. Theor. Appl. Clim. 2015, 121, 113-119. [CrossRef]

36. Leung, A.; Gough, W.A. Air mass distribution and the heterogeneity of the climate change signal in the Hudson Bay/Foxe Basin region, Canada. Theor. Appl. Clim. 2016, 125, 583-592. [CrossRef] 